\title{
Pd-Catalyzed Synthesis of Aryl and Heteroaryl Triflones from Reactions of Sodium Triflinate $\left(\mathrm{NaSO}_{2} \mathrm{CF}_{3}\right)$ with Aryl(Heteroaryl) Triflates
}

Lynette A. Smyth, ${ }^{\dagger}$ Eric M. Phillips, ${ }^{\ddagger}$ Vincent S. Chan, ${ }^{\star}$ Jose G. Napolitano, ${ }^{\S}$ Rodger Henry ${ }^{\S}$ and Shashank Shekhar,*

${ }^{\dagger}$ AbbVie Deutschland GmbH \& Co. KG, Knollstraße, 67061 Ludwigshafen, Germany

${ }^{\ddagger}$ AbbVie Inc., Process Research and Development, 1 North Waukegan Road, North Chicago, IL 60064, USA

$\S$ AbbVie Inc., Discovery Chemistry and Technology, 1 North Waukegan Road, North Chicago, IL 60064, USA

Email Address: Shashank.shekhar@abbvie.com

\section{Supporting Informtaion}

\section{Table of Contents}

\begin{tabular}{ll}
\hline Title & Page \\
\hline Evaluation of reaction parameters & S2 \\
Comparison of initial rates of reaction & S2 \\
NMR Spectra & S5 \\
\hline
\end{tabular}


Table S1. Evaluation of reaction parameters for Pd-catalyzed formation of aryltriflone

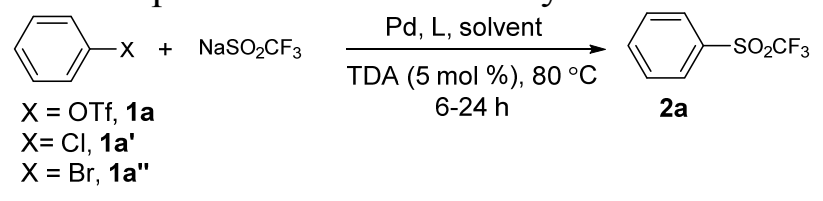

\begin{tabular}{|c|c|c|c|c|c|c|}
\hline Entry & $\mathrm{X}$ & $\mathrm{Pd}(\mathrm{mol} \%)$ & $\mathrm{L}(\mathrm{mol} \%)$ & Solvent & Time $(\mathrm{h})$ & $2 a(\%)^{a}$ \\
\hline 1 & OTf & $\mathrm{Pd}_{2}(\mathrm{dba})_{3}(2.5)$ & I (10) & toluene & 6 & 7 \\
\hline 2 & OTf & $\mathrm{Pd}_{2}(\mathrm{dba})_{3}(2.5)$ & II (6) & toluene & 6 & 23 \\
\hline 3 & OTf & $\mathrm{Pd}_{2}(\mathrm{dba})_{3}(2.5)$ & III (6) & toluene & 2 & $>95(84)^{b}$ \\
\hline 4 & OTf & $\mathrm{Pd}_{2}(\mathrm{dba})_{3}(2.5)$ & IV (6) & toluene & 5 & 75 \\
\hline 5 & OTf & $\mathrm{Pd}_{2}(\mathrm{dba})_{3}(2.5)$ & V (10) & toluene & 24 & 5 \\
\hline 6 & OTf & $\mathrm{Pd}_{2}(\mathrm{dba})_{3}(2.5)$ & VI (6) & toluene & 6 & 0 \\
\hline 7 & OTf & VII (5) & NA & toluene & 6 & 0 \\
\hline 8 & OTf & VIII (5) & NA & toluene & 6 & 0 \\
\hline 9 & OTf & $\mathrm{Pd}_{2}(\mathrm{dba})_{3}(2.5)$ & $\mathbf{I X}(10)$ & toluene & 6 & 0 \\
\hline $10^{\mathrm{c}}$ & $\mathrm{Cl}$ & $\mathrm{Pd}_{2}(\mathrm{dba})_{3}(2.5)$ & III (6) & toluene & 25 & 50 \\
\hline $11^{\mathrm{c}}$ & $\mathrm{Br}$ & $\mathrm{Pd}_{2}(\mathrm{dba})_{3}(2.5)$ & III (6) & toluene & 25 & 7 \\
\hline $12^{\mathrm{d}}$ & OTf & $\mathrm{Pd}_{2}(\mathrm{dba})_{3}(2.5)$ & III (6) & toluene & 6 & 74 \\
\hline 13 & OTf & $\mathrm{Pd}_{2}(\mathrm{dba})_{3}(2.5)$ & III (6) & 1,4-dioxane & 6 & 28 \\
\hline 14 & OTf & $\mathrm{Pd}_{2}(\mathrm{dba})_{3}(2.5)$ & III (6) & tert-AmOH & 6 & 11 \\
\hline 15 & OTf & $\mathrm{Pd}_{2}(\mathrm{dba})_{3}(2.5)$ & III (6) & DMF & 6 & 0 \\
\hline 16 & OTf & {$[\mathrm{Pd}(\text { cinnamyl }) \mathrm{Cl}]_{2}(2.5)$} & III (6) & toluene & 3 & 78 \\
\hline 17 & OTf & $\mathrm{Pd}(\mathrm{OAc})_{2}(5)$ & III (6) & toluene & 3 & $<5$ \\
\hline $18^{\mathrm{e}}$ & OTf & $\mathrm{Pd}(\mathrm{OAc})_{2}(5)$ & III (6) & toluene & 3 & $<5$ \\
\hline 19 & OTf & $\mathrm{Pd}(\mathrm{MeCN})_{2} \mathrm{Cl}_{2}(5)$ & III (6) & toluene & 3 & $<5$ \\
\hline
\end{tabular}

All experiments were conducted with phenyl triflate/chlorobenzene/ bromobenzene ( 1 equiv), and $\mathrm{NaSO}_{2} \mathrm{CF}_{3}(2$ equiv) at $0.5 \mathrm{M}$ concentration in solvent for the indicated time. (a) Assay yield based on HPLC analysis at $210 \mathrm{~nm}$. (b) Isolated yield. (c) The reaction was performed at $100{ }^{\circ} \mathrm{C}$. (d) No TDA was added. (e) Water $(20 \mathrm{~mol} \%)$ was used for catalyst activation. ${ }^{[1]}$

\section{Comparison of Initial rates of Reactions (Table 4)}

In a glove box, a reaction vial equipped with a magnetic stirring bar and fitted with a Teflon screw cap was charged $\mathrm{Pd}_{2}(\mathrm{dba})_{3}(1.5 \mathrm{~mol} \%$ ) and ligand III (3.6 mol \%). The solids were diluted with toluene $(1 \mathrm{~mL})$ and heated at $80{ }^{\circ} \mathrm{C}$ for 30 minutes. The vial was removed from the heating block and charged with a solution of the desired aryl triflate $(200 \mathrm{mg})$, a known amount of 4,4'-dimethyl-1,1'-biphenyl (internal standard), and tris(2-(2-methoxyethoxy)ethyl)amine (5 mol \%) in toluene $(1 \mathrm{~mL})$. Sodium sulfinate (1.5 equiv) was then added to the mixture. The reaction vial was then returned to the heating block and heated at $80{ }^{\circ} \mathrm{C}$. A $10 \mu \mathrm{L}$ aliquot was withdrawn from the reaction mixture at the indicated times. The aliquot was diluted with acetonitrile $(1 \mathrm{~mL})$ and injected onto a reverse phase HPLC instrument. The amount (mmol) of product was determined. The concentration of product $(\mathrm{mM})$ was plotted against time. The initial rate of the reaction was then determined. 


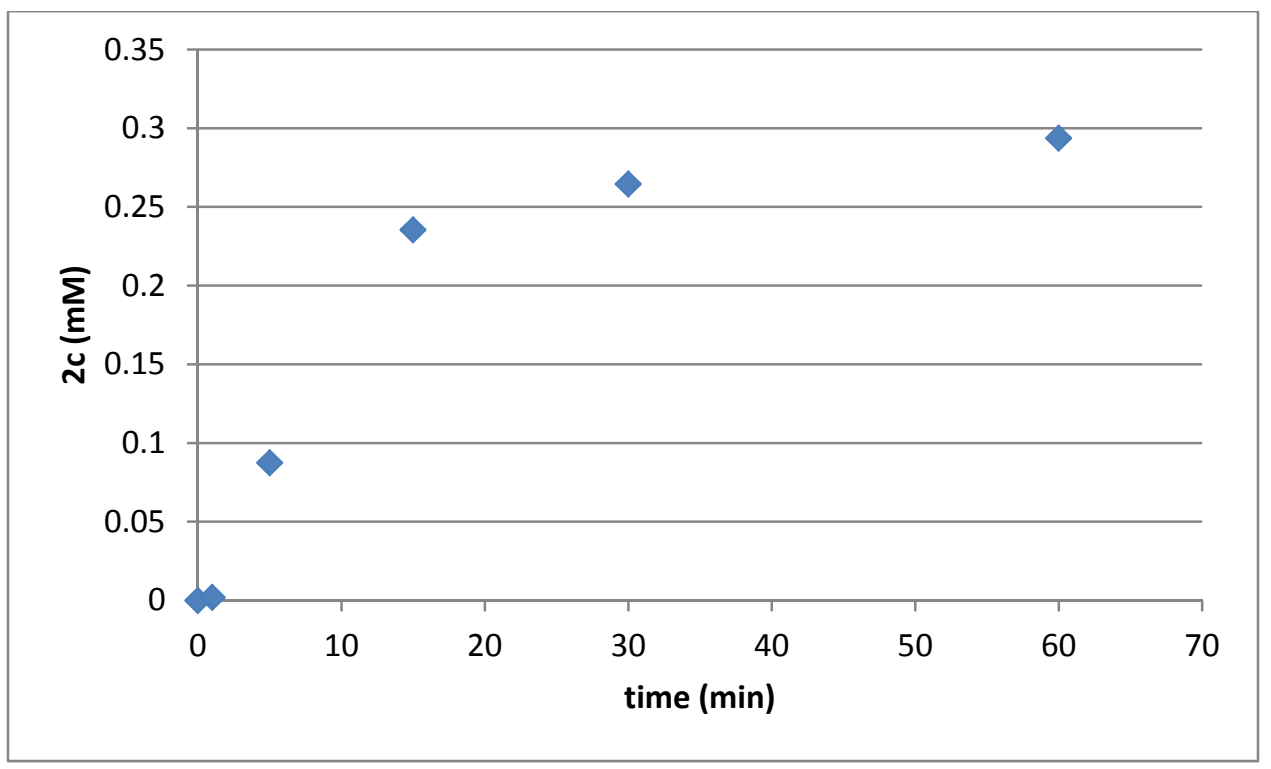

Figure S1. Initial rate determination for 2c. The initial rate of reaction was calculated from the slope of the line connecting time points at 1 and 5 minutes.

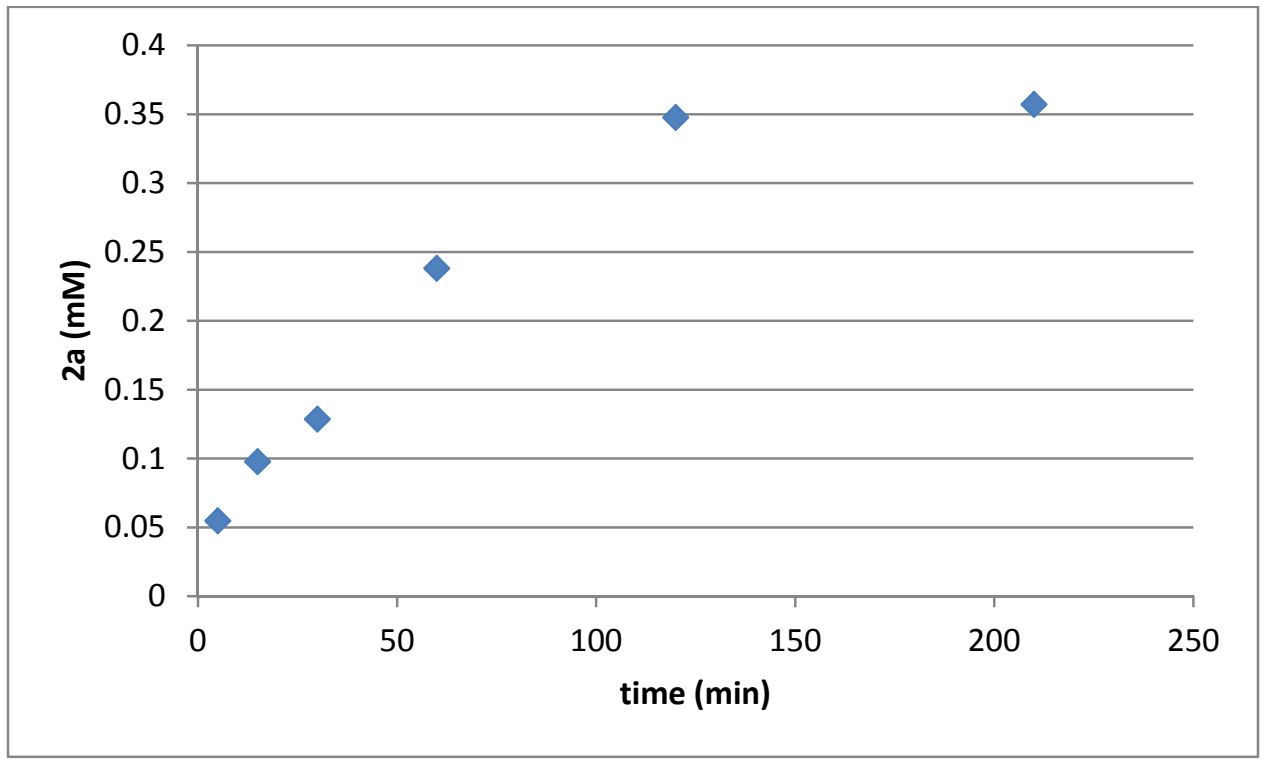

Figure S2. Initial rate determination for 2a. The initial rate of reaction was calculated from the slope of the line connecting time point 5 and 15 minutes. 


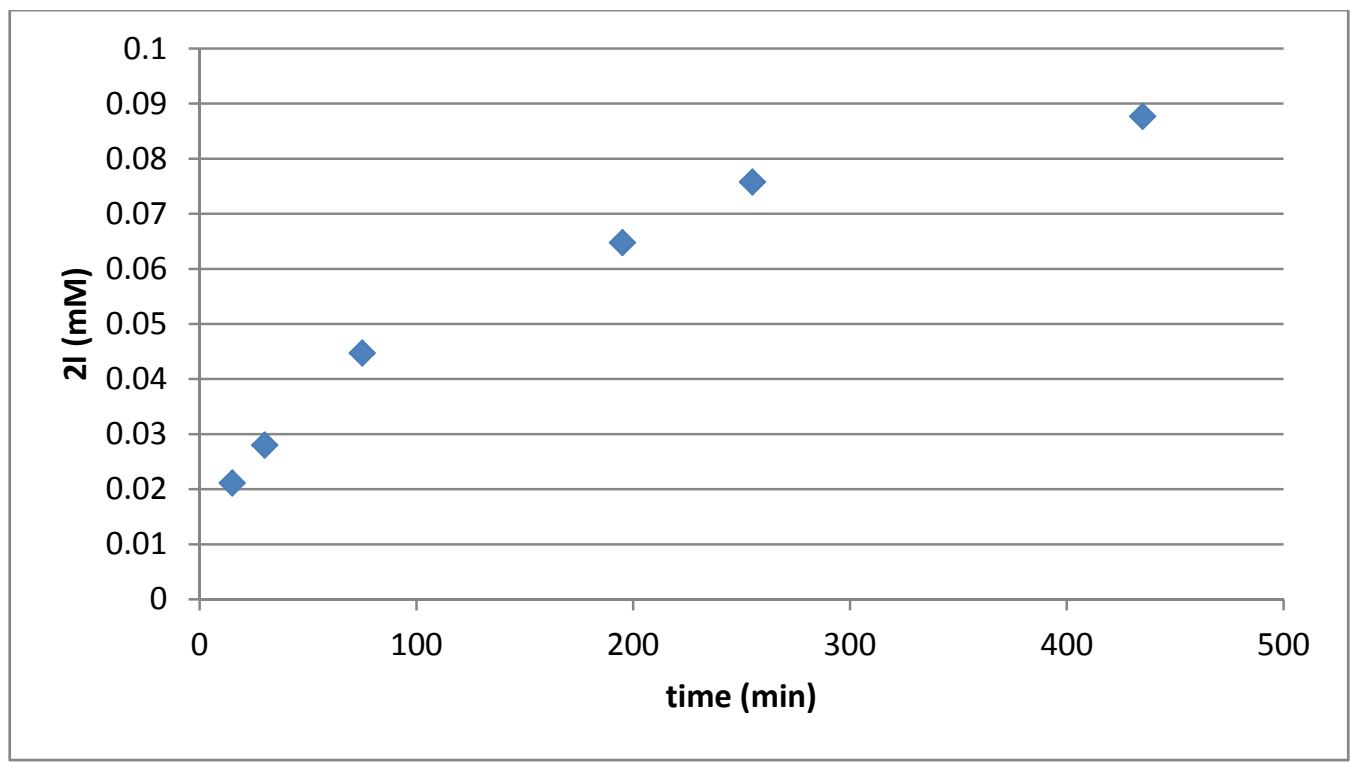

Figure S2. Initial rate determination for sulfone $\mathbf{2 l}$. The initial rate of reaction was calculated from the slope of the line connecting time point 15 and 30 minutes. 


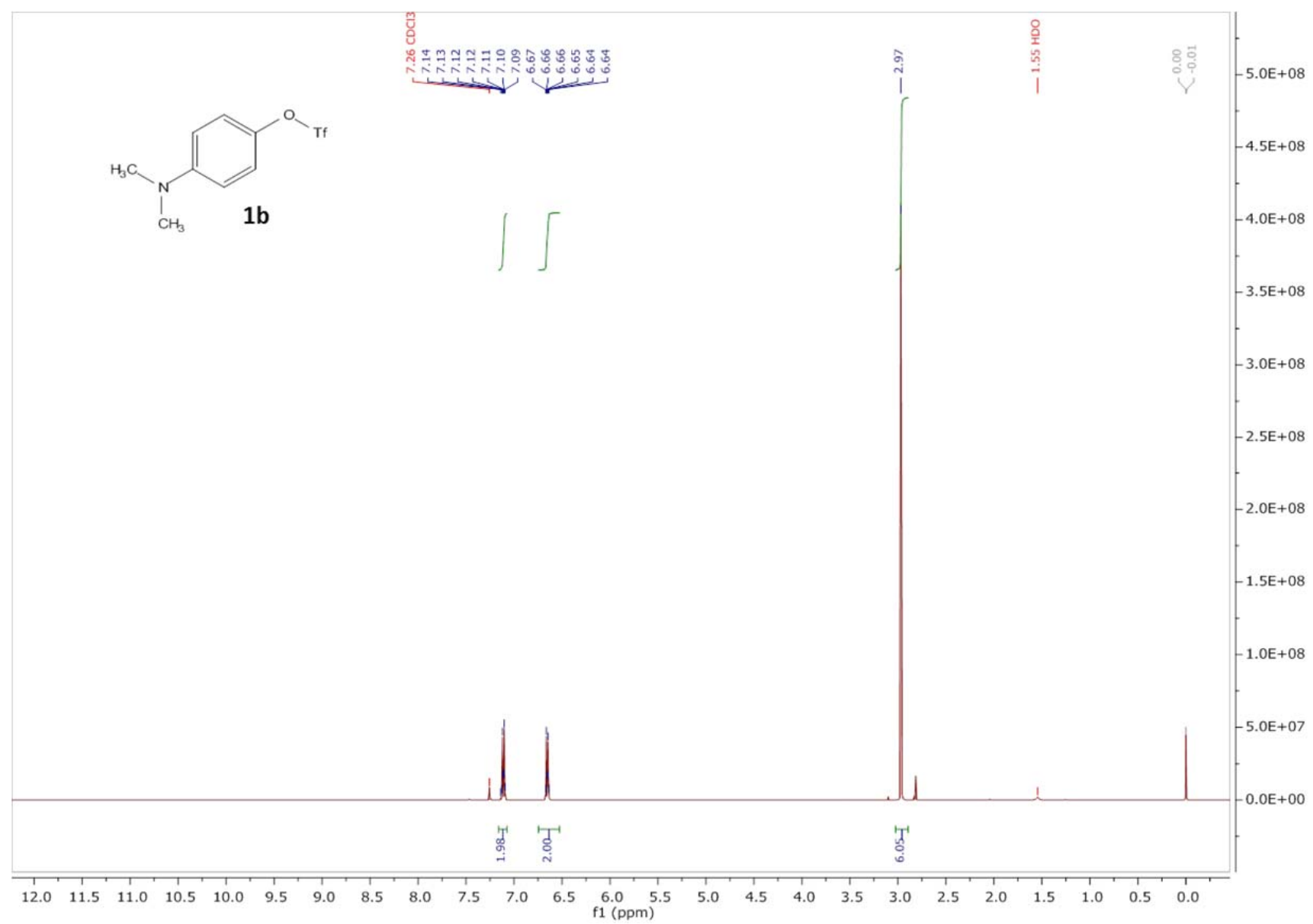




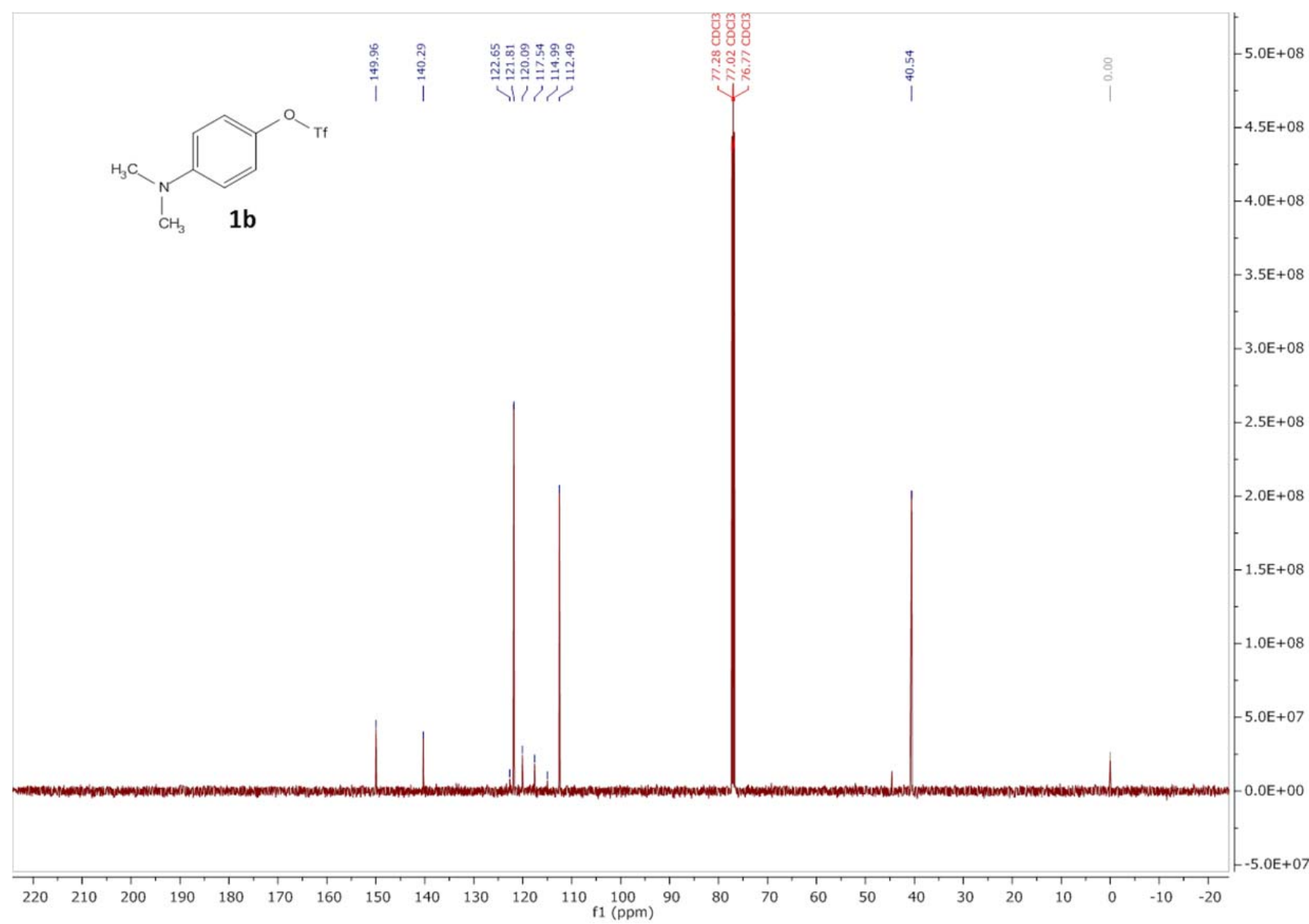




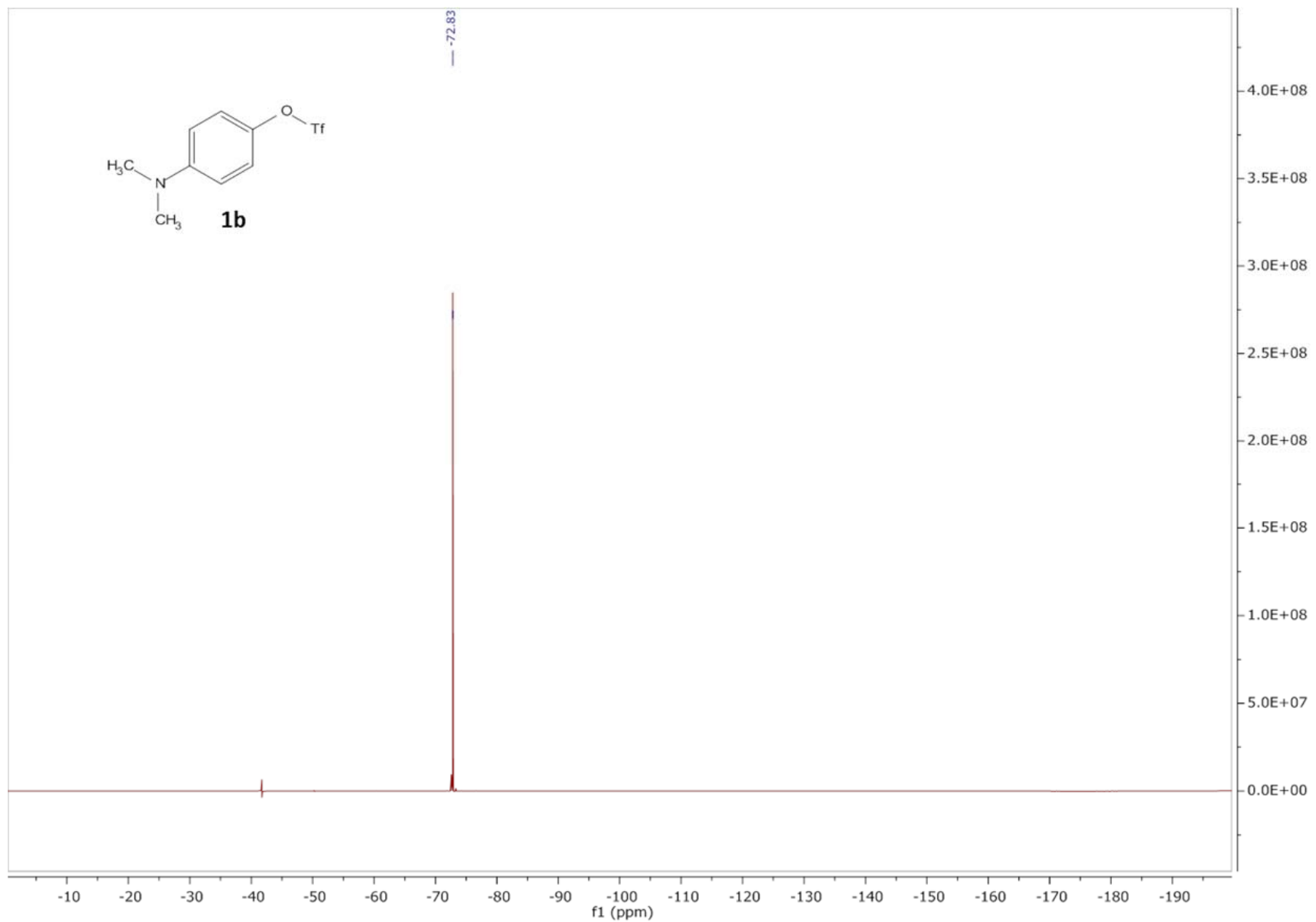




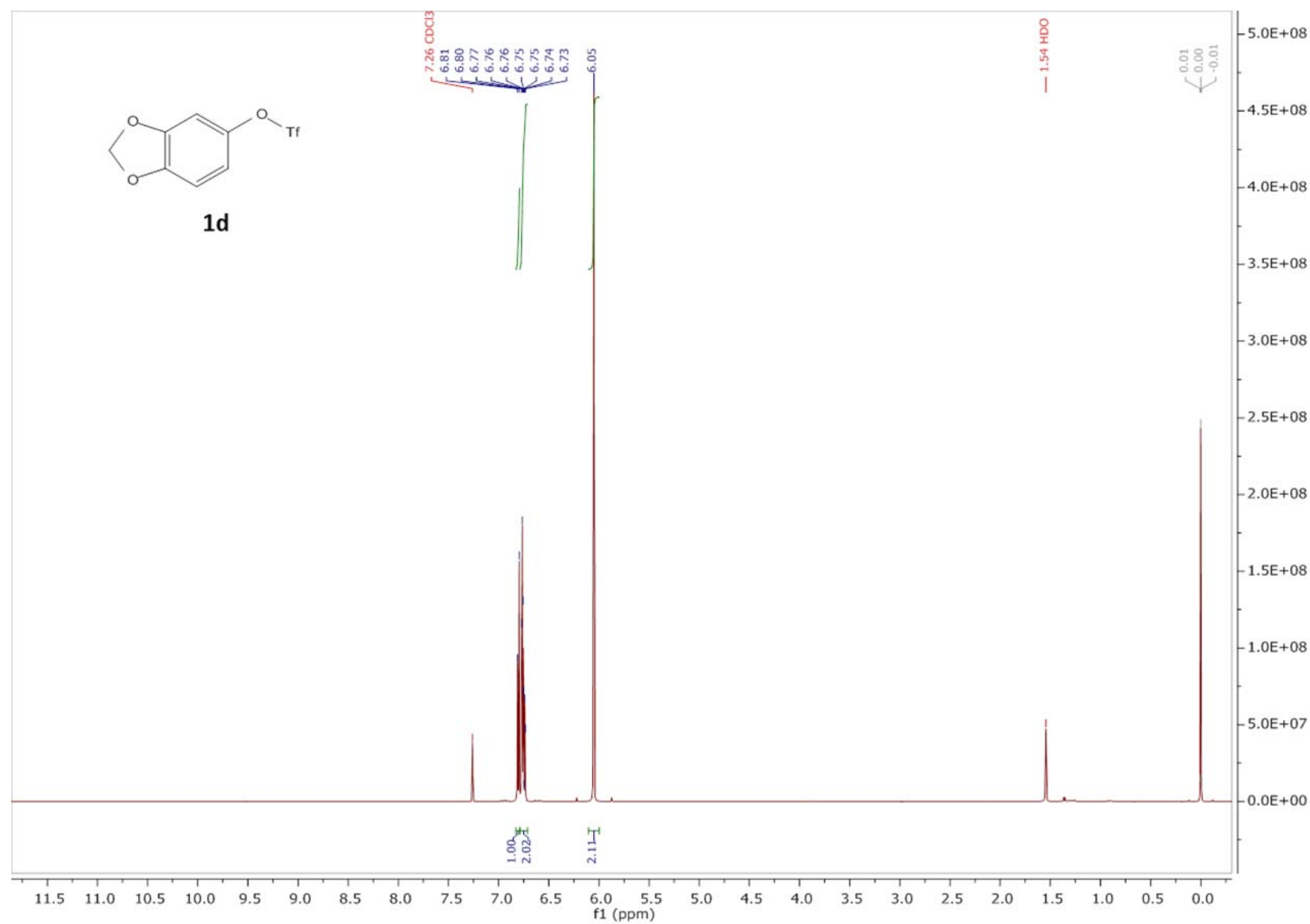




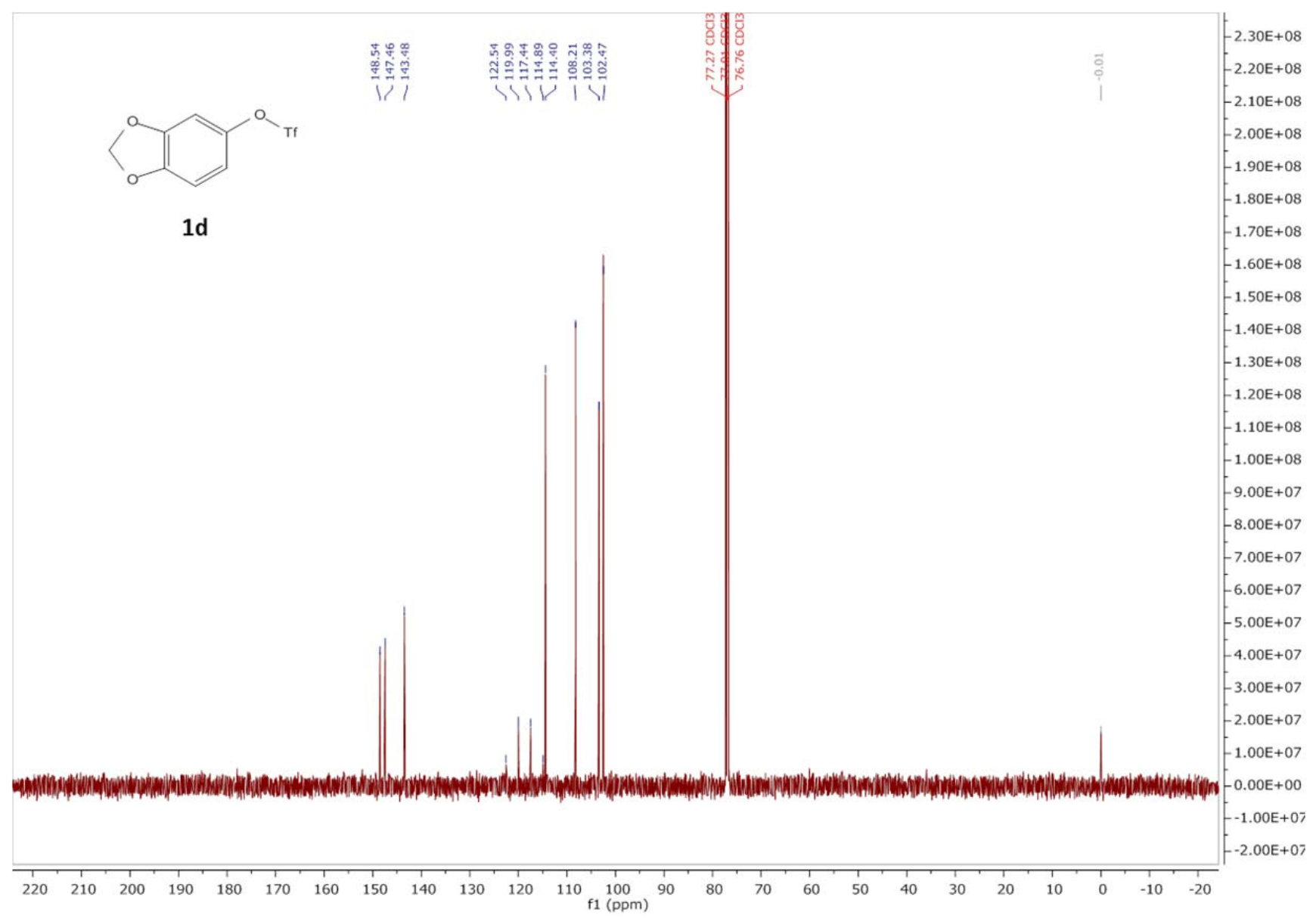




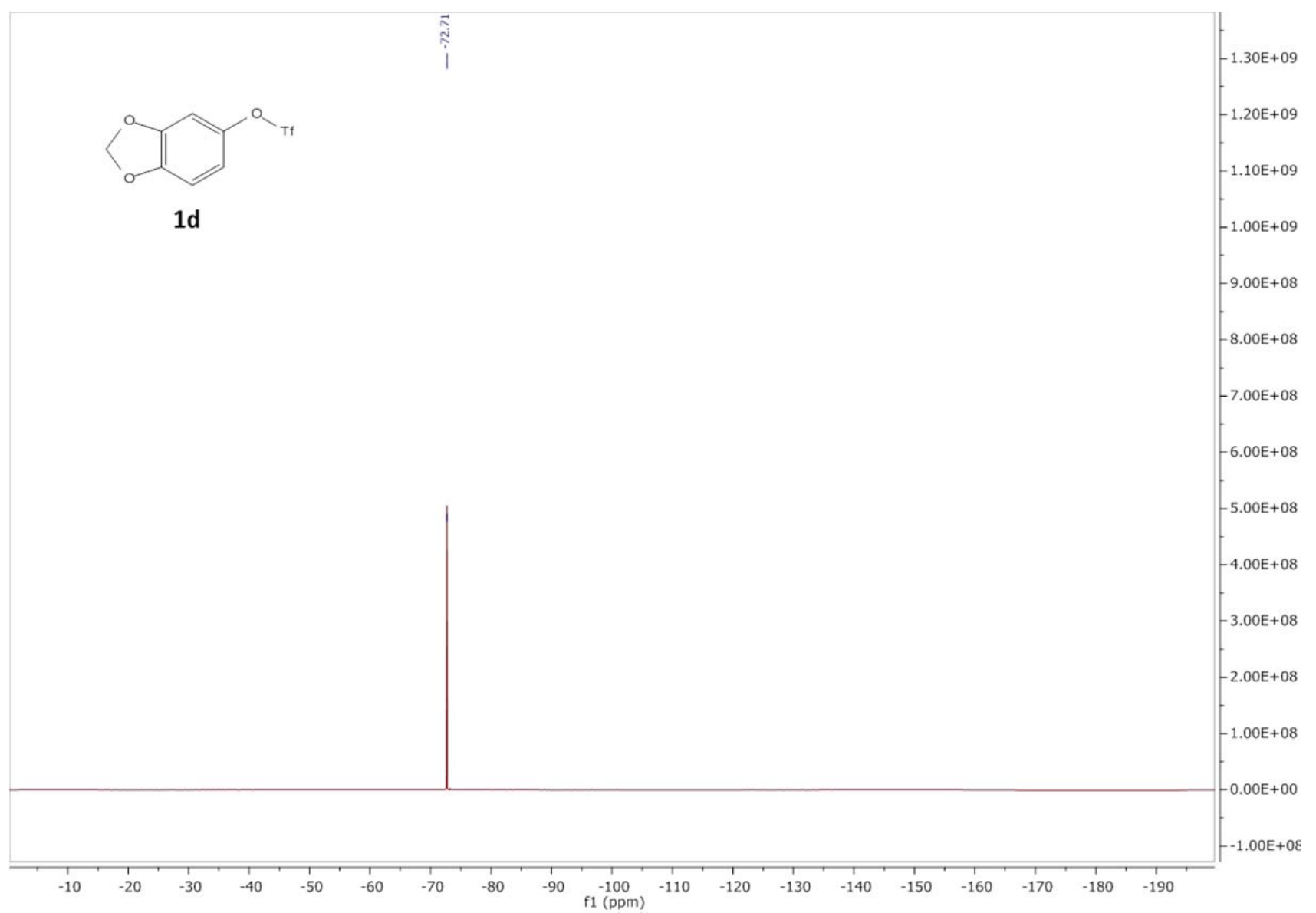




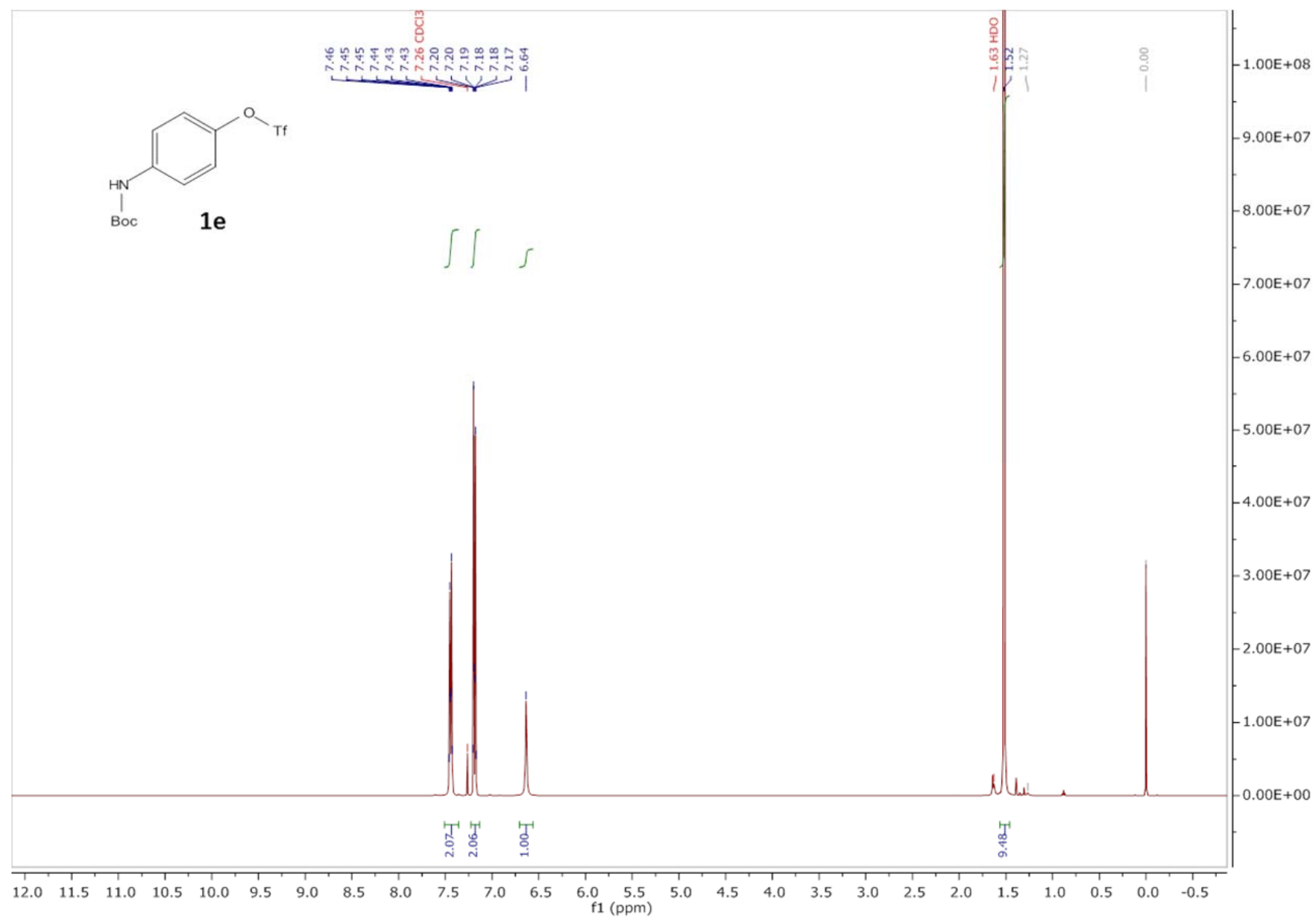




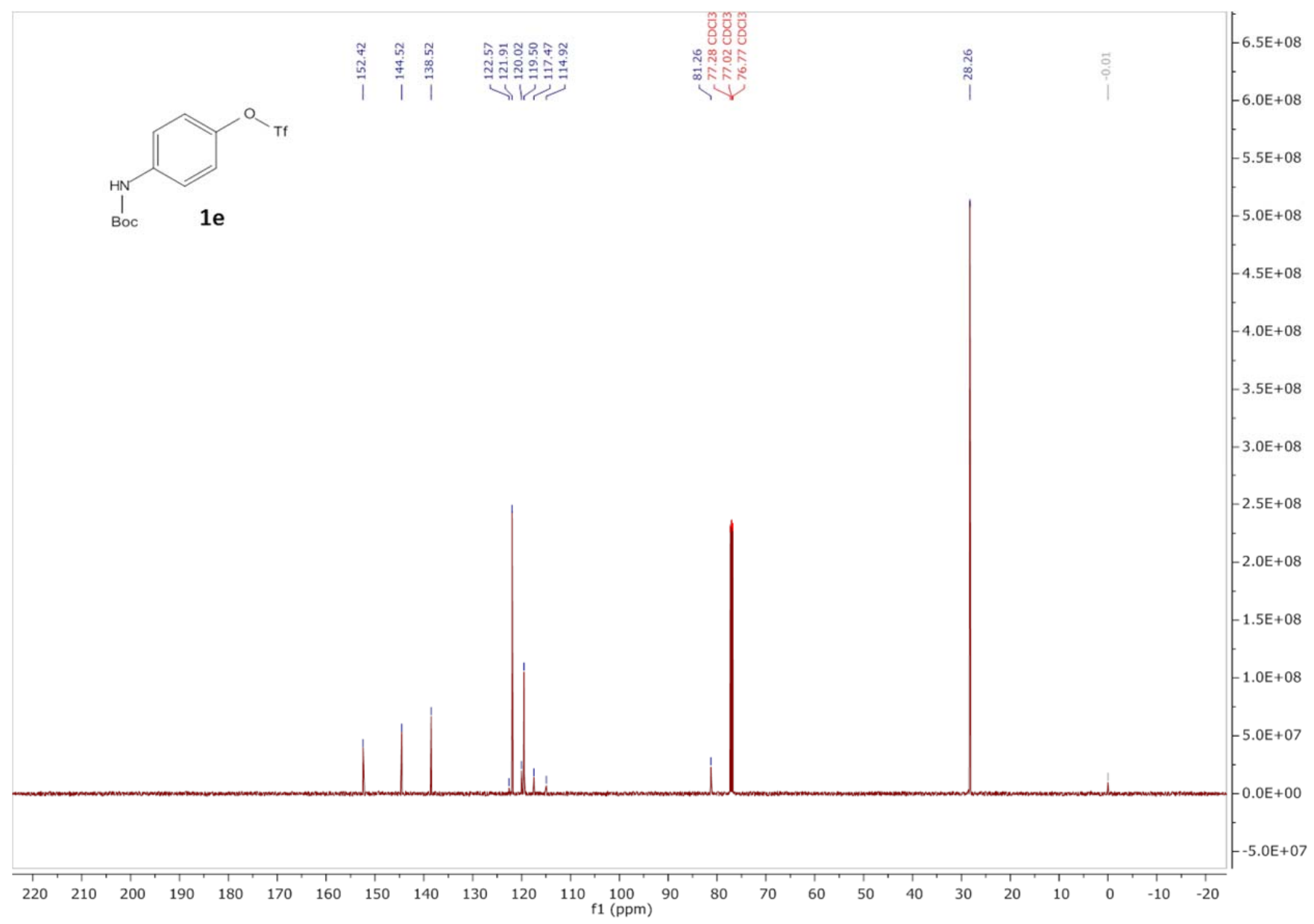




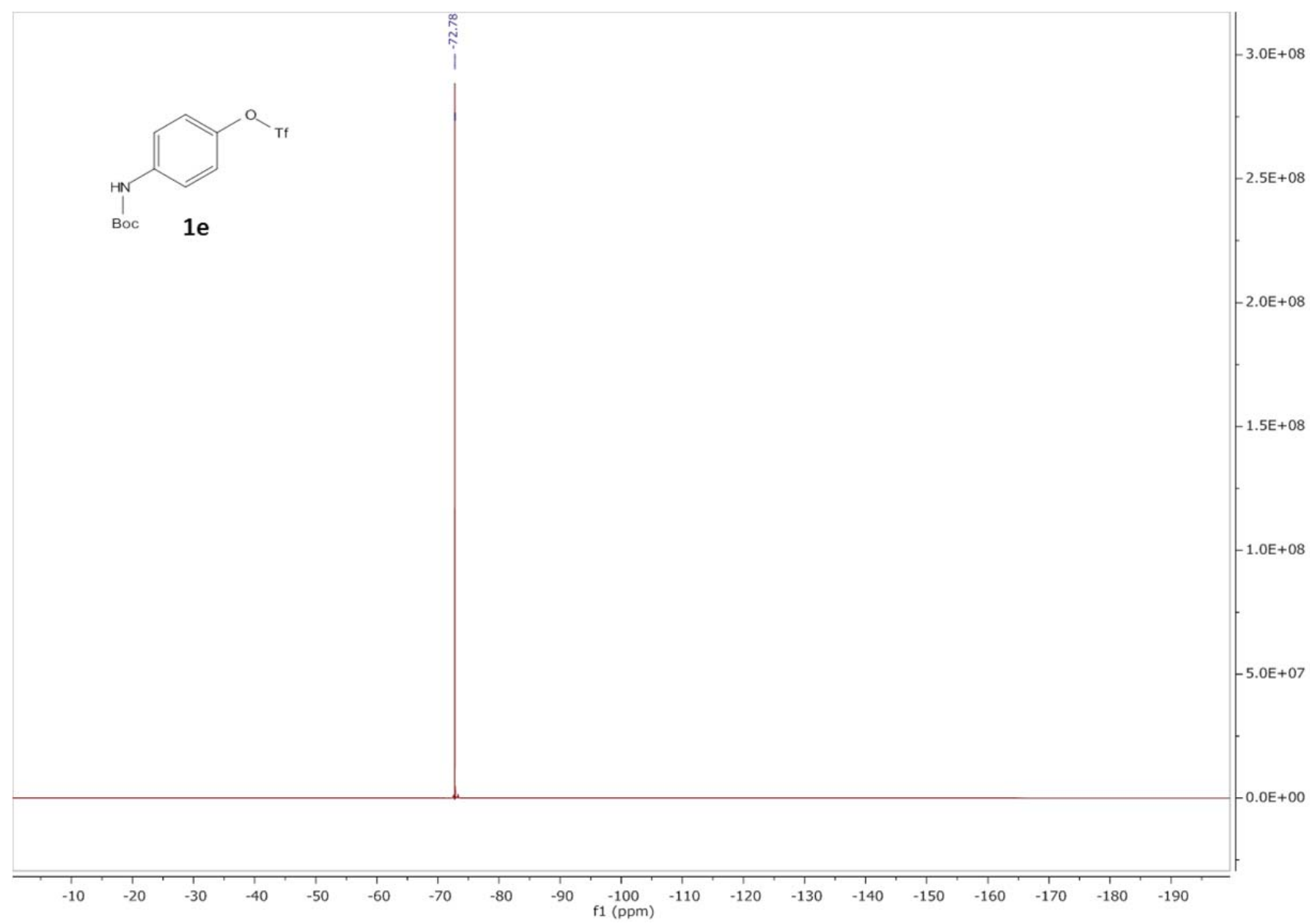




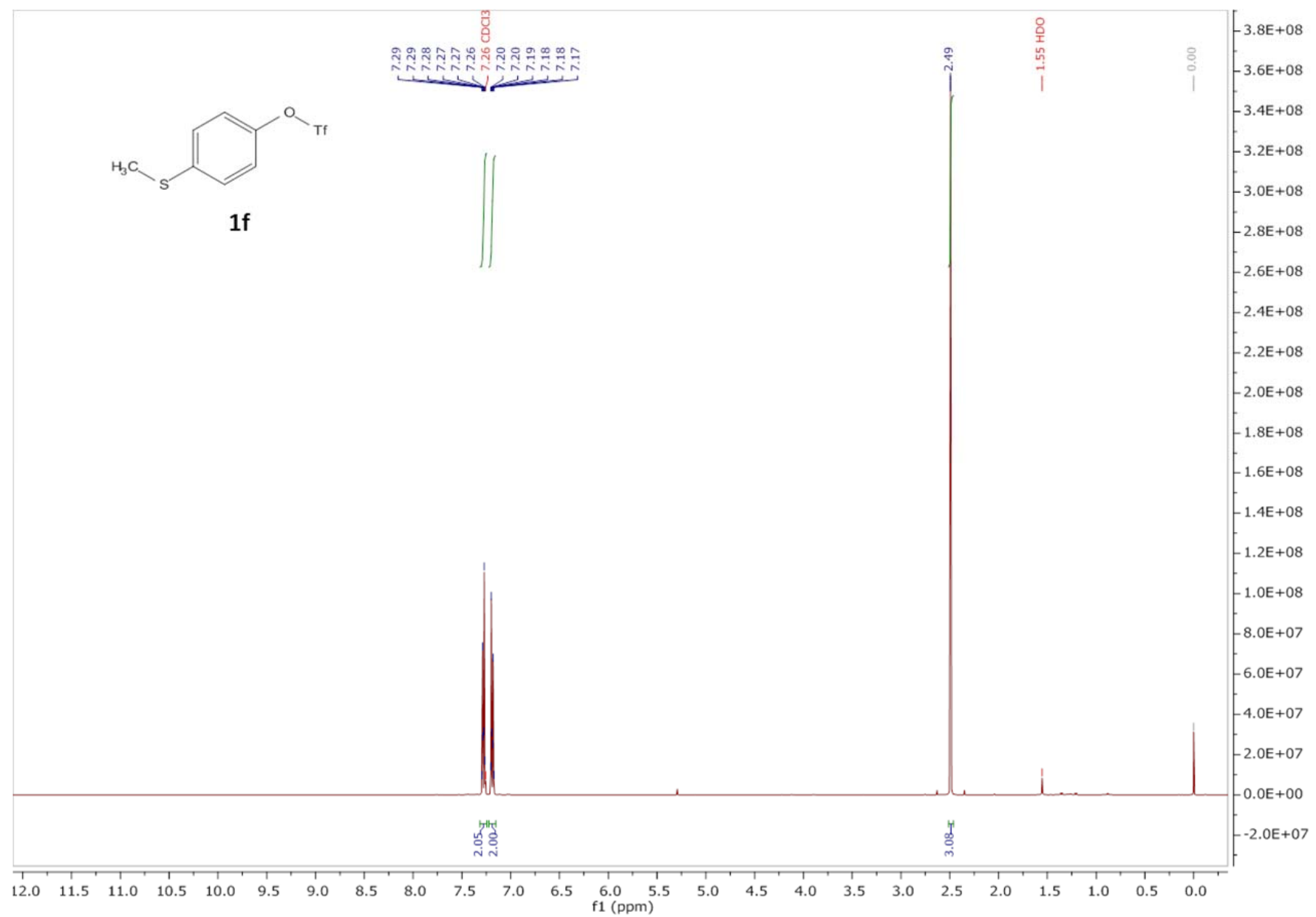




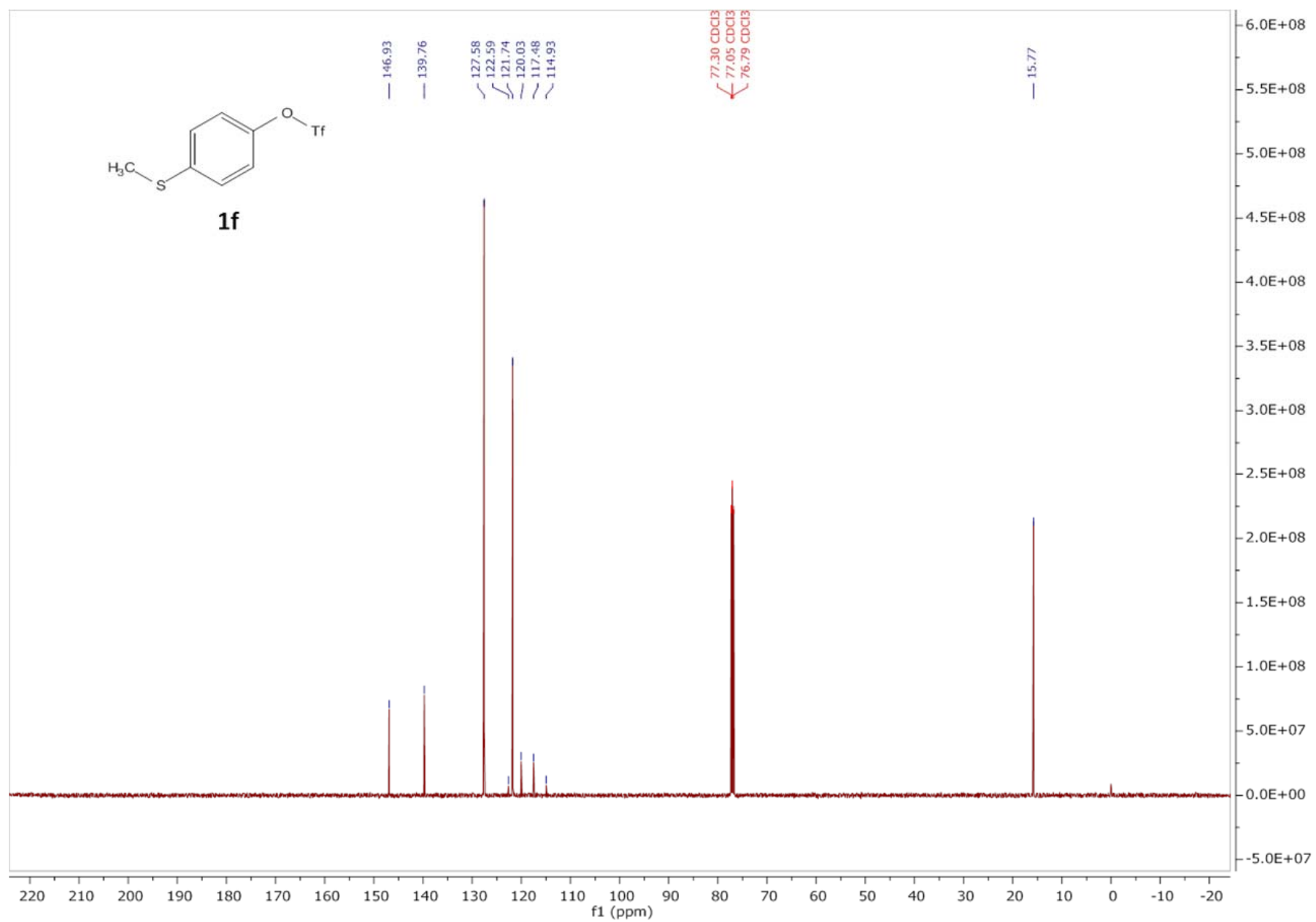




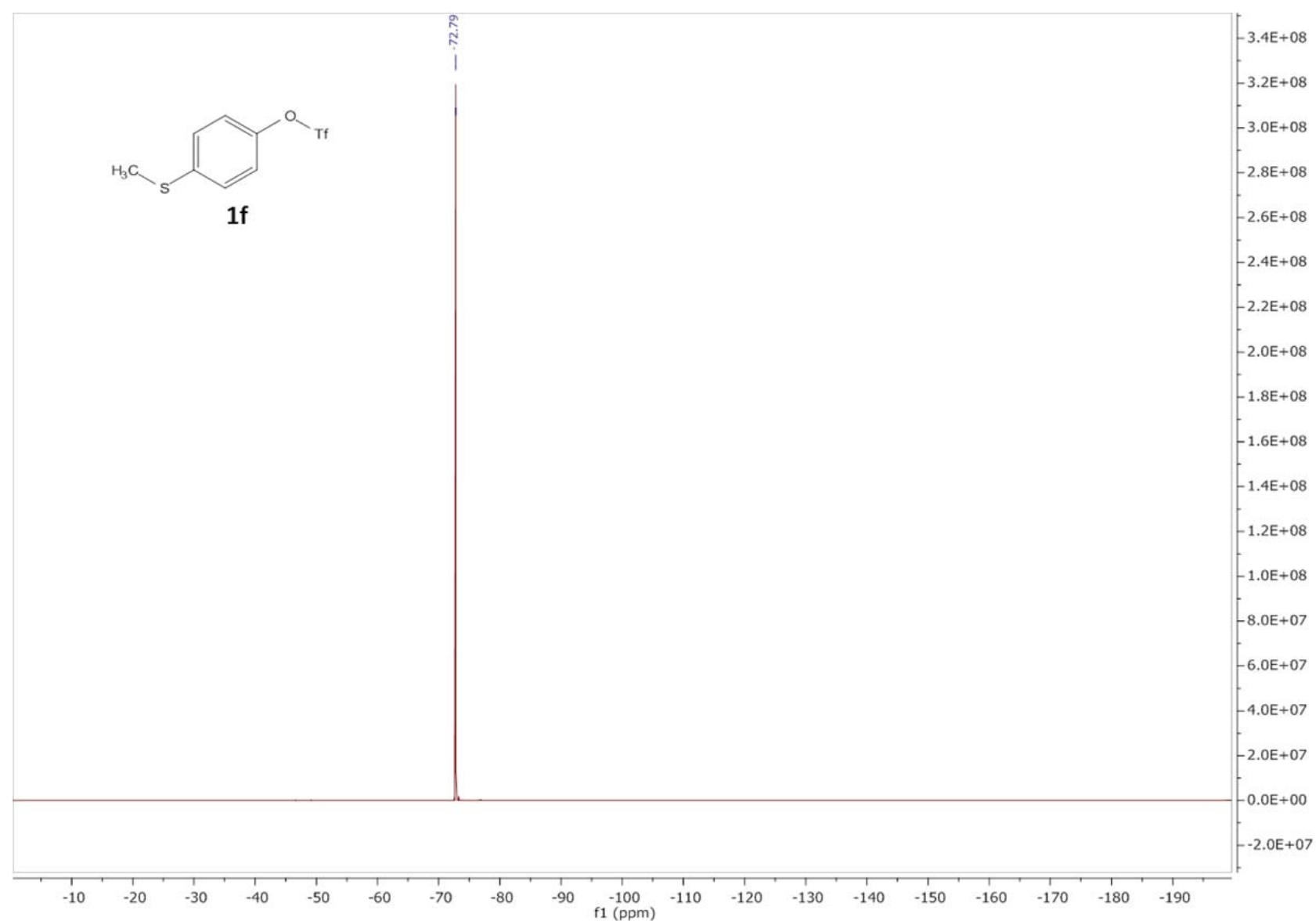




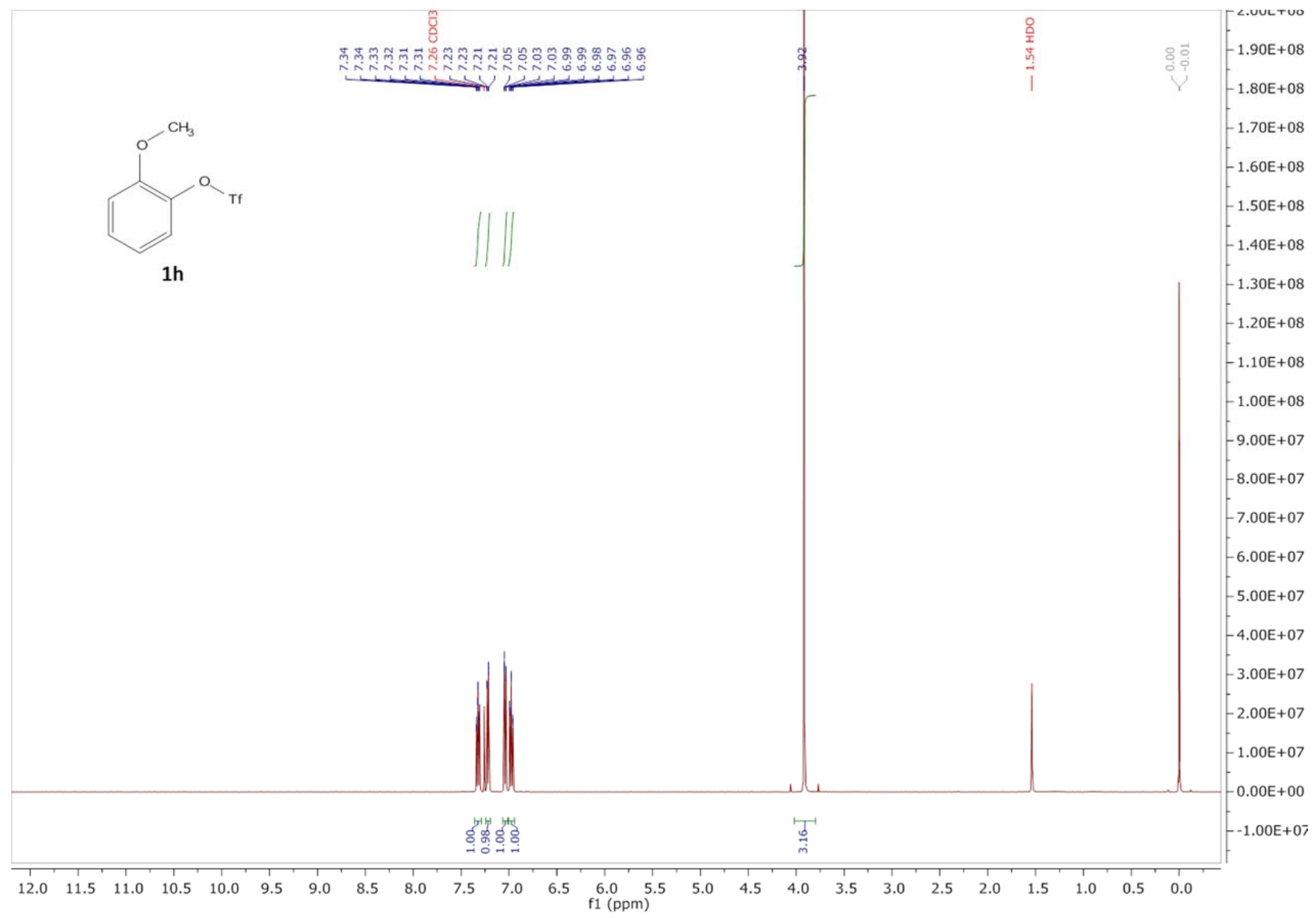




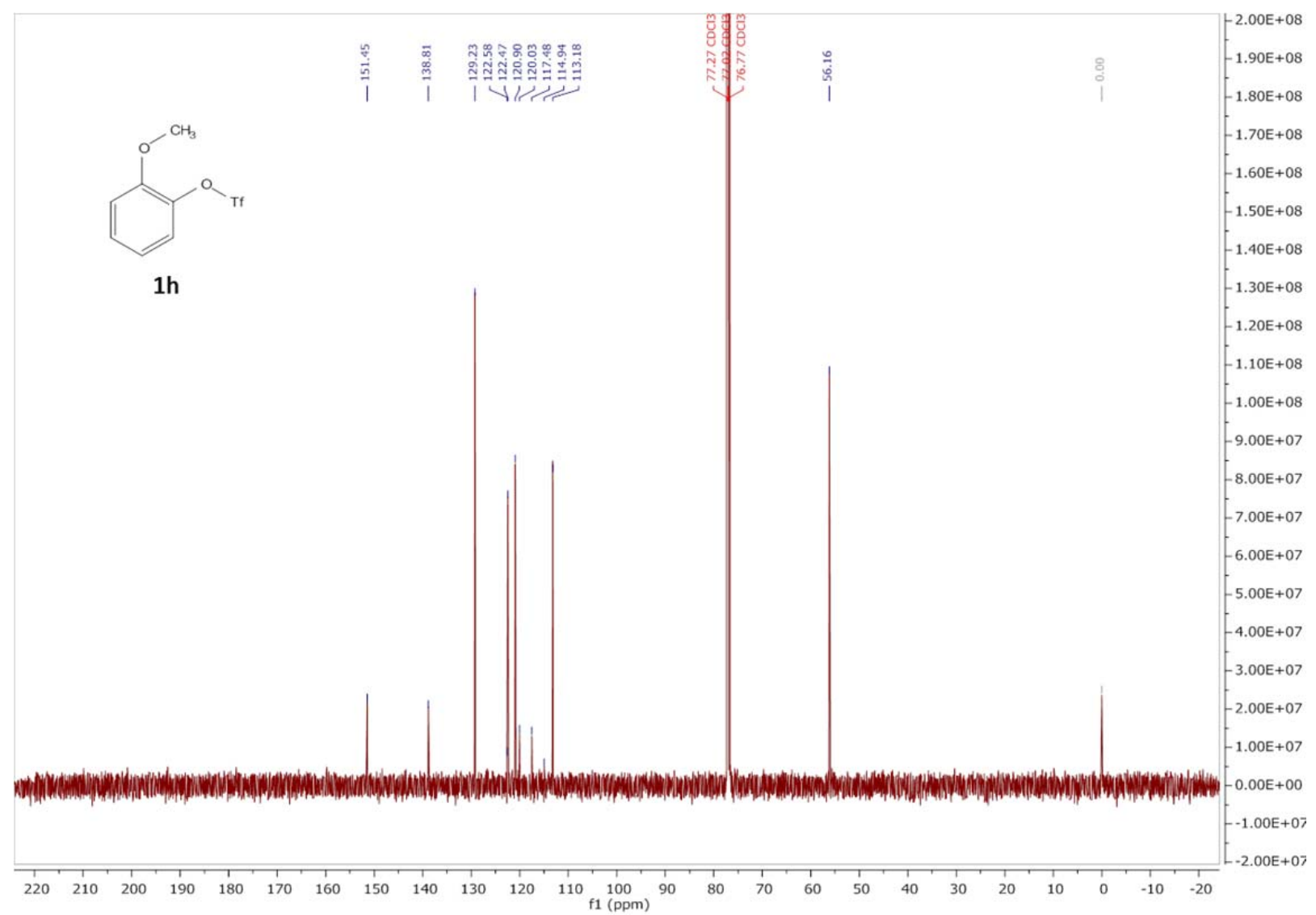




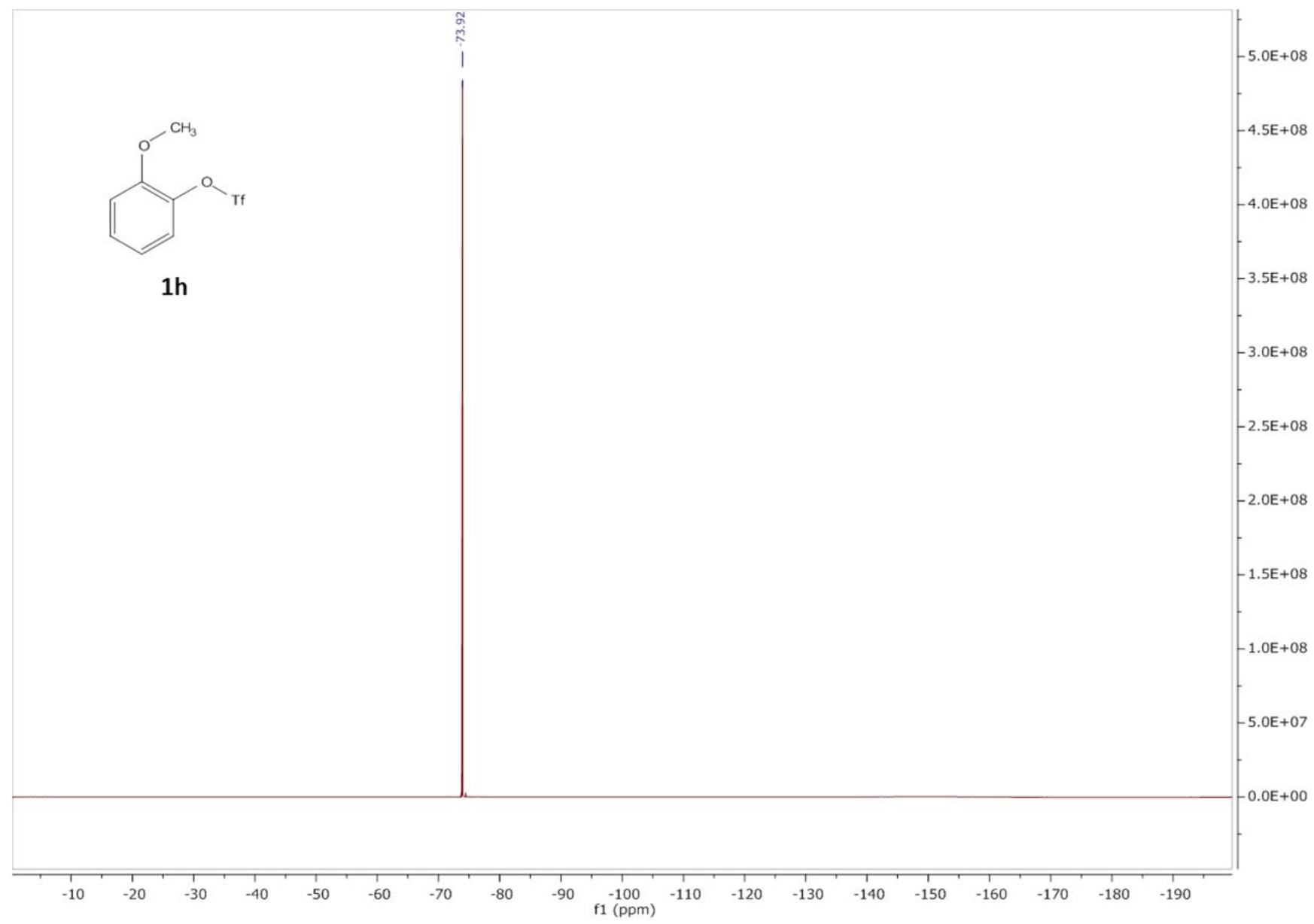




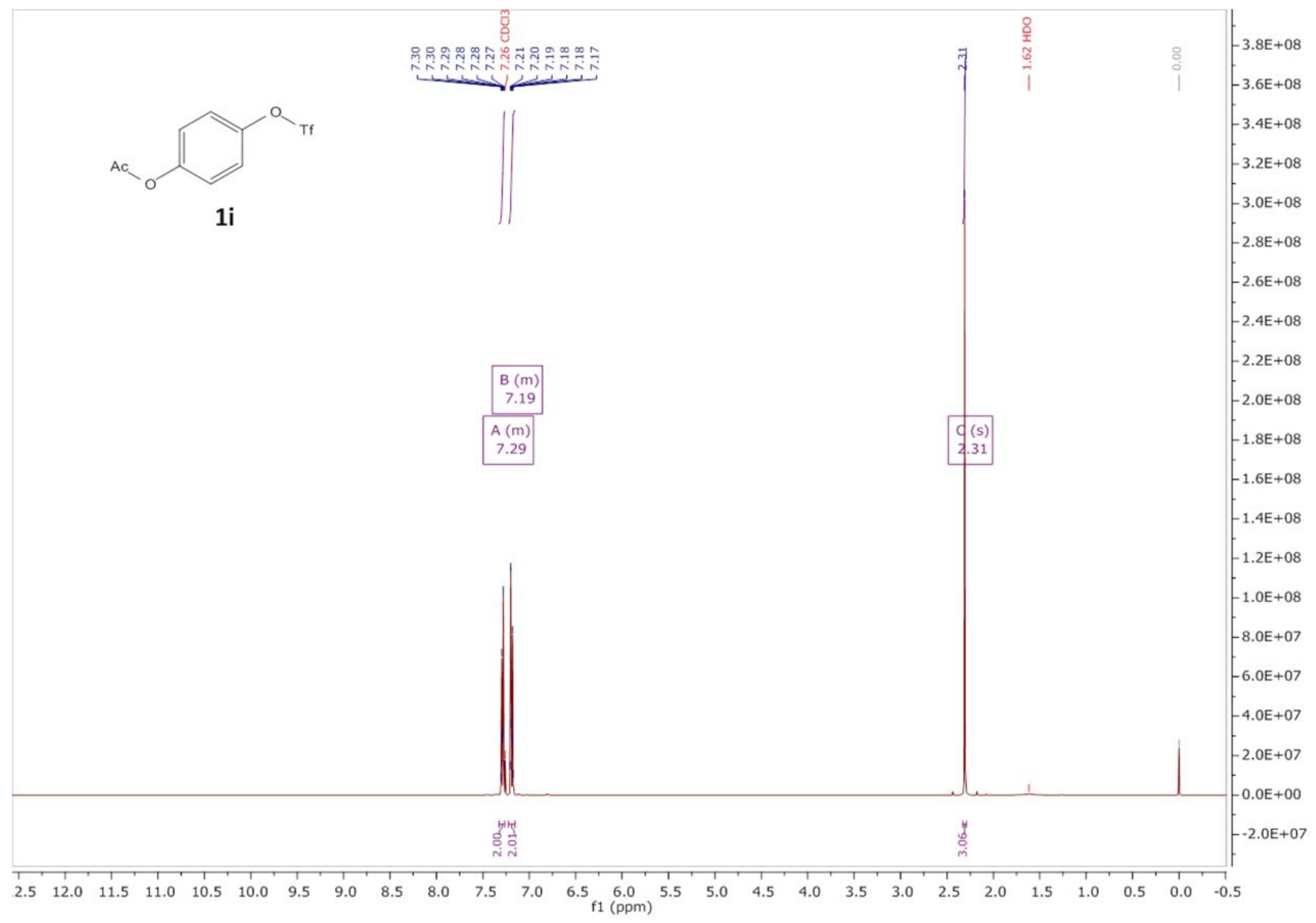




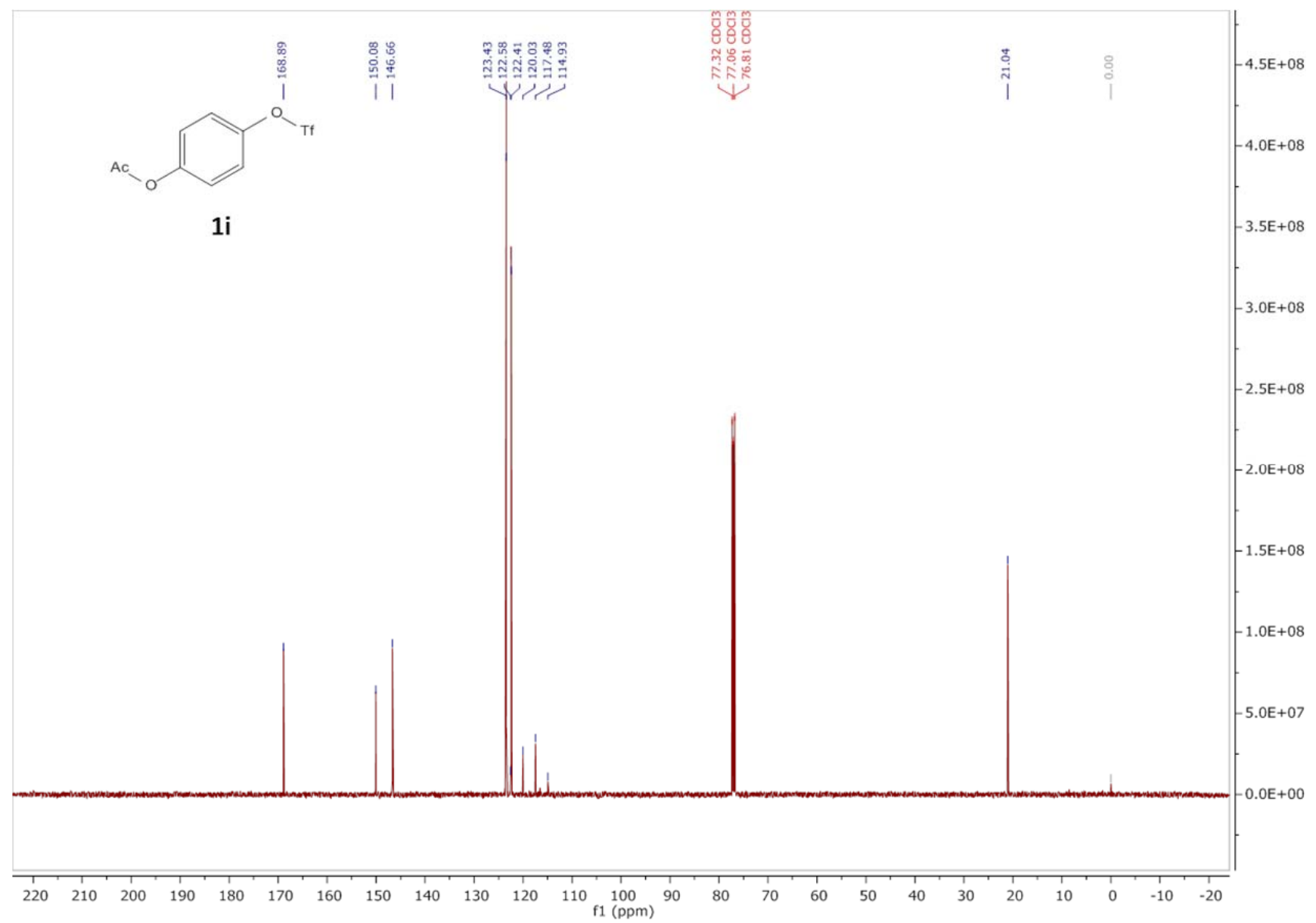




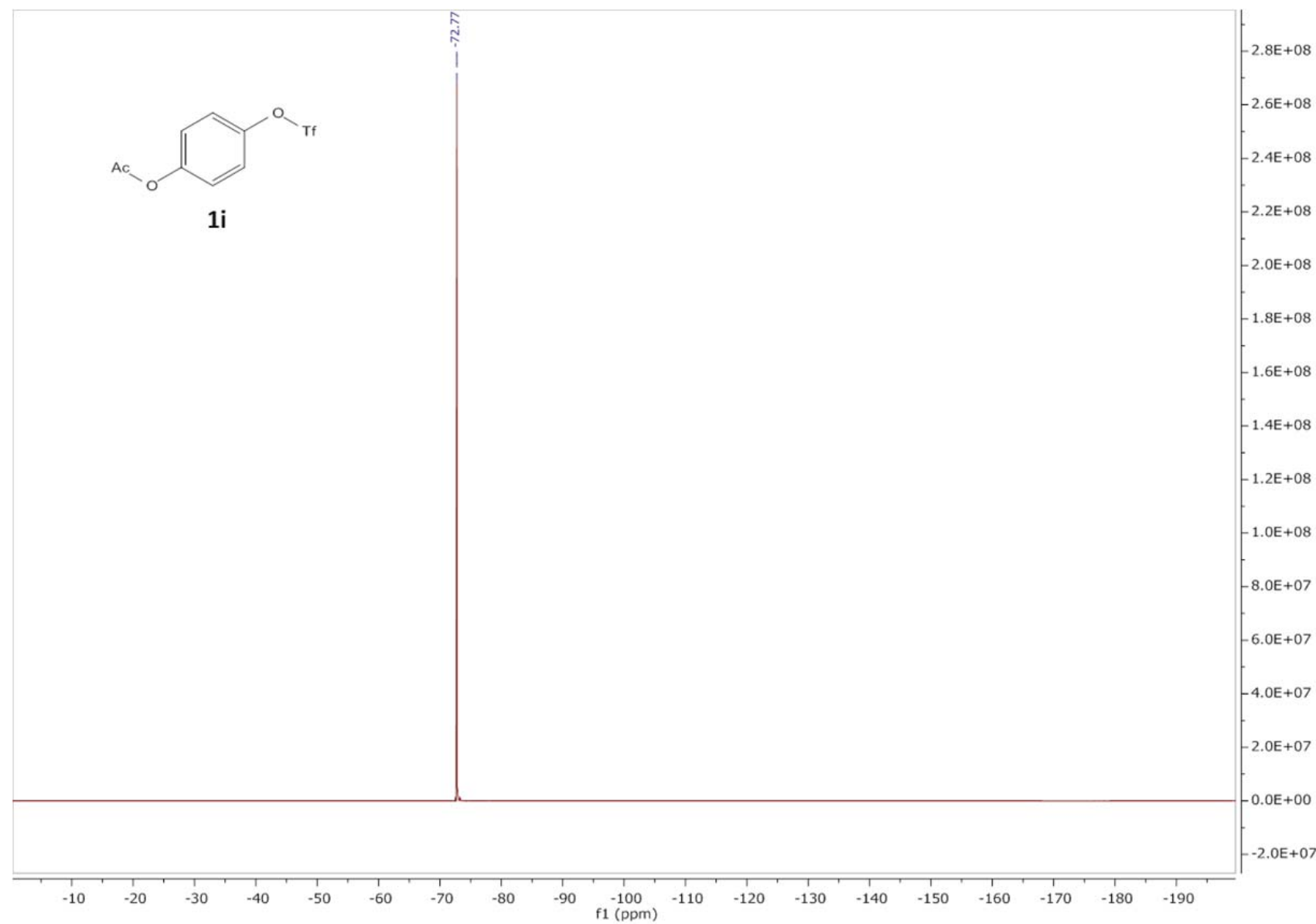




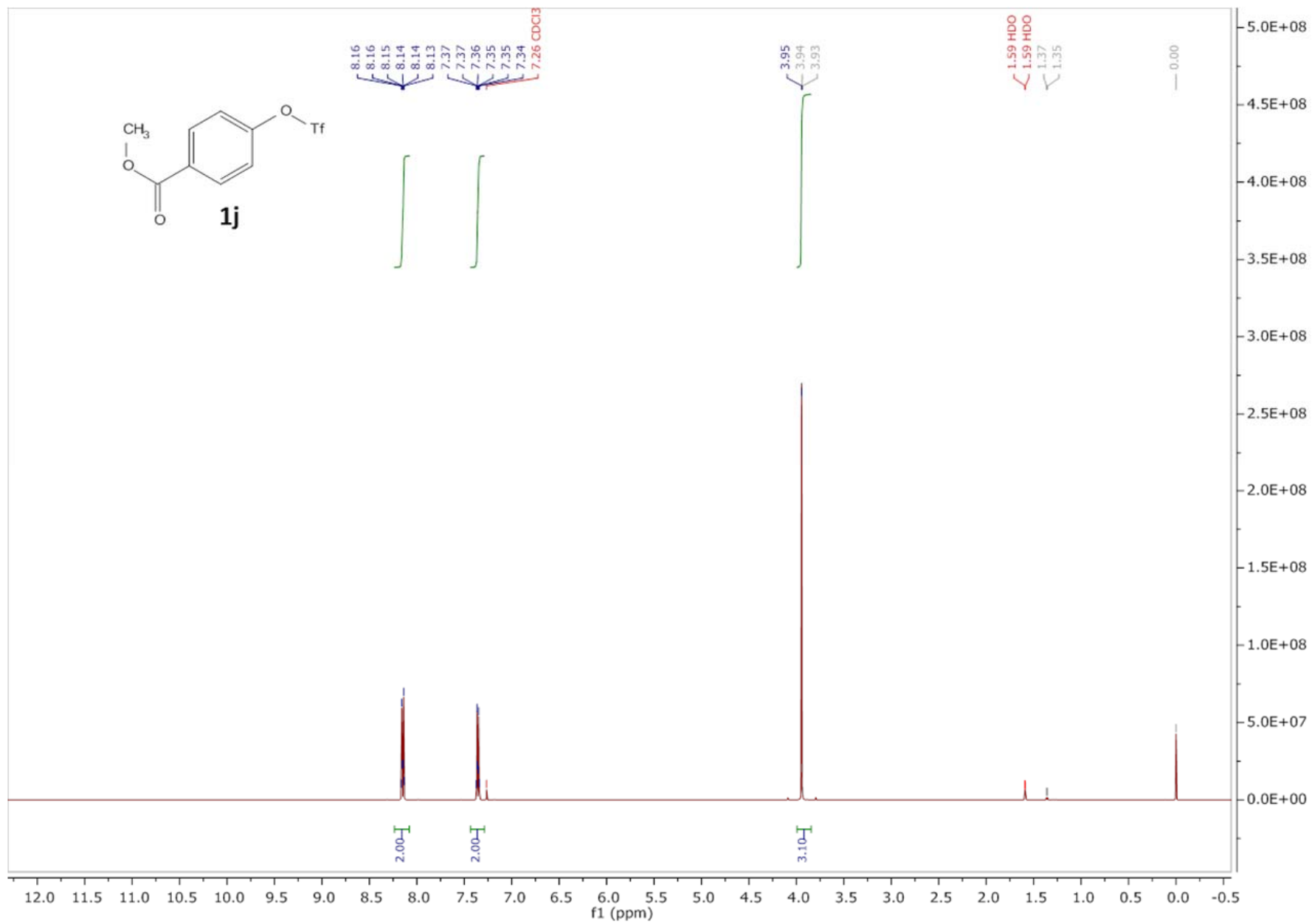




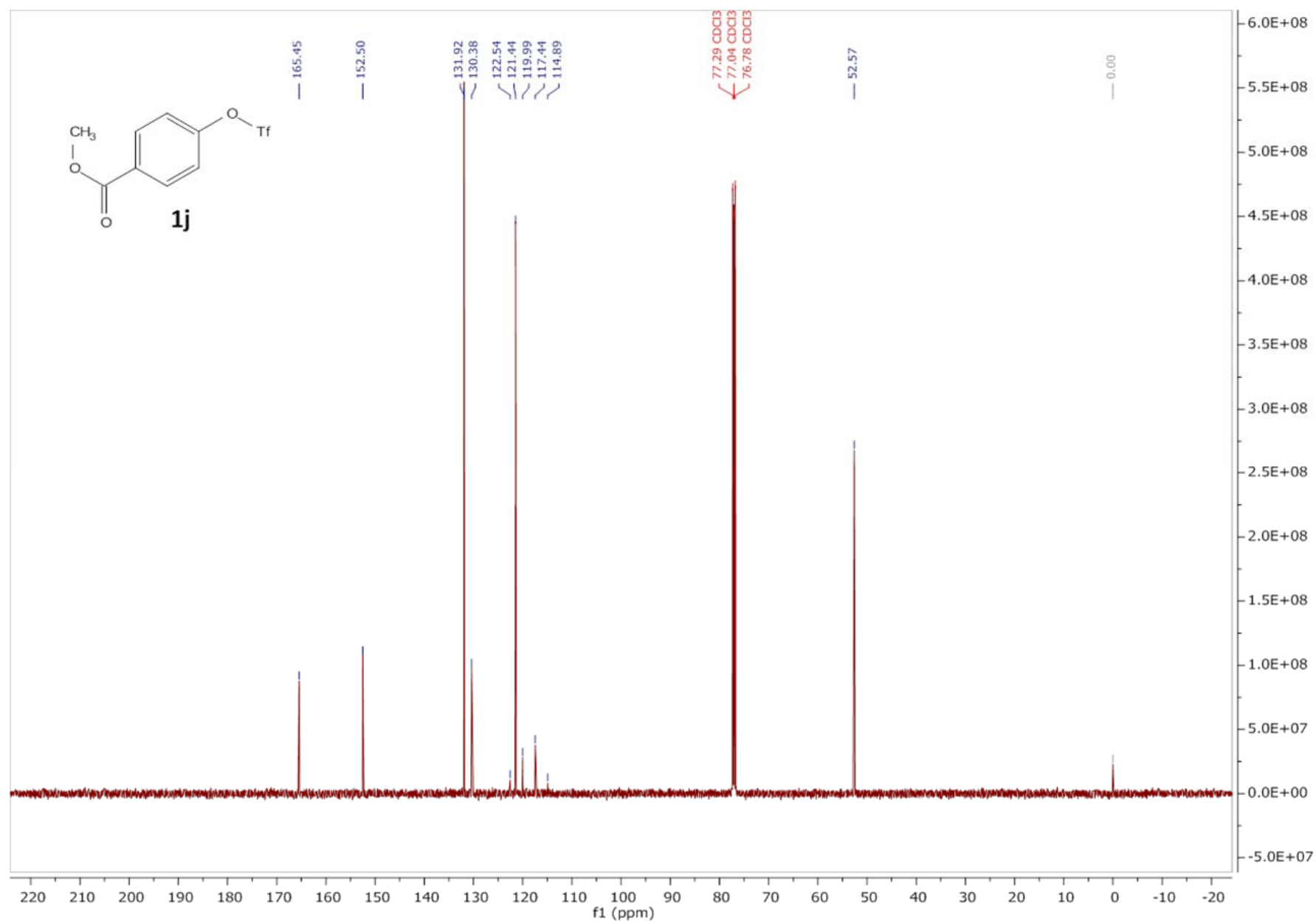




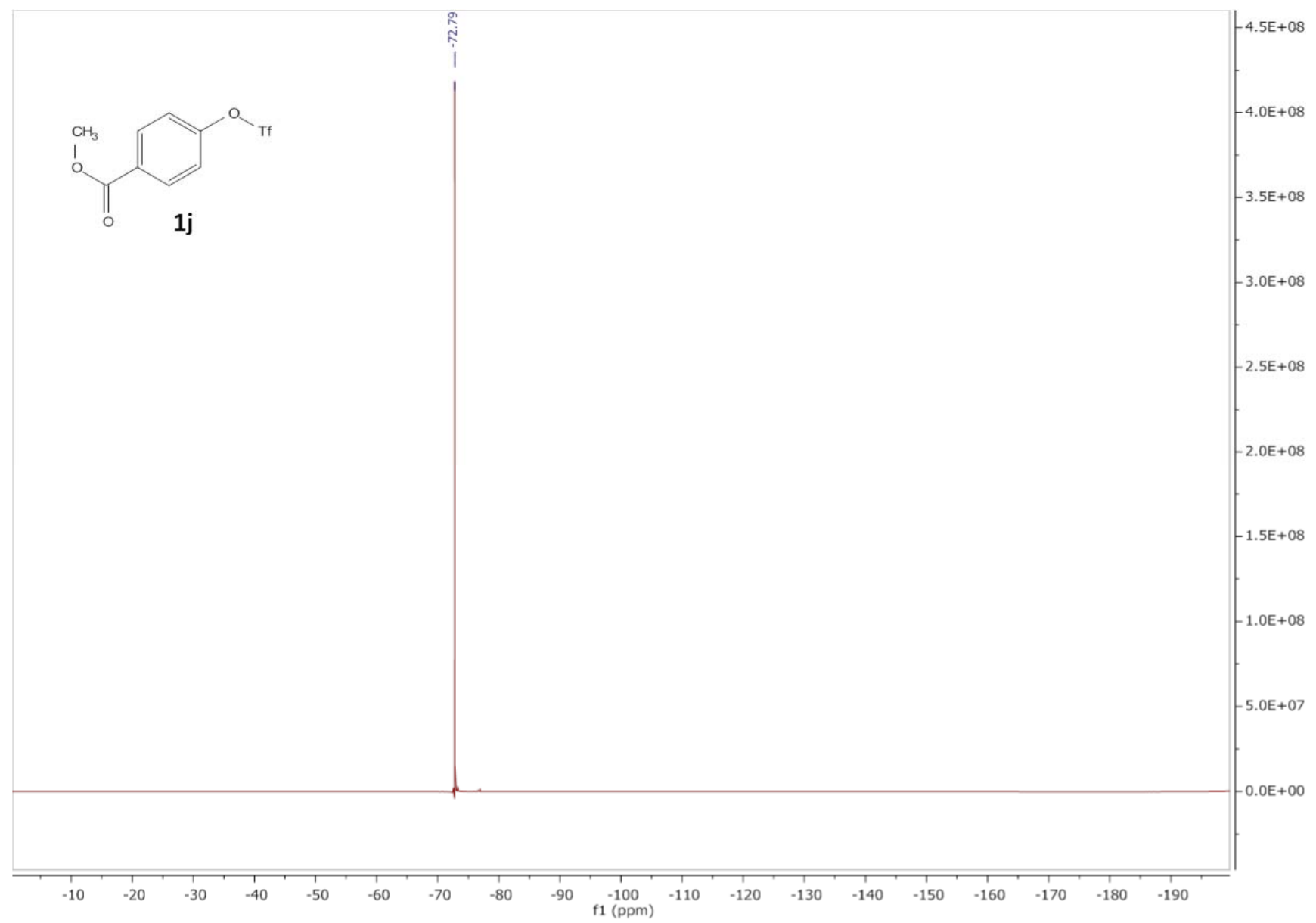




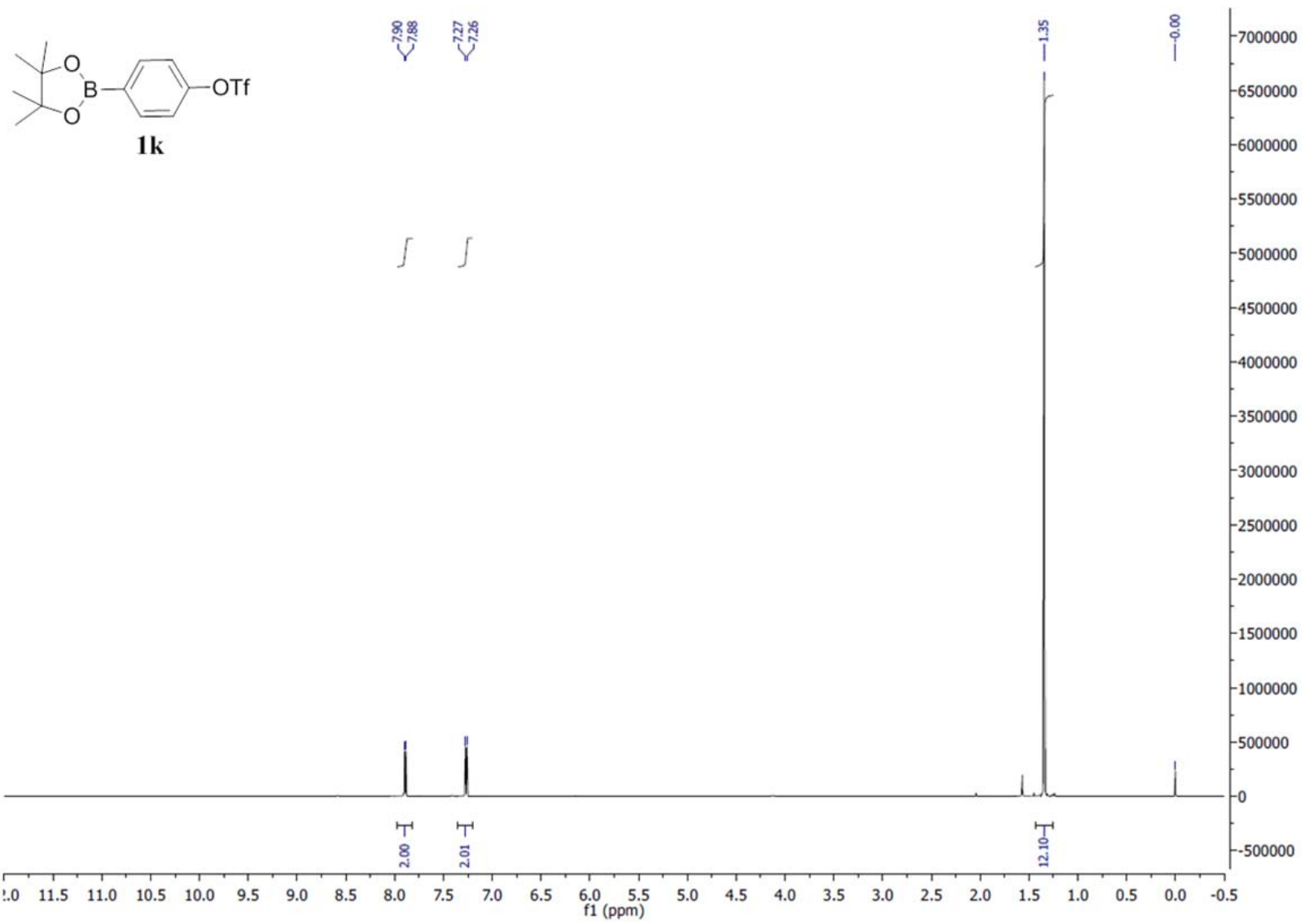




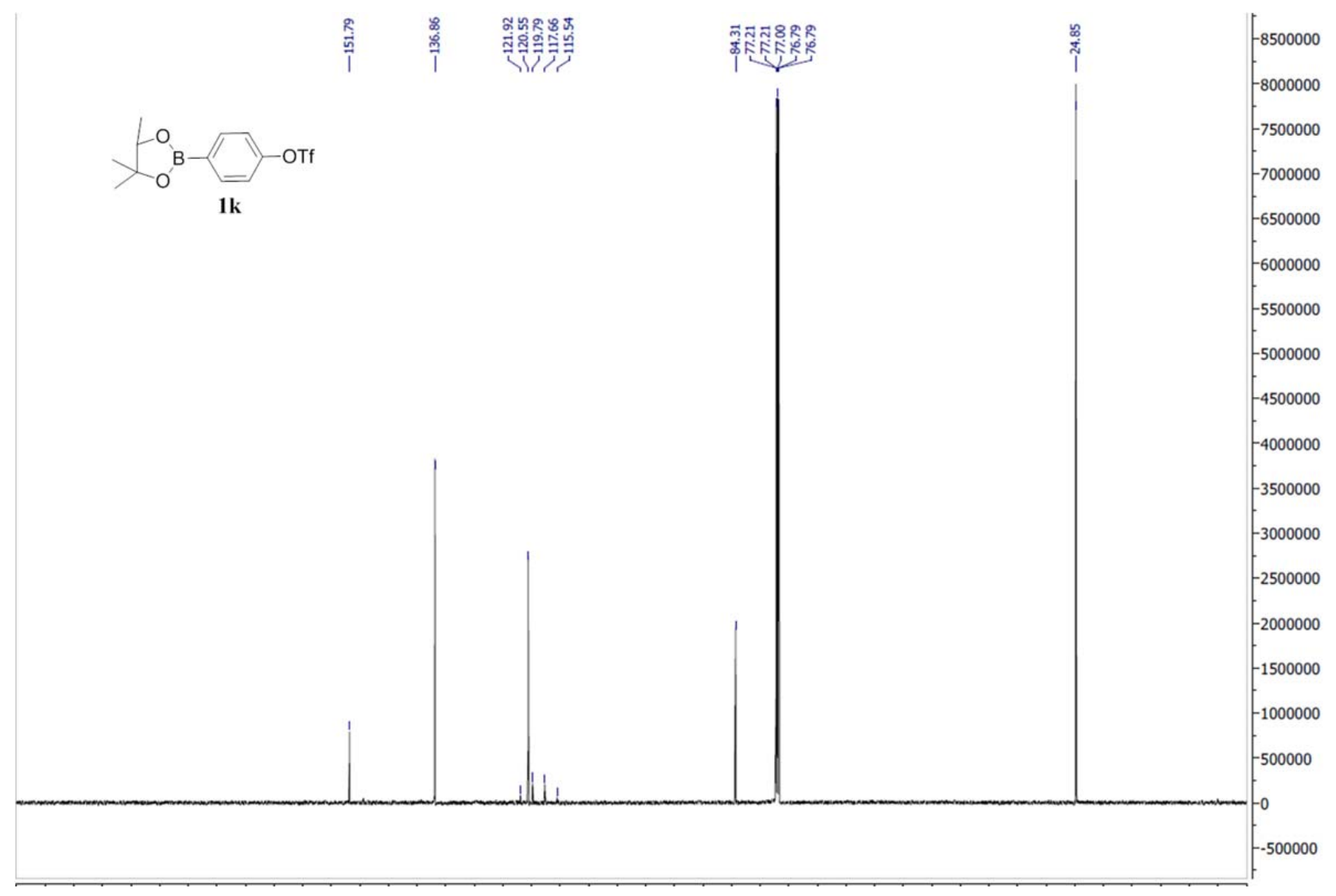




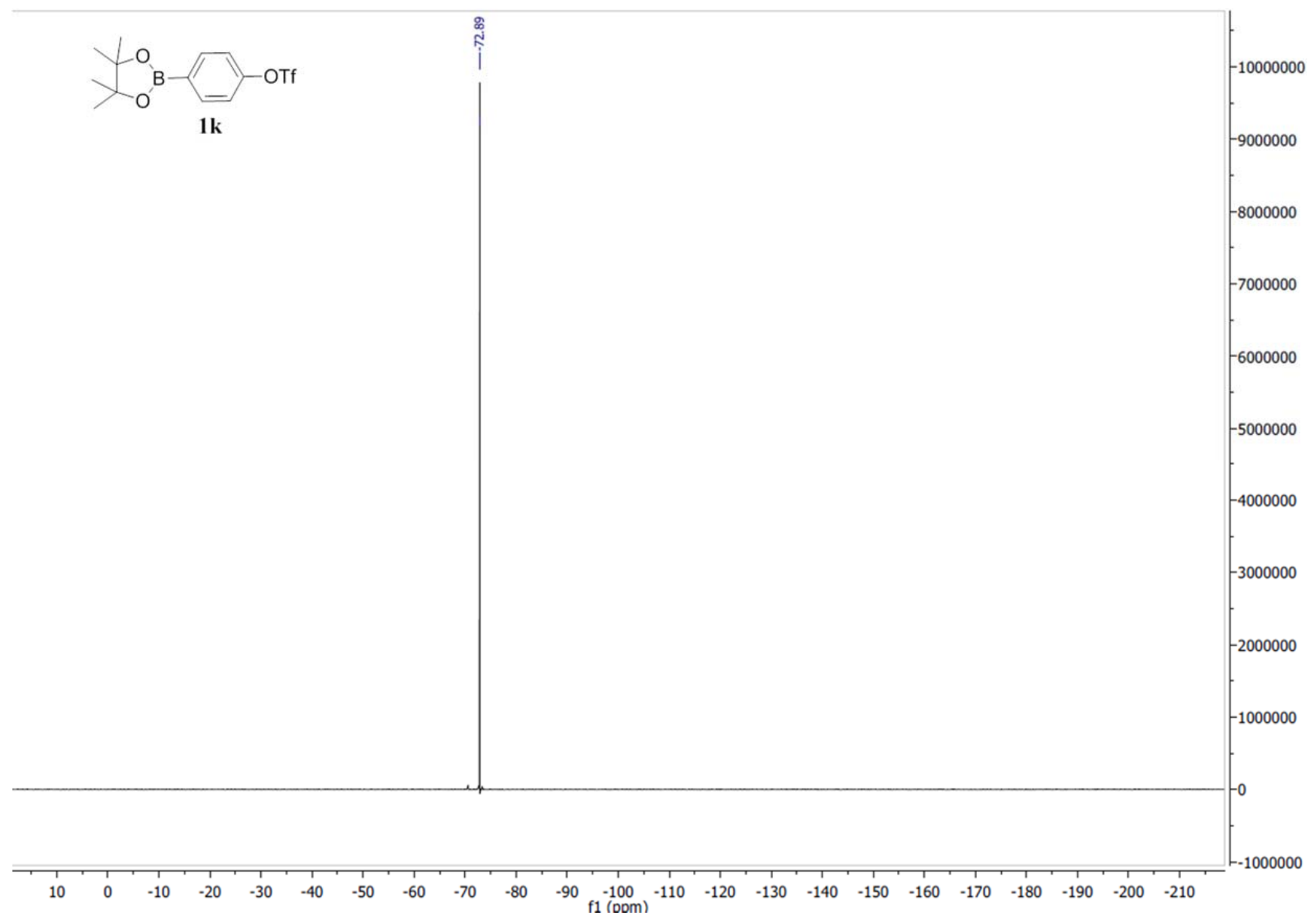




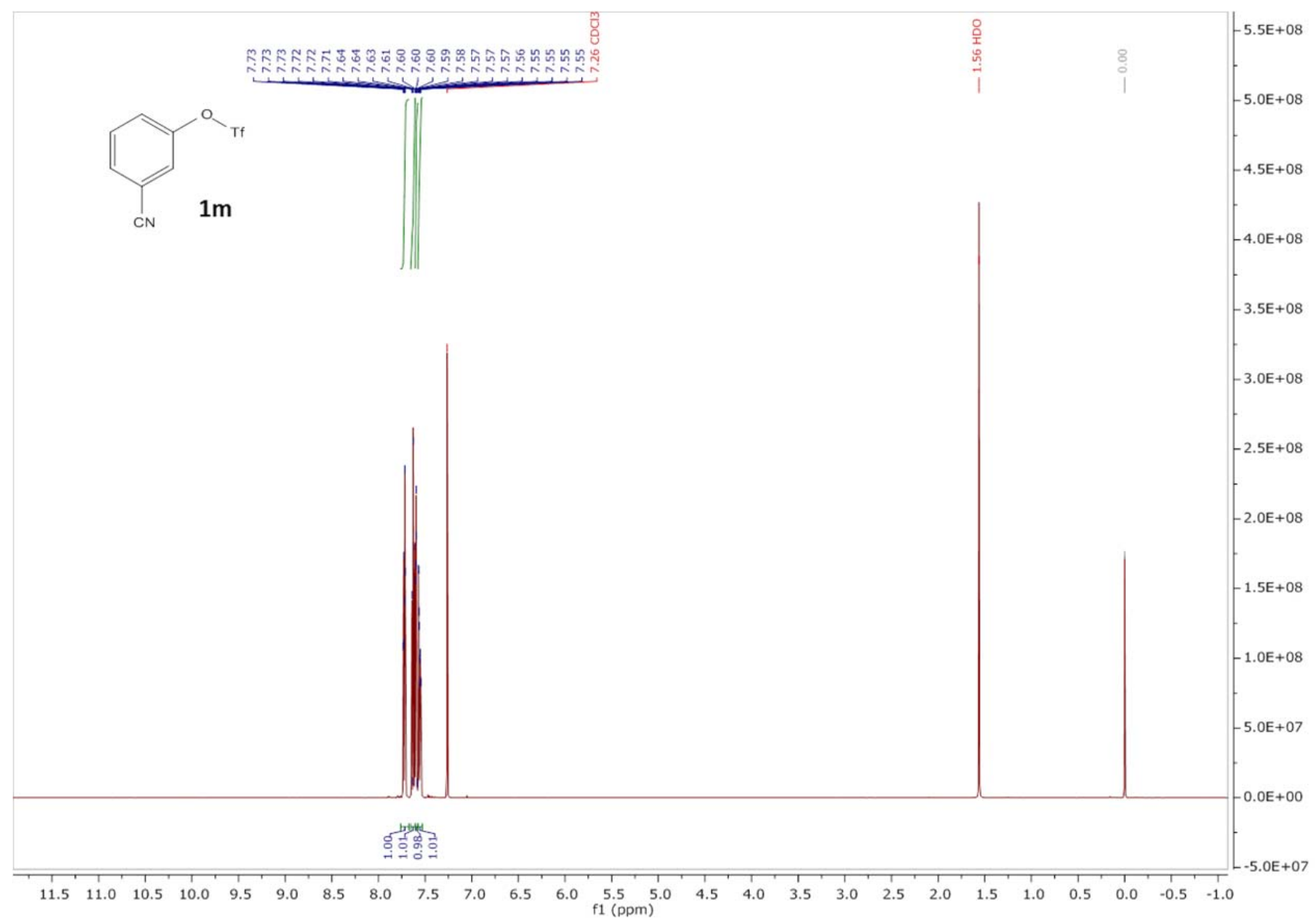




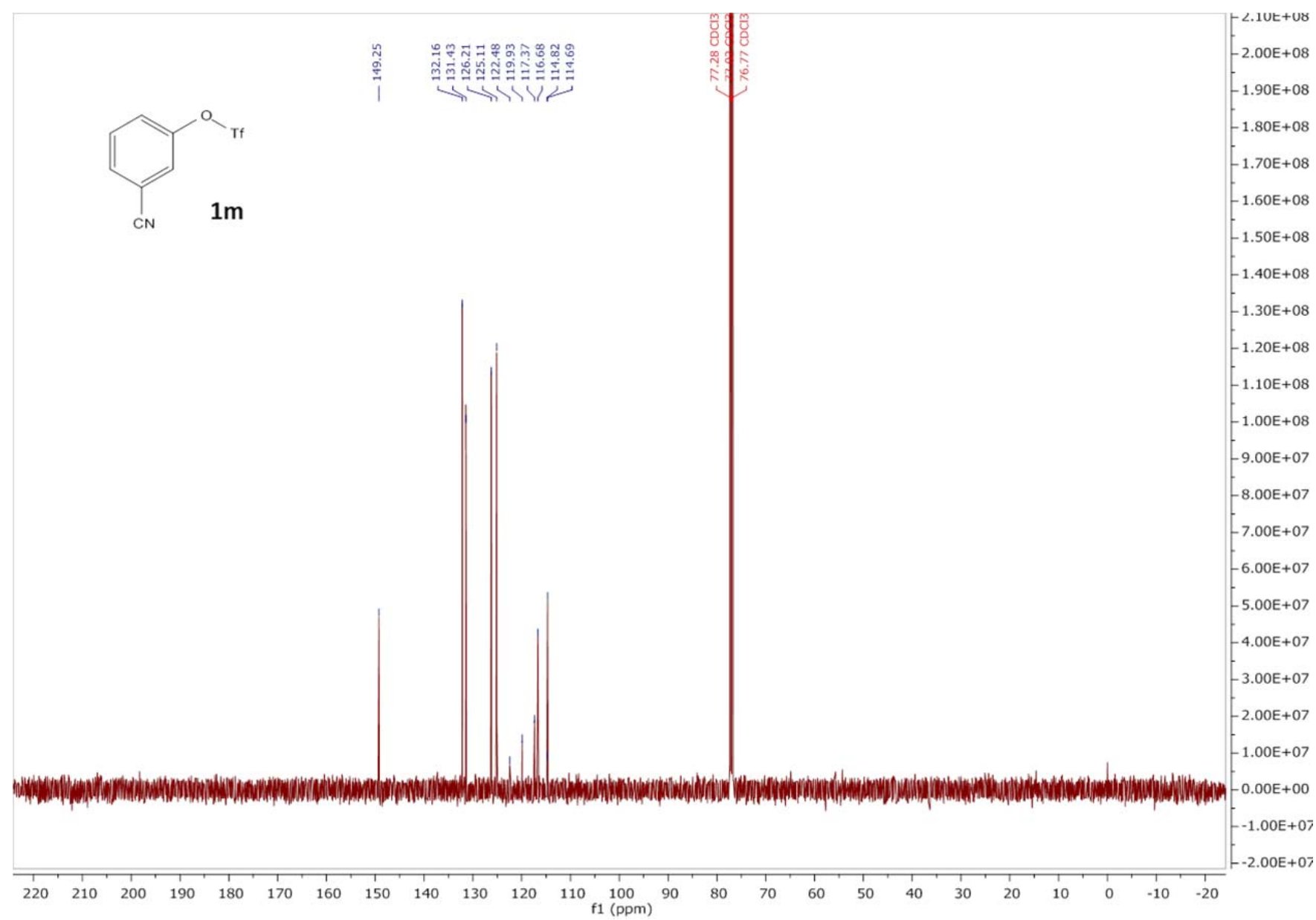




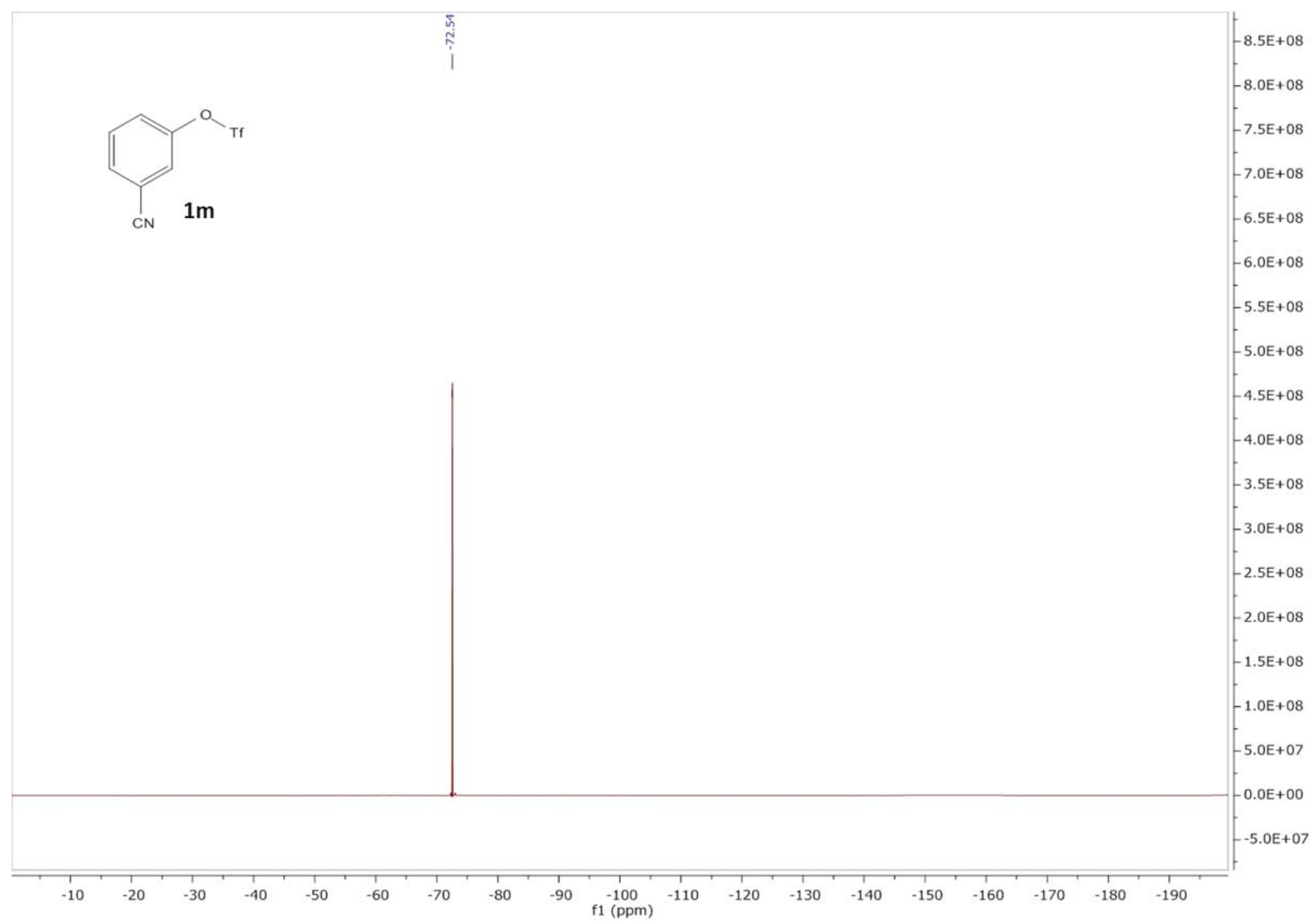




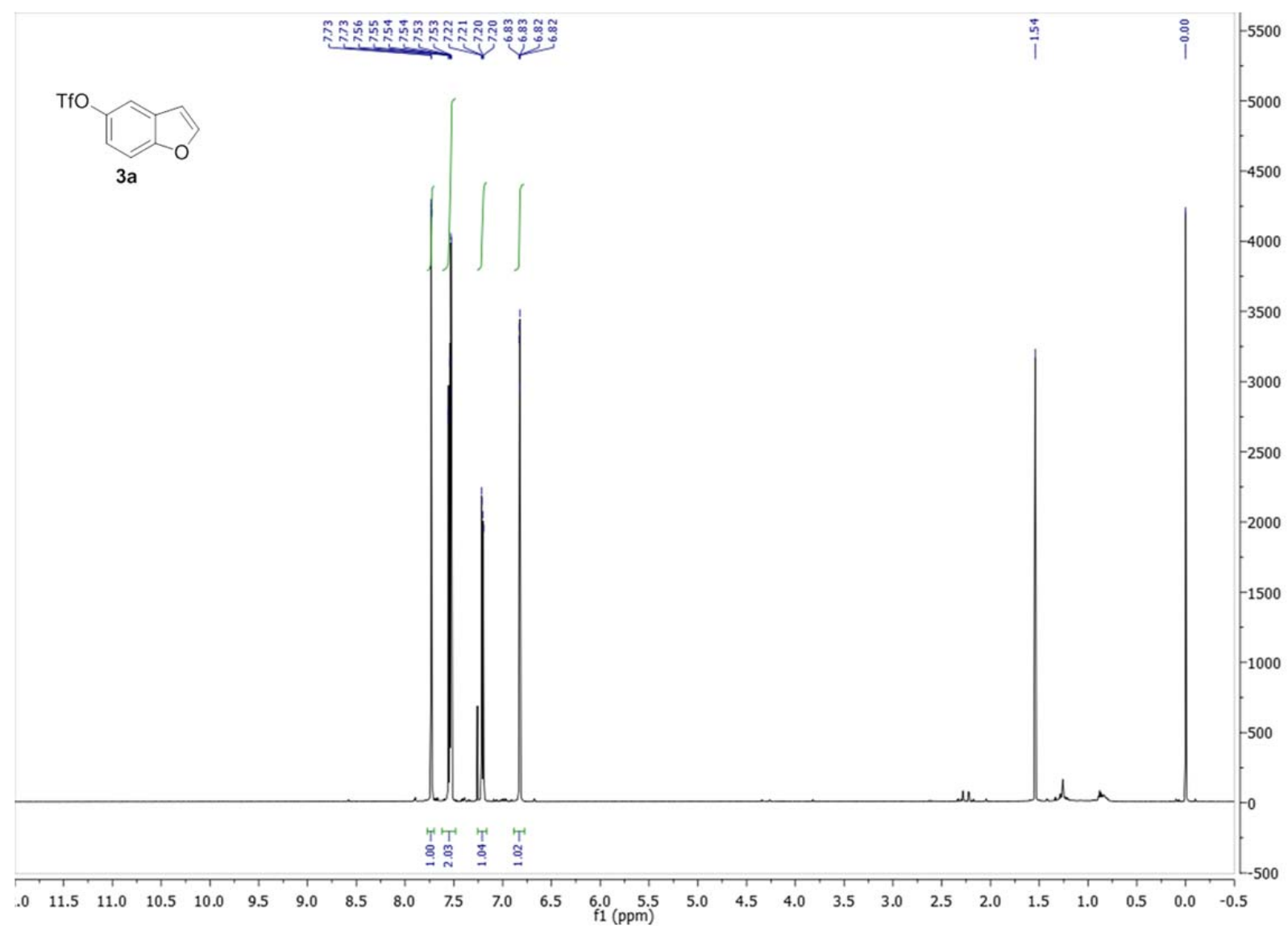




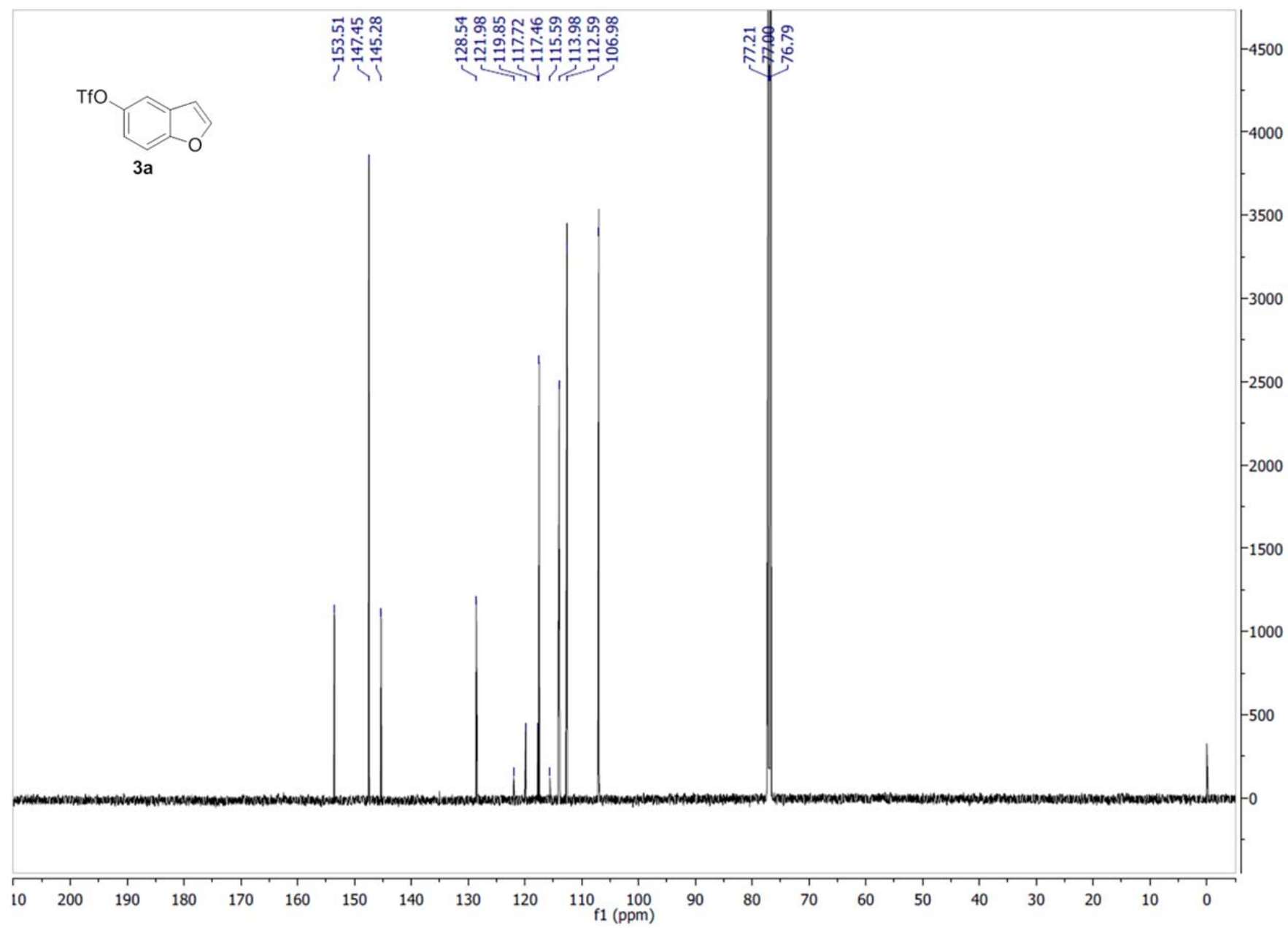




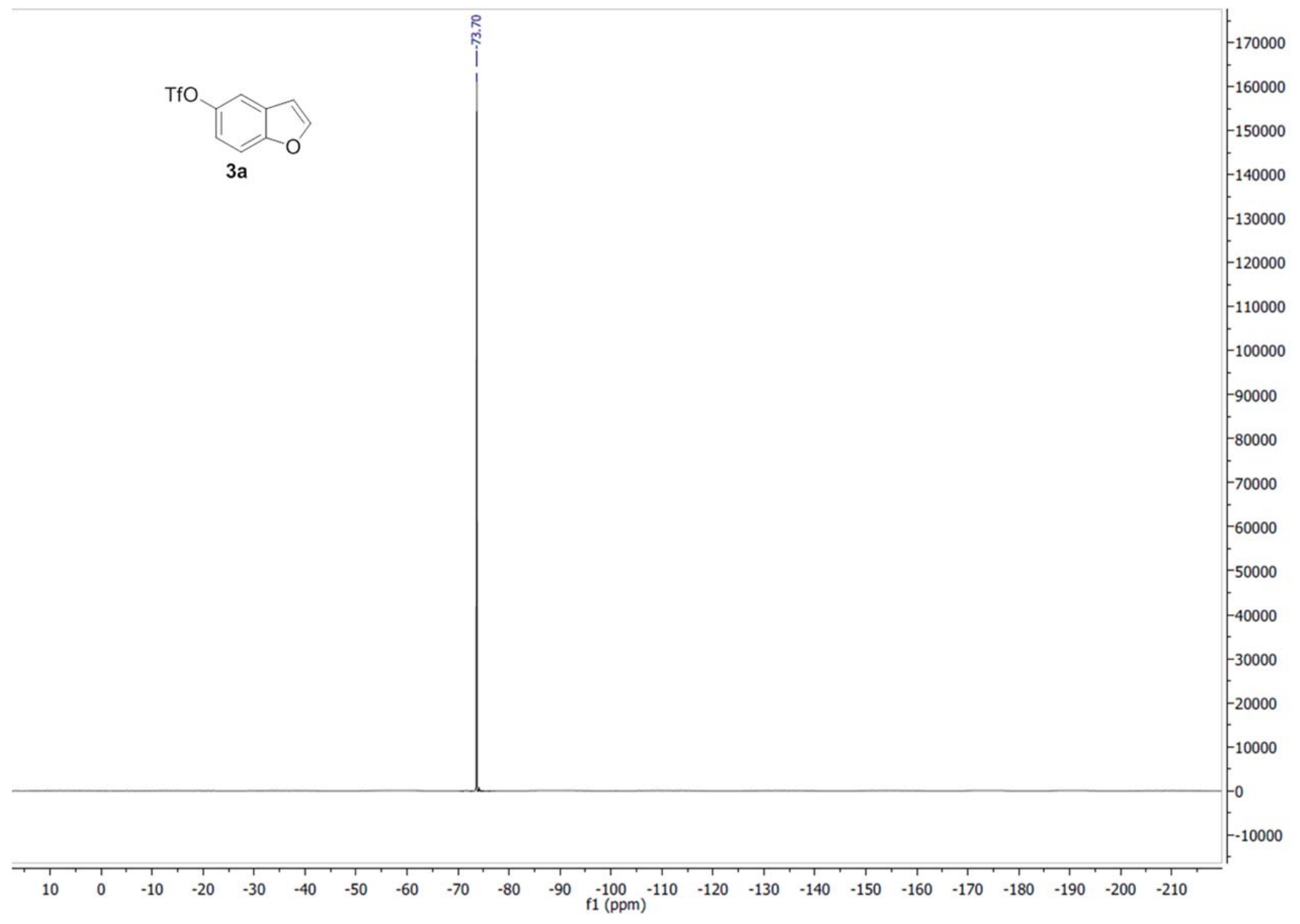




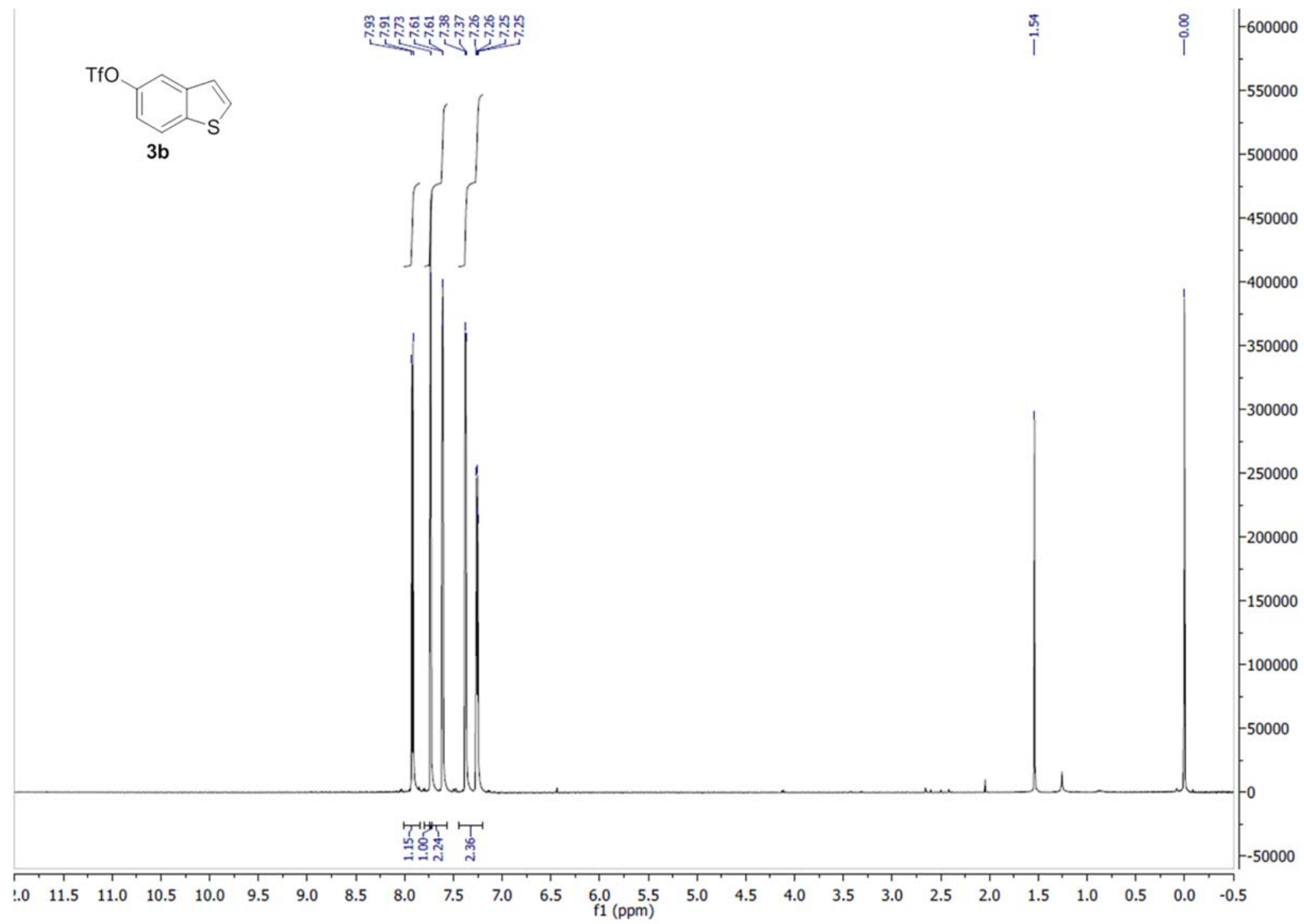




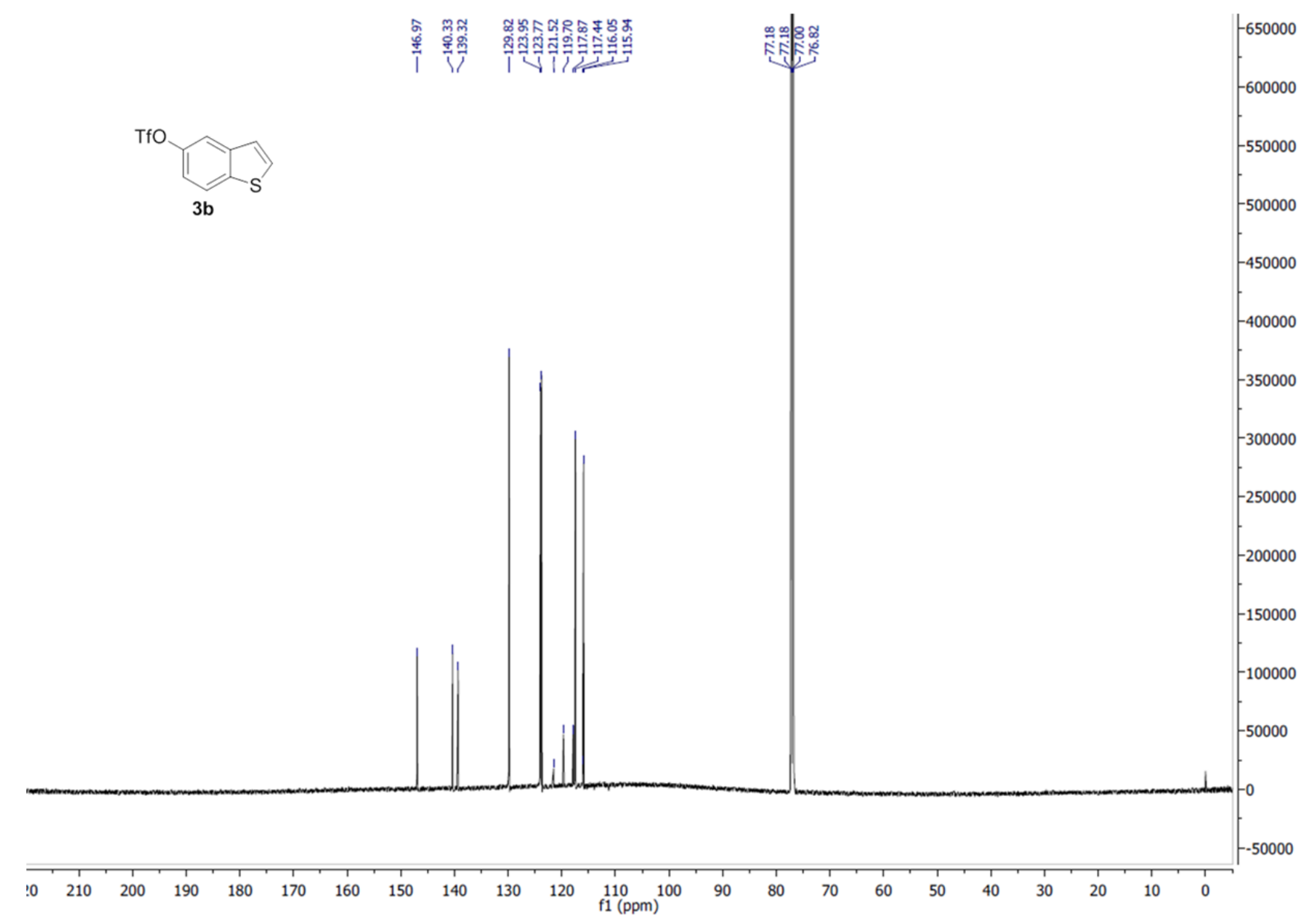




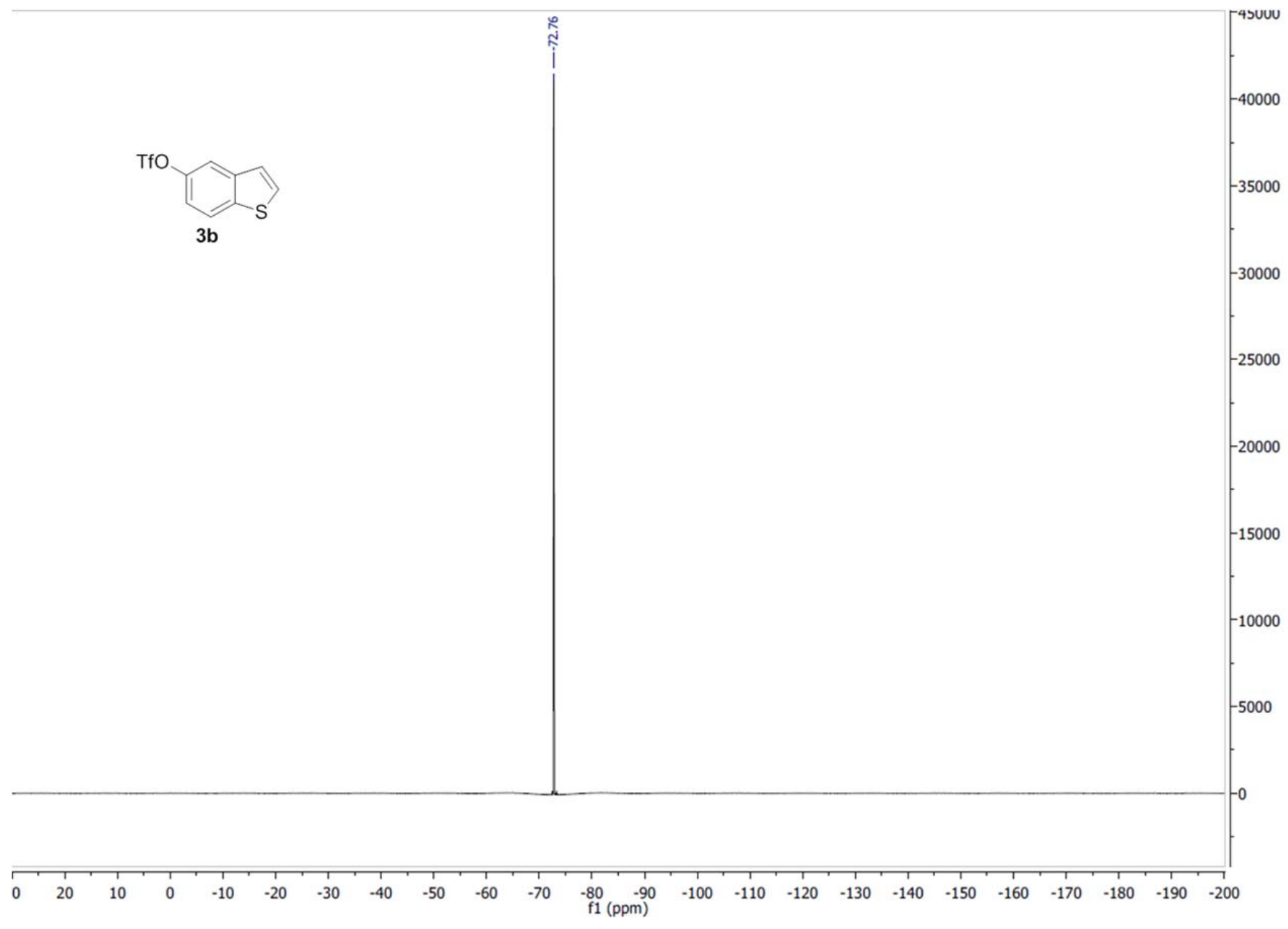




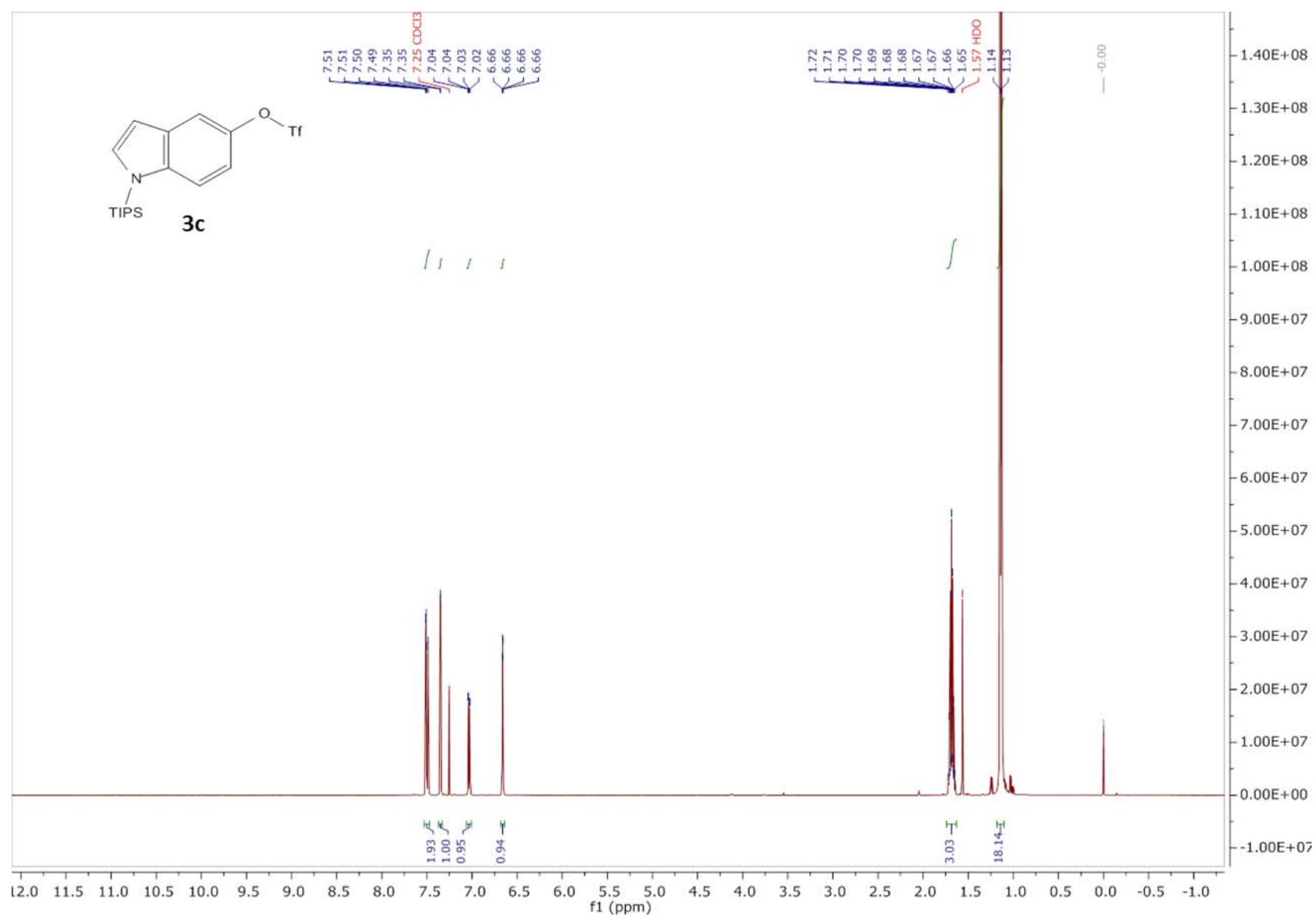




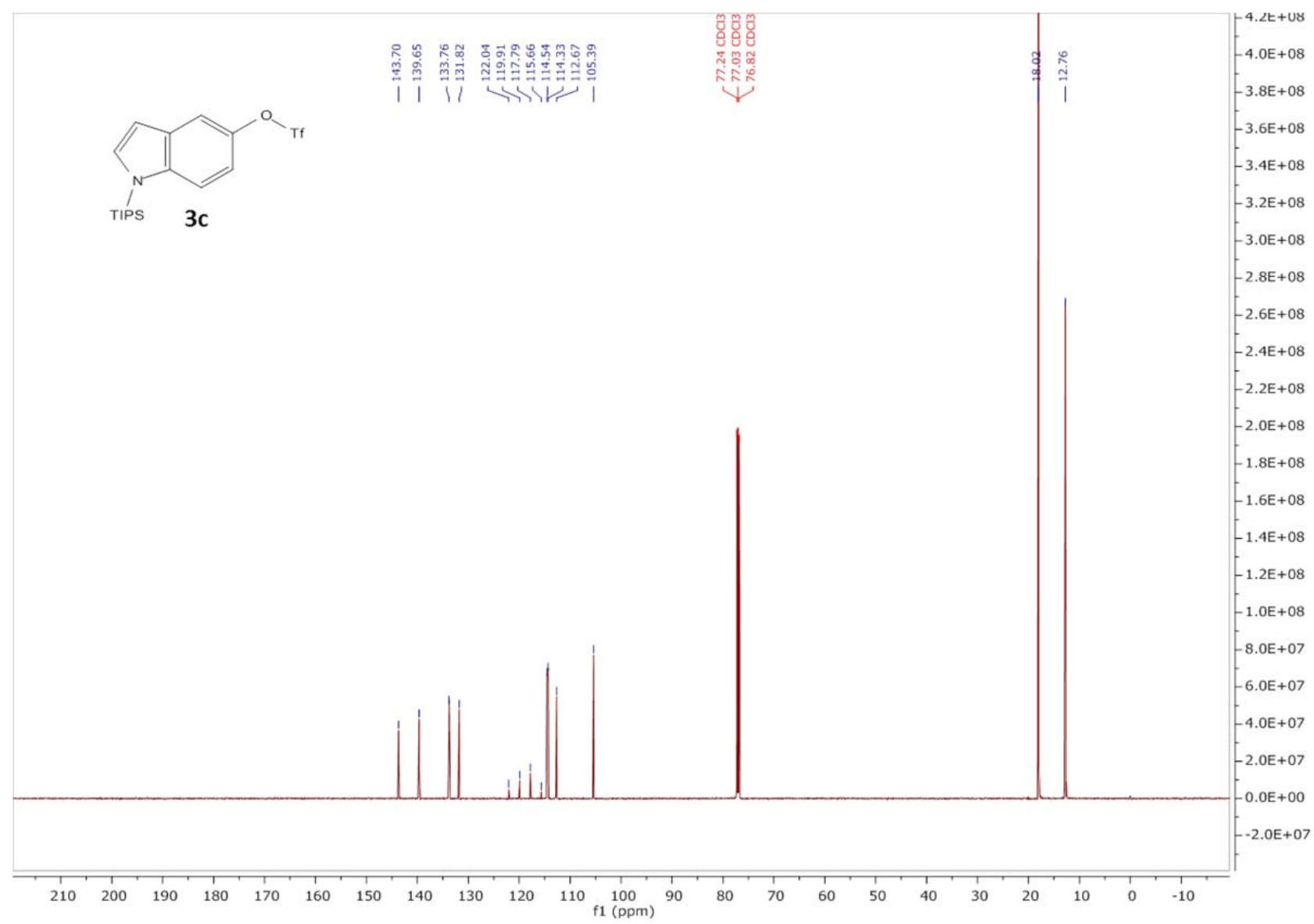




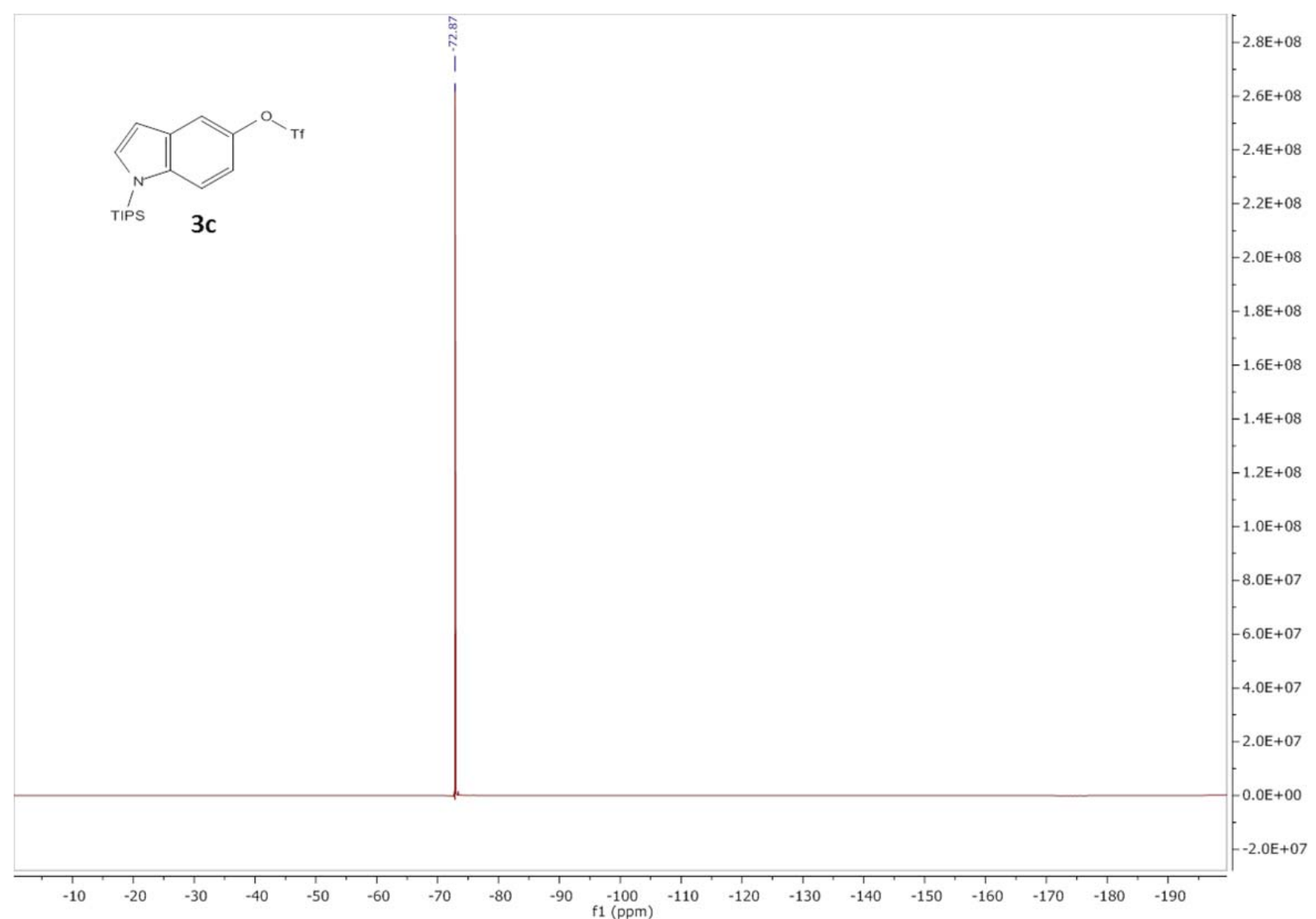




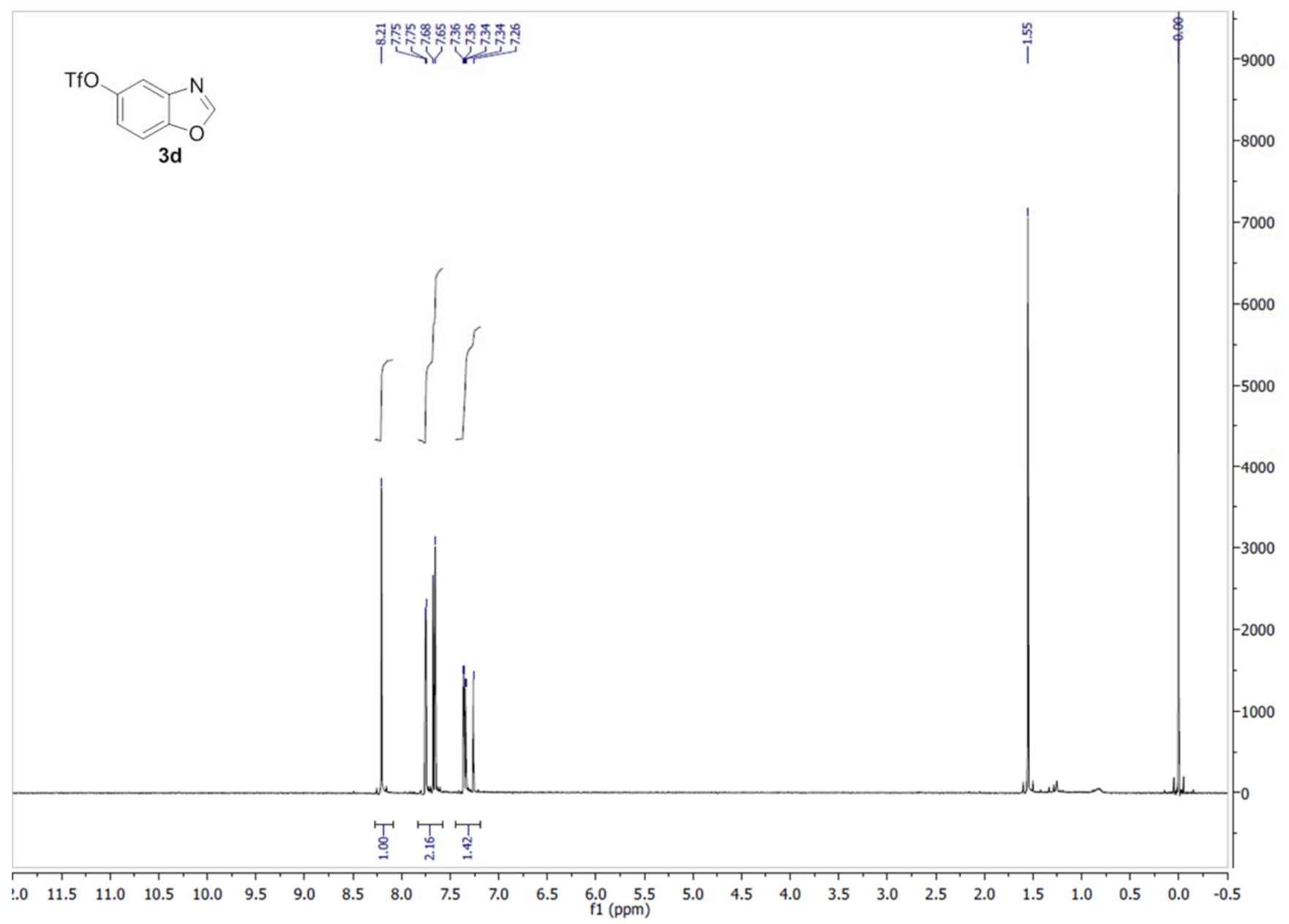




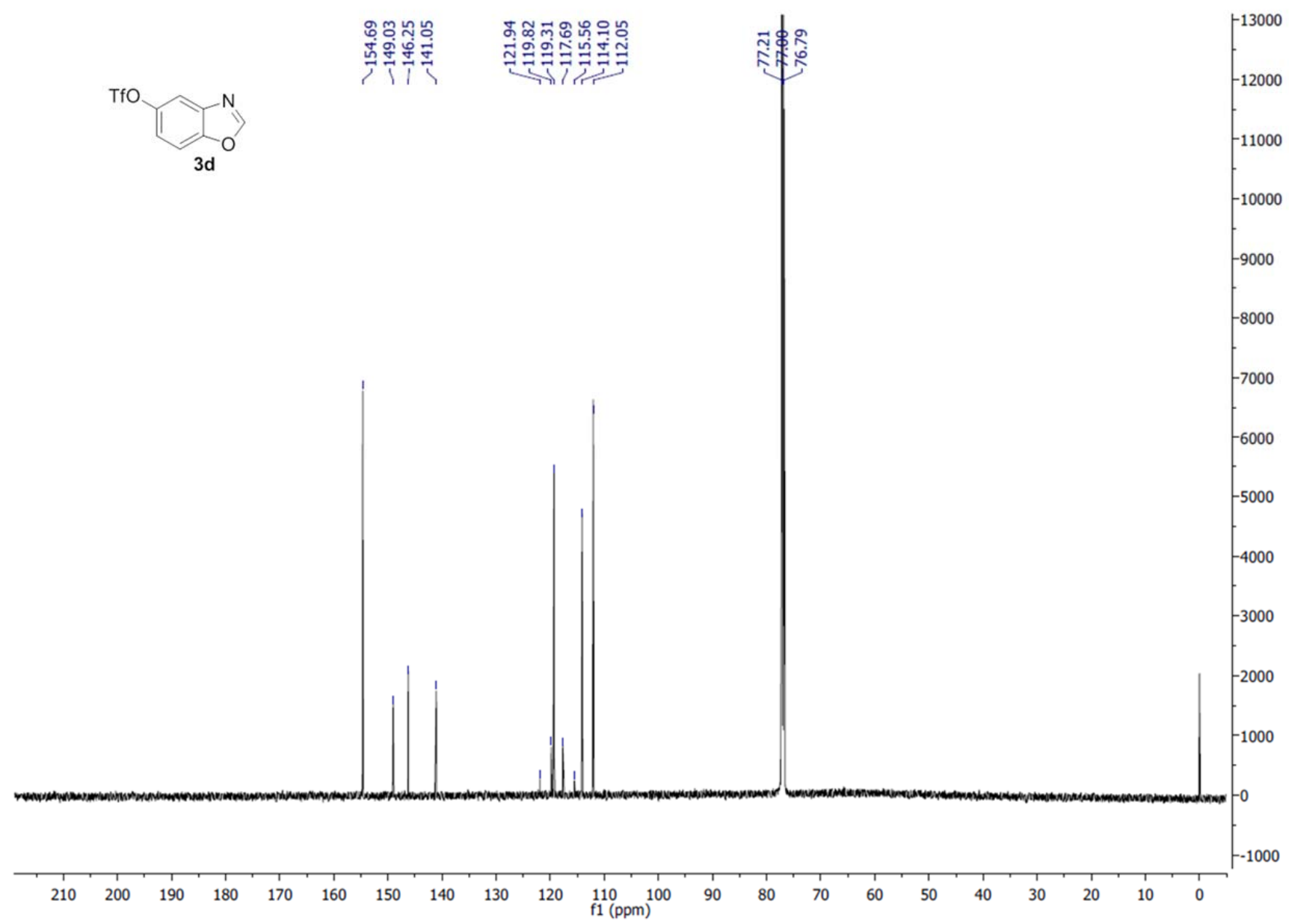




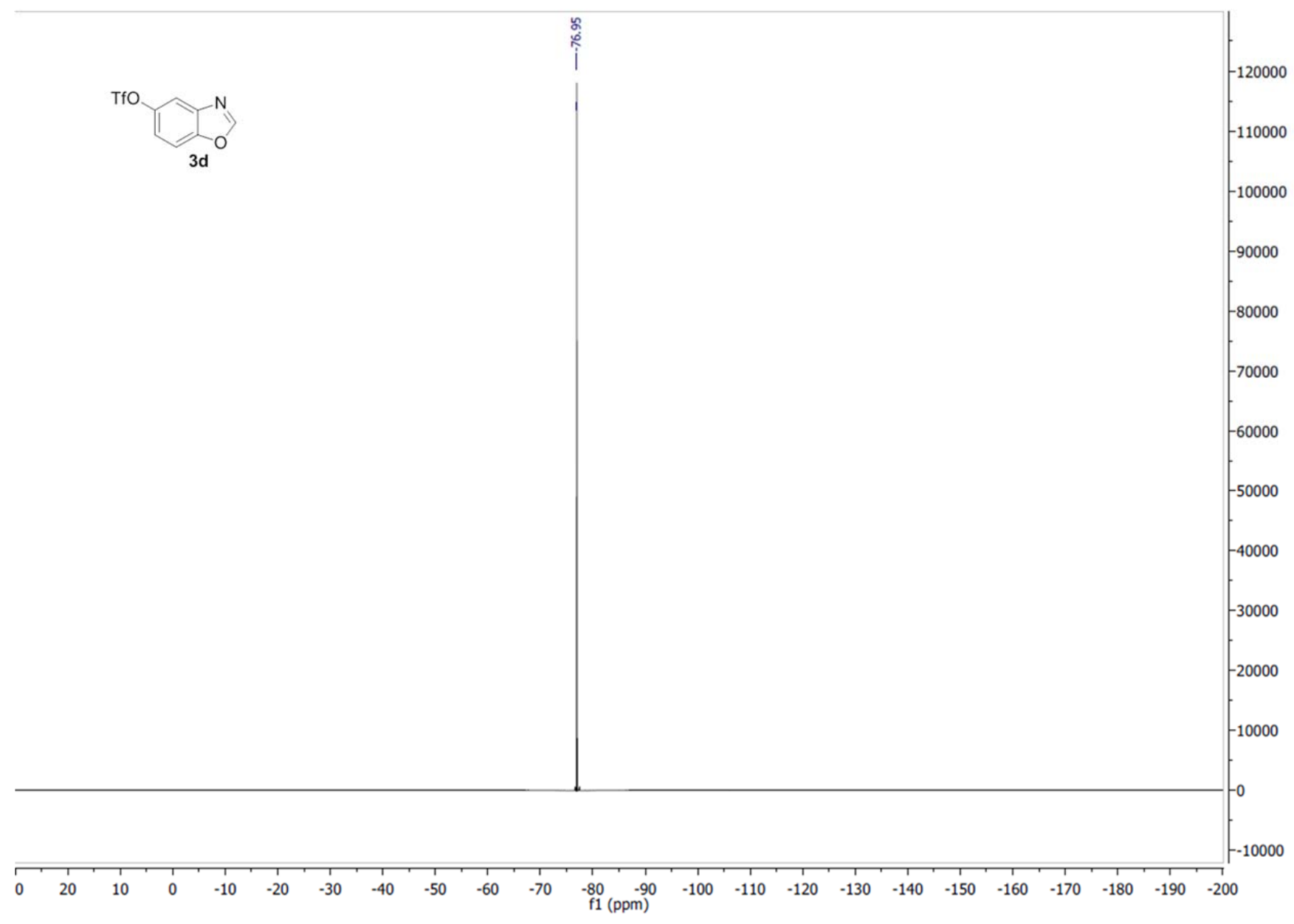




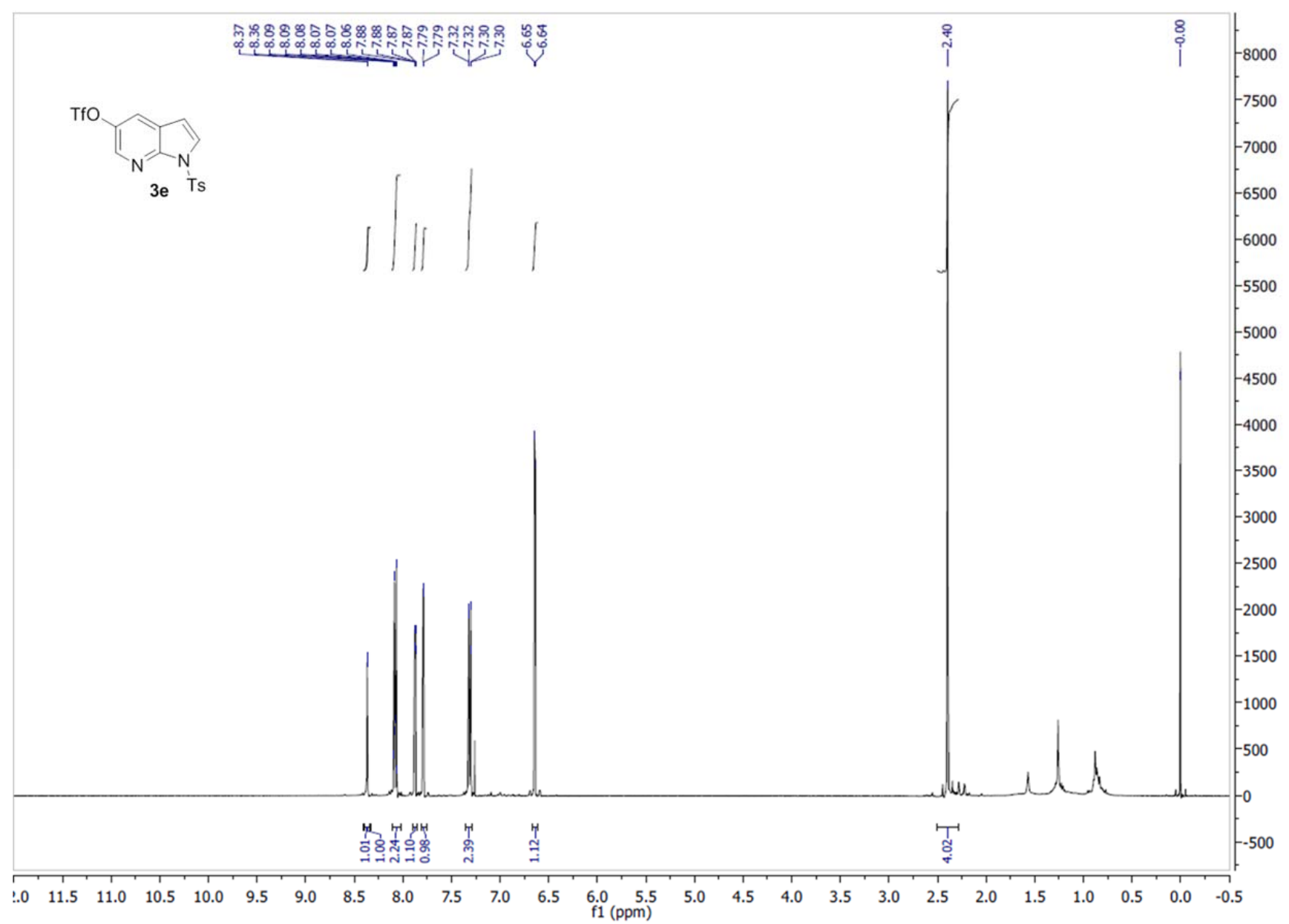




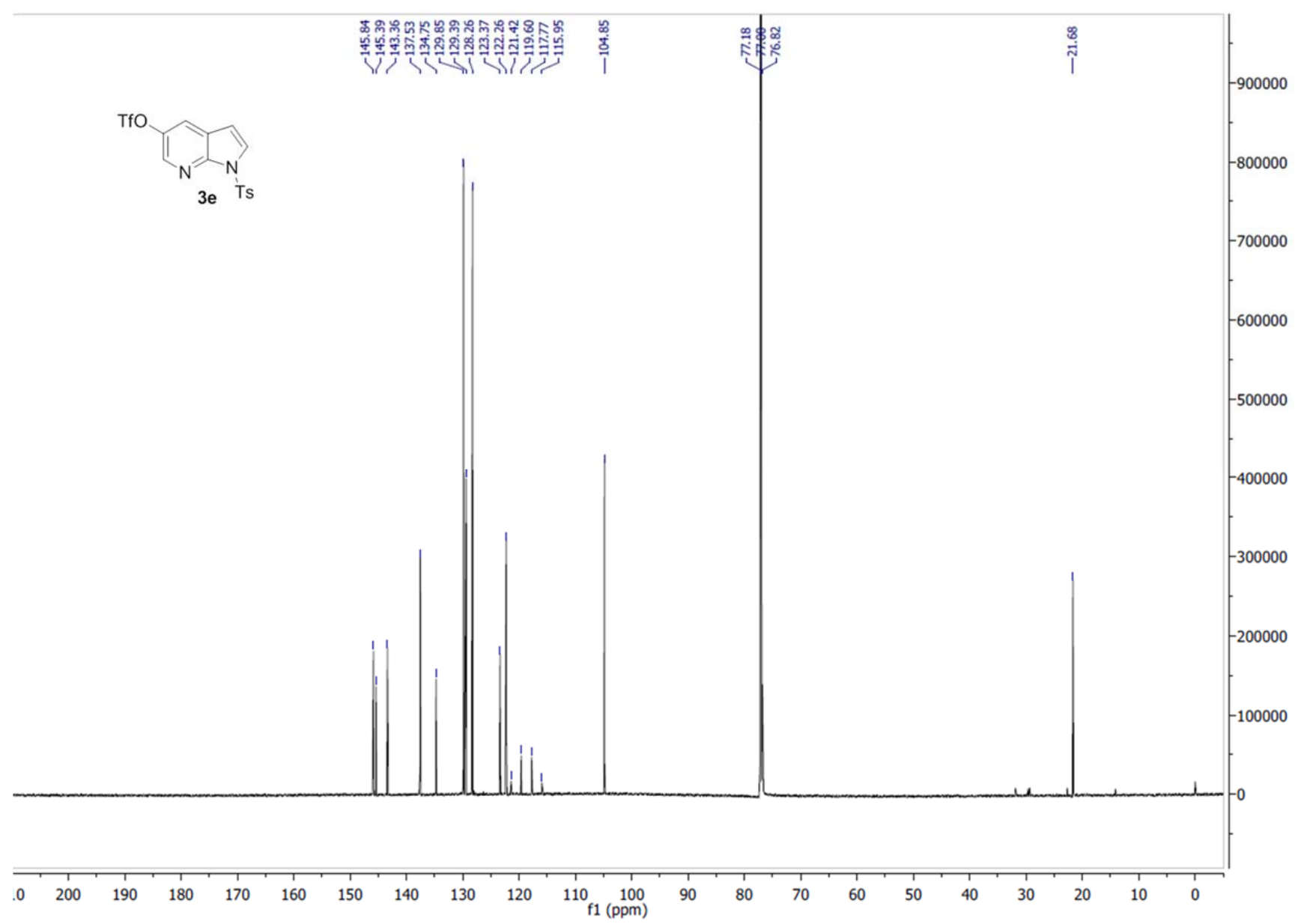




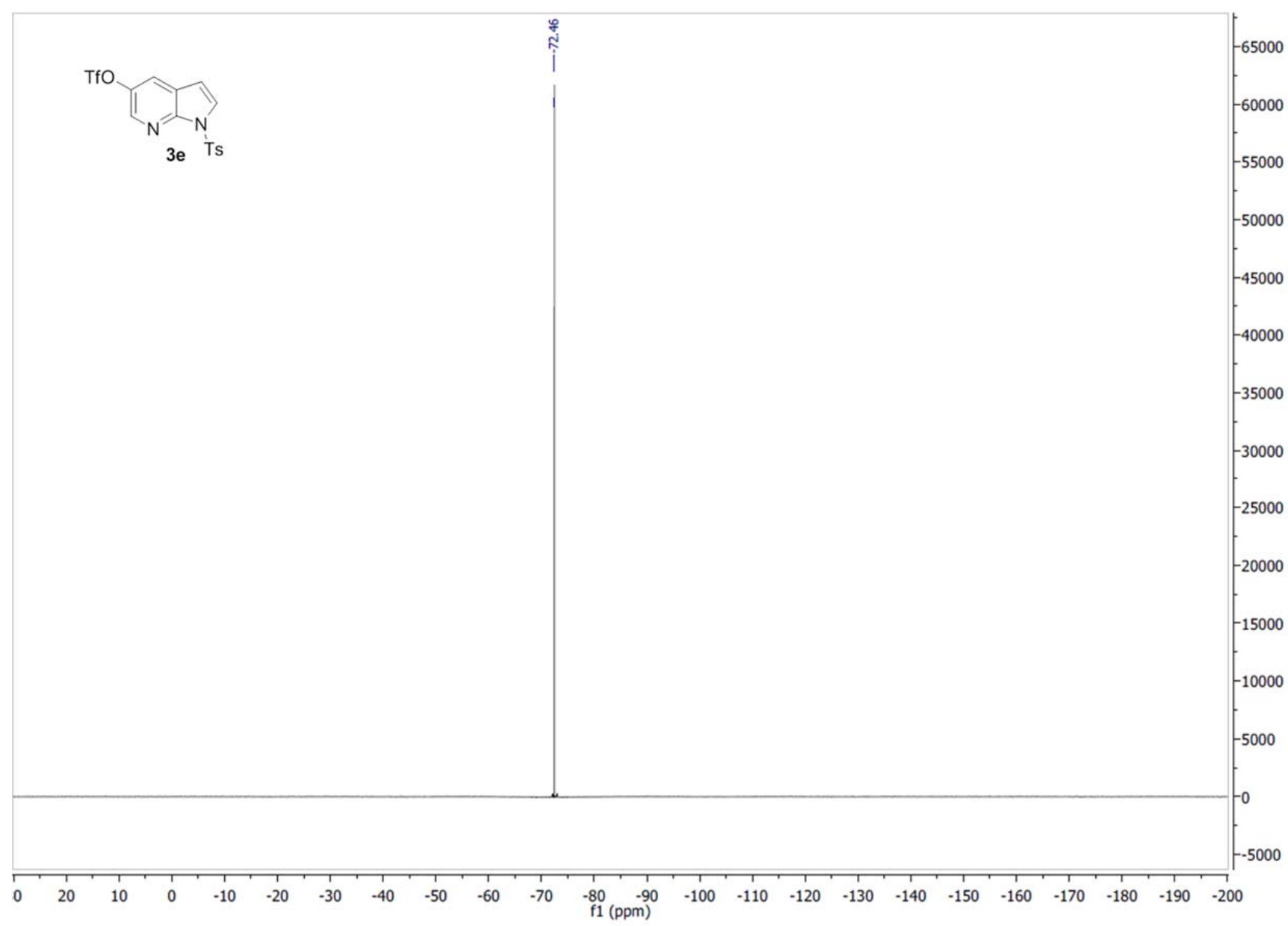




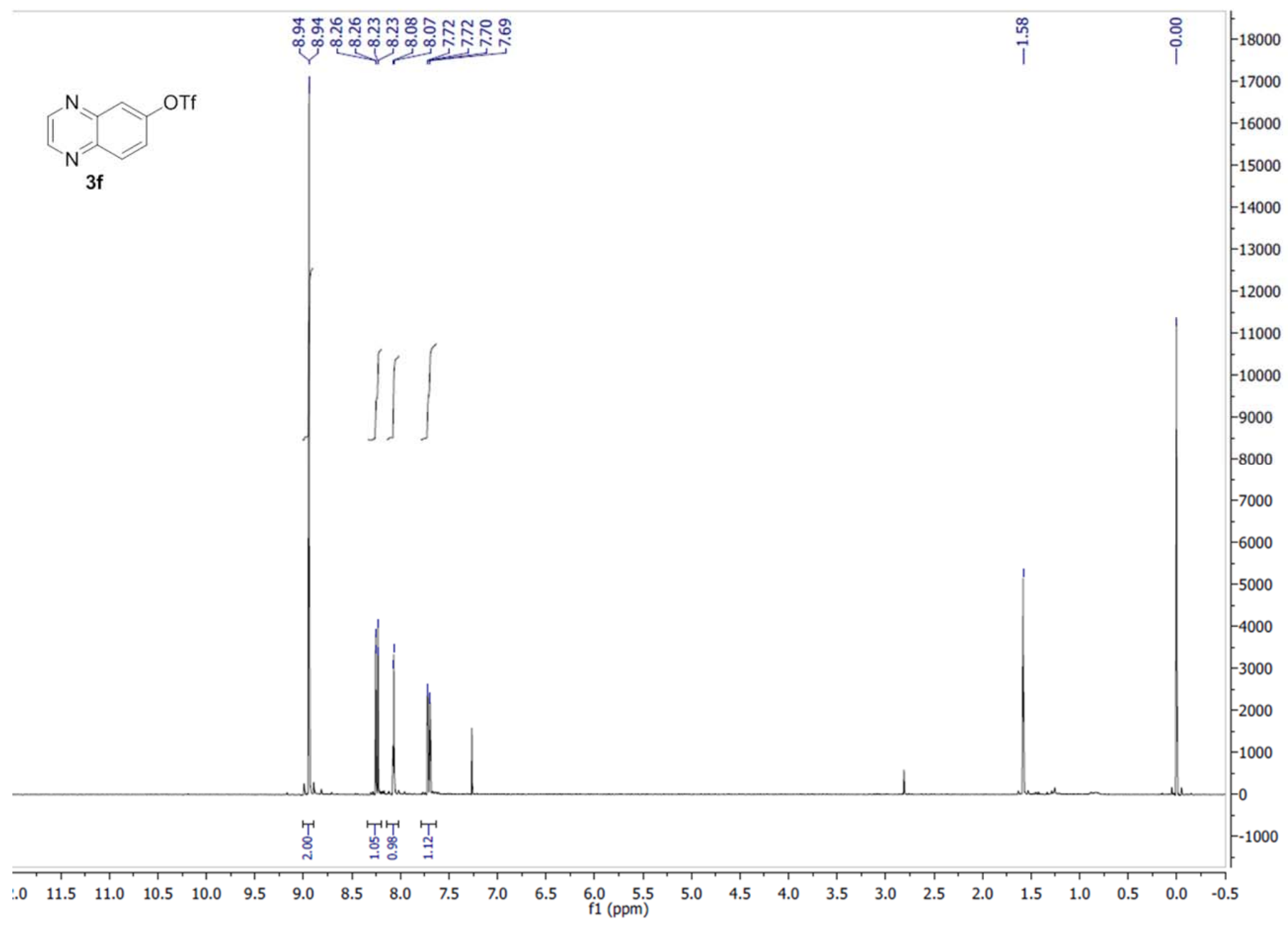




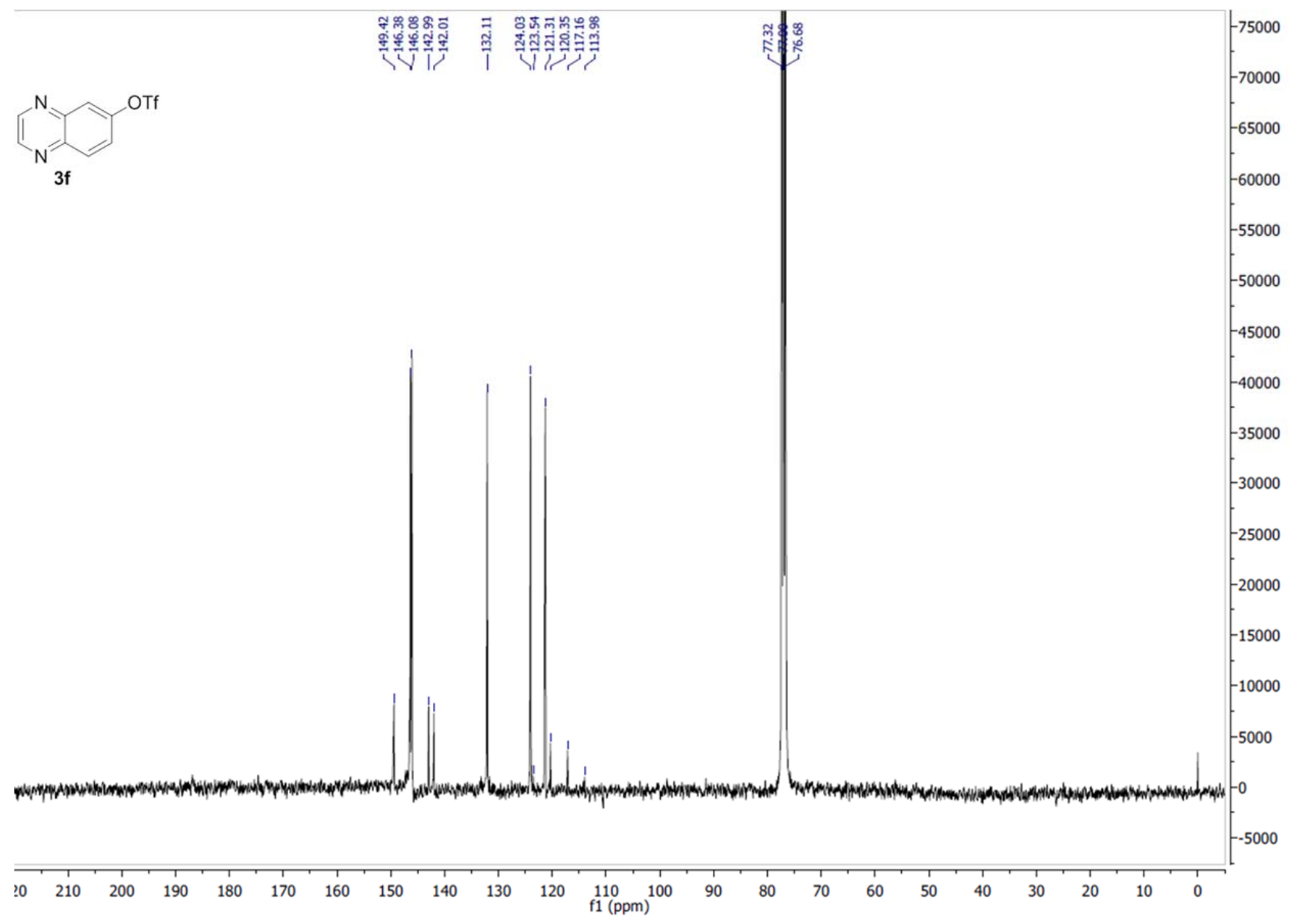




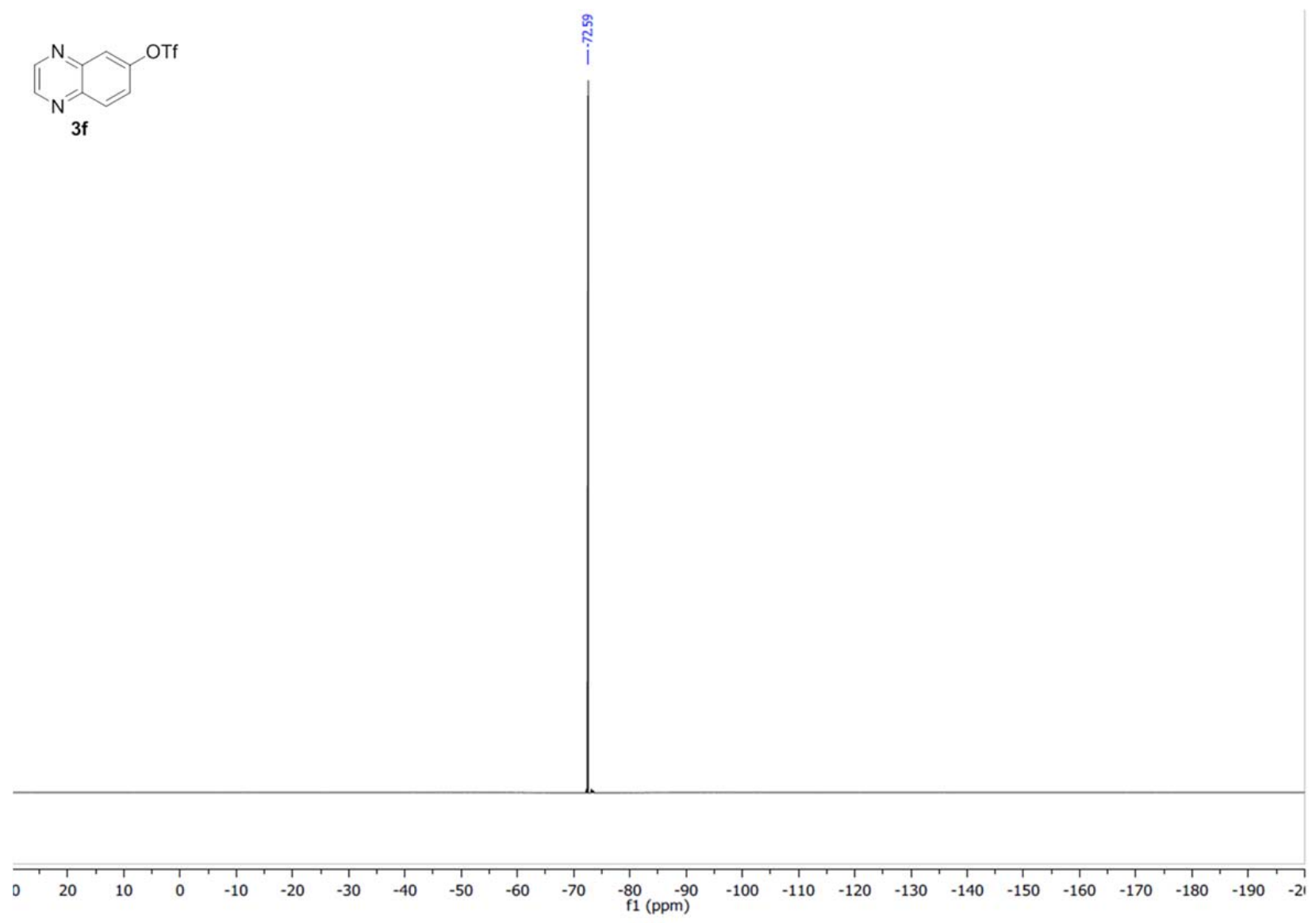




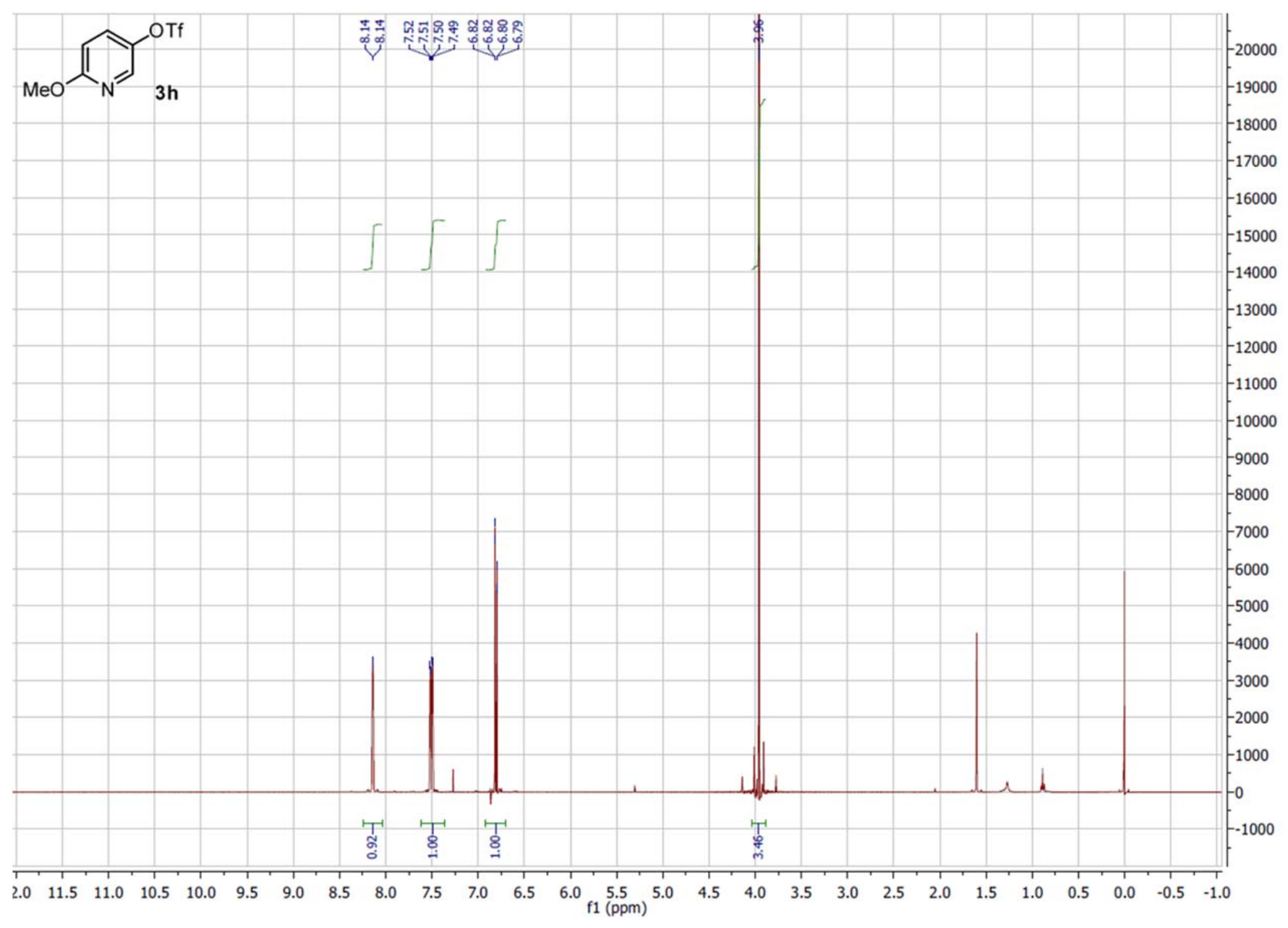




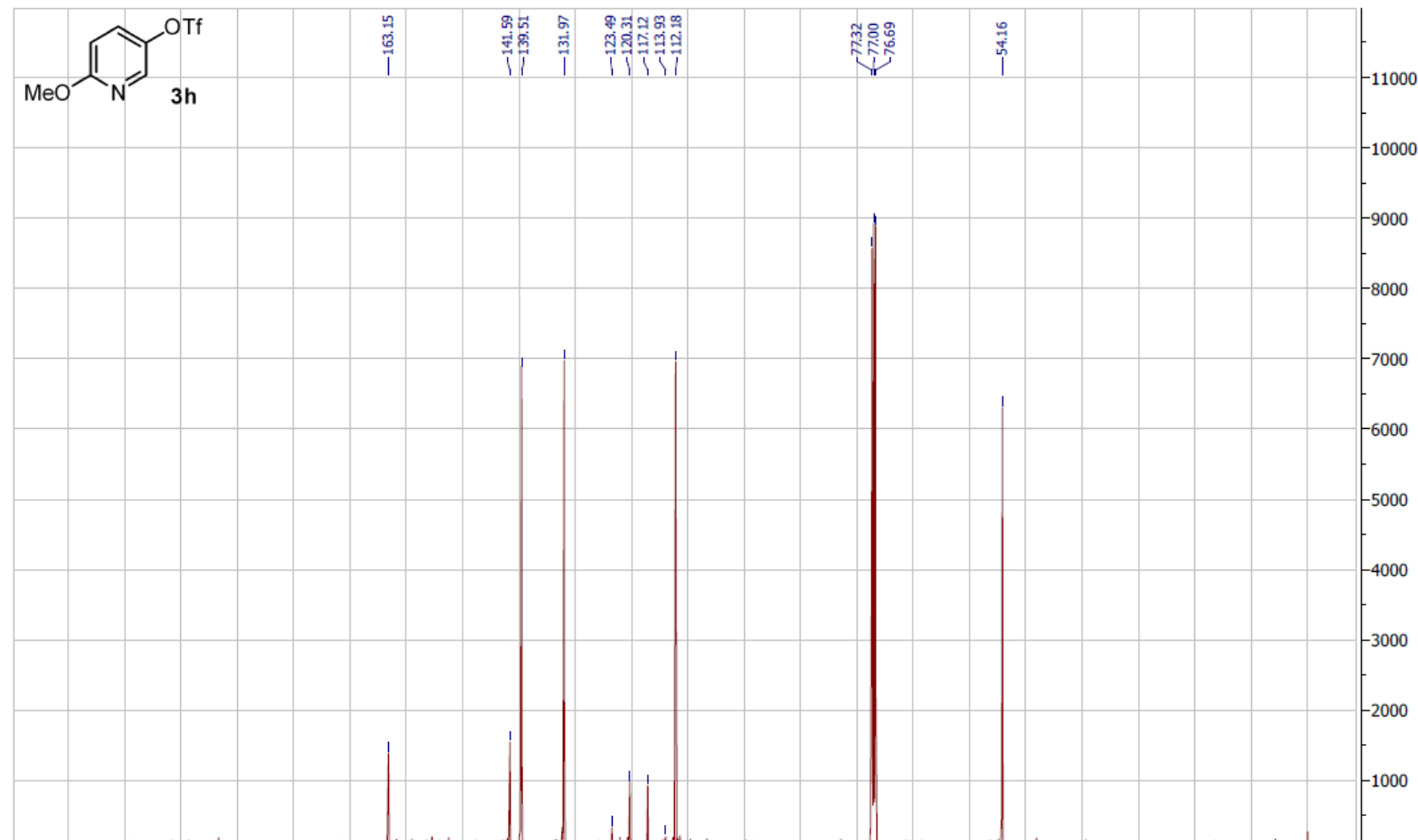

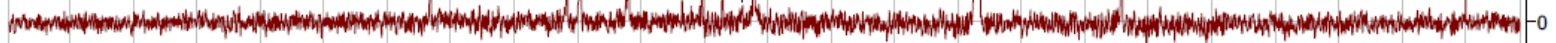

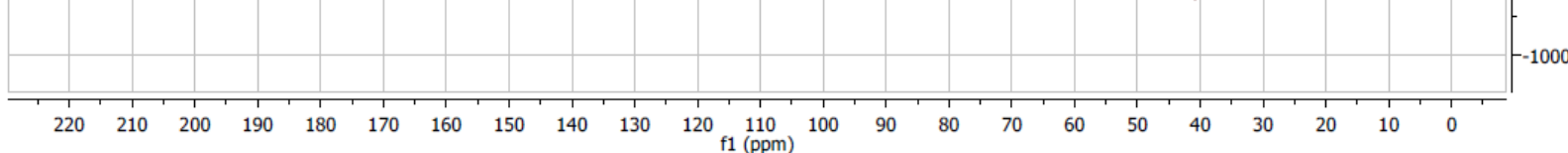




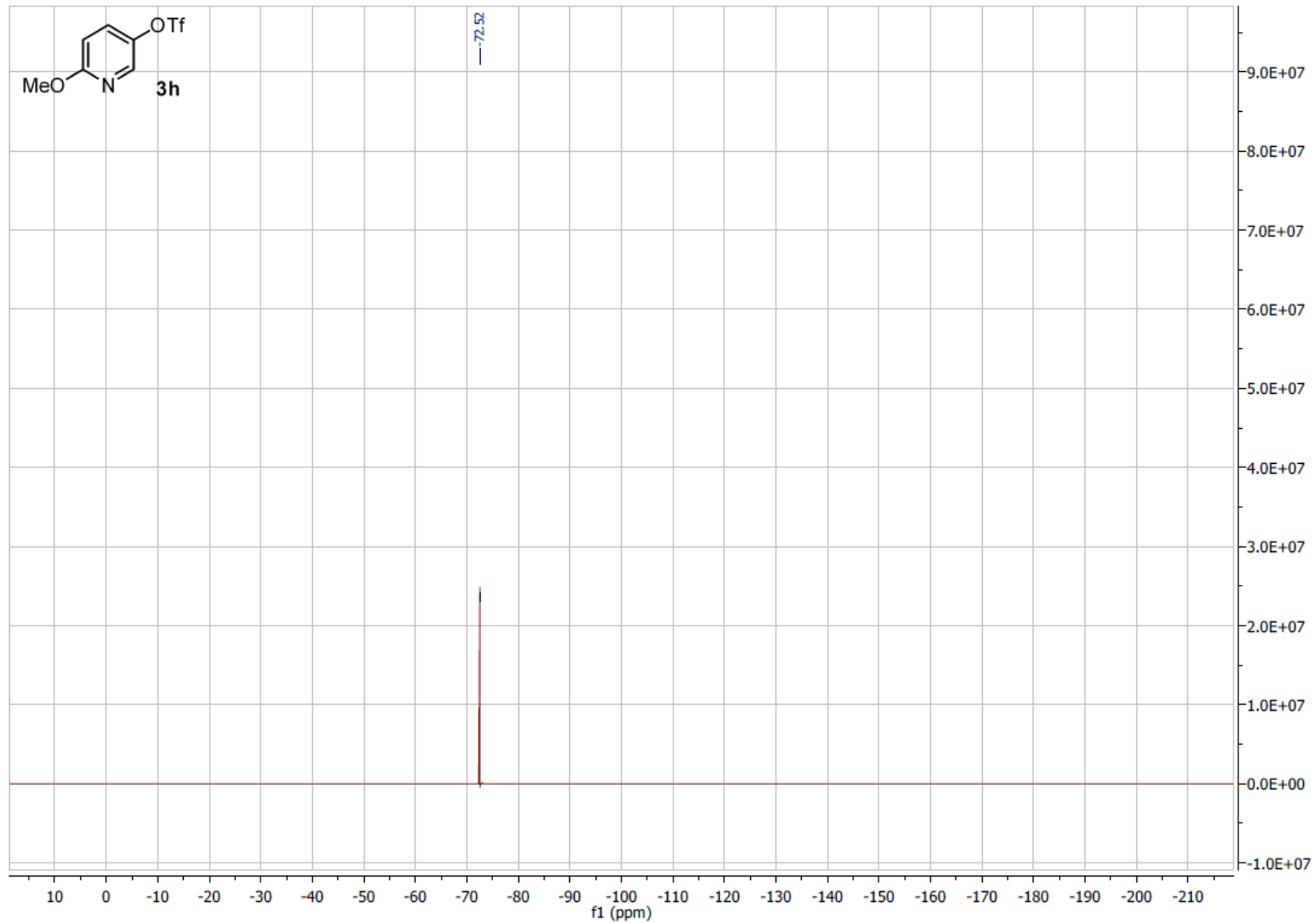




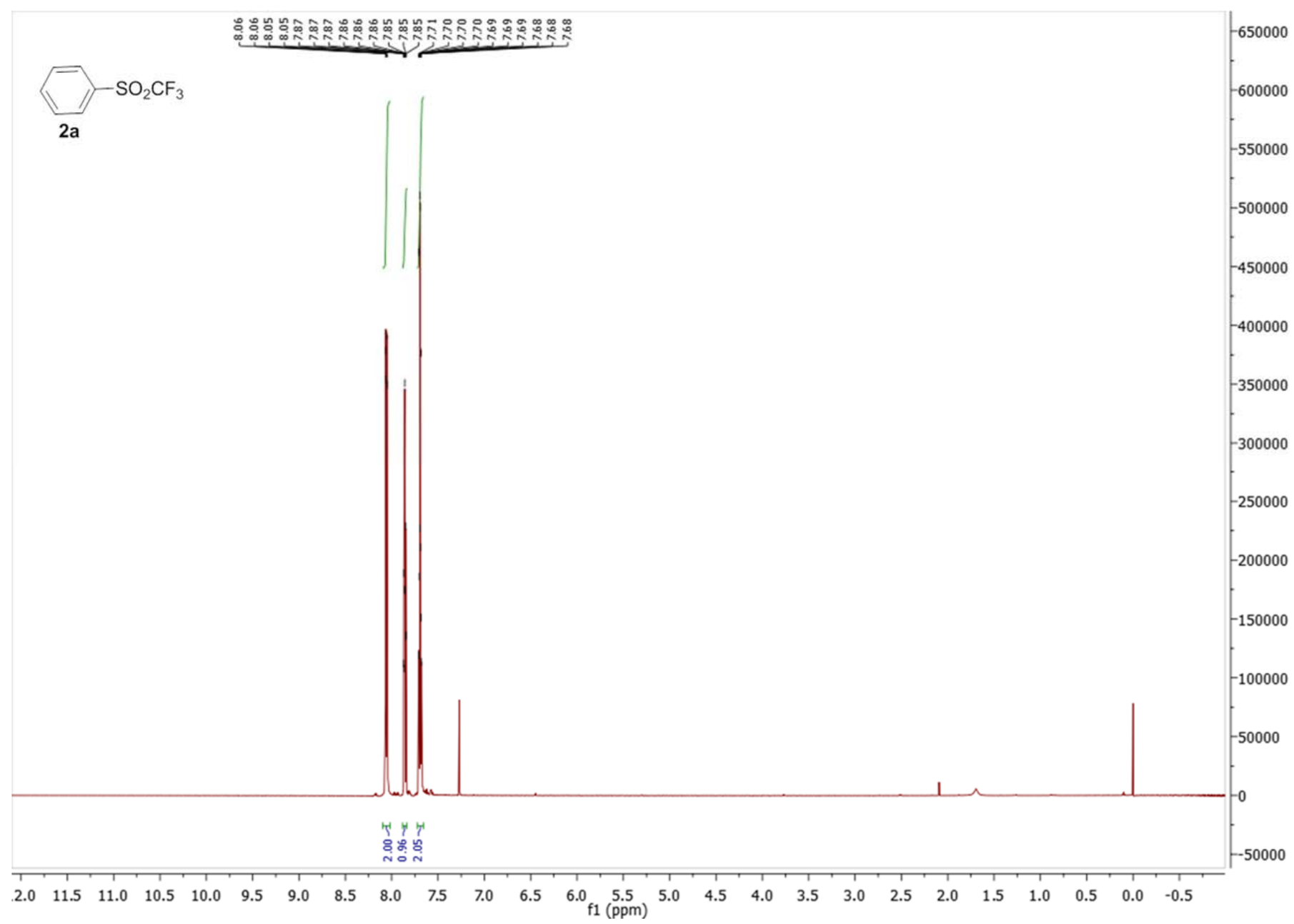




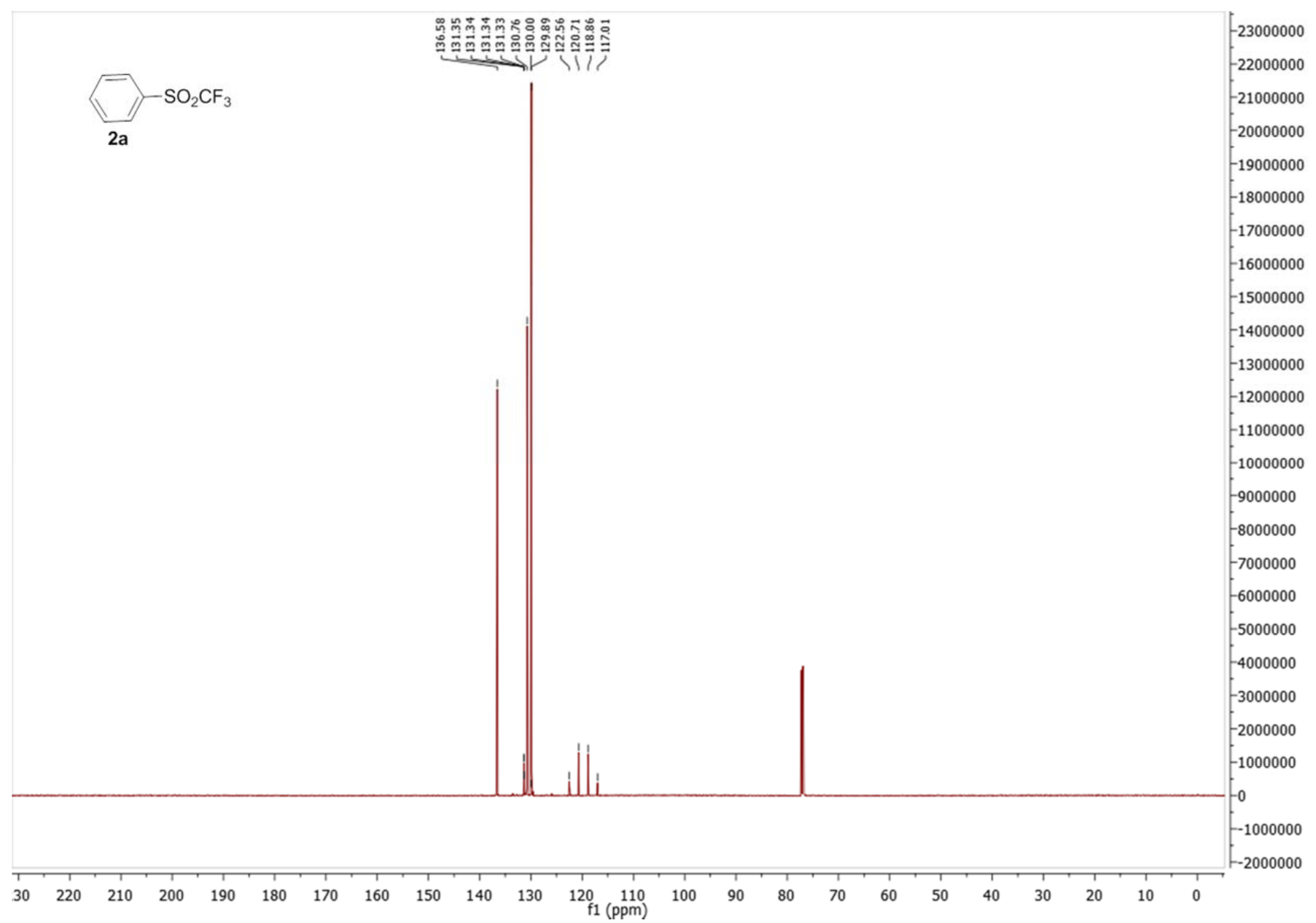




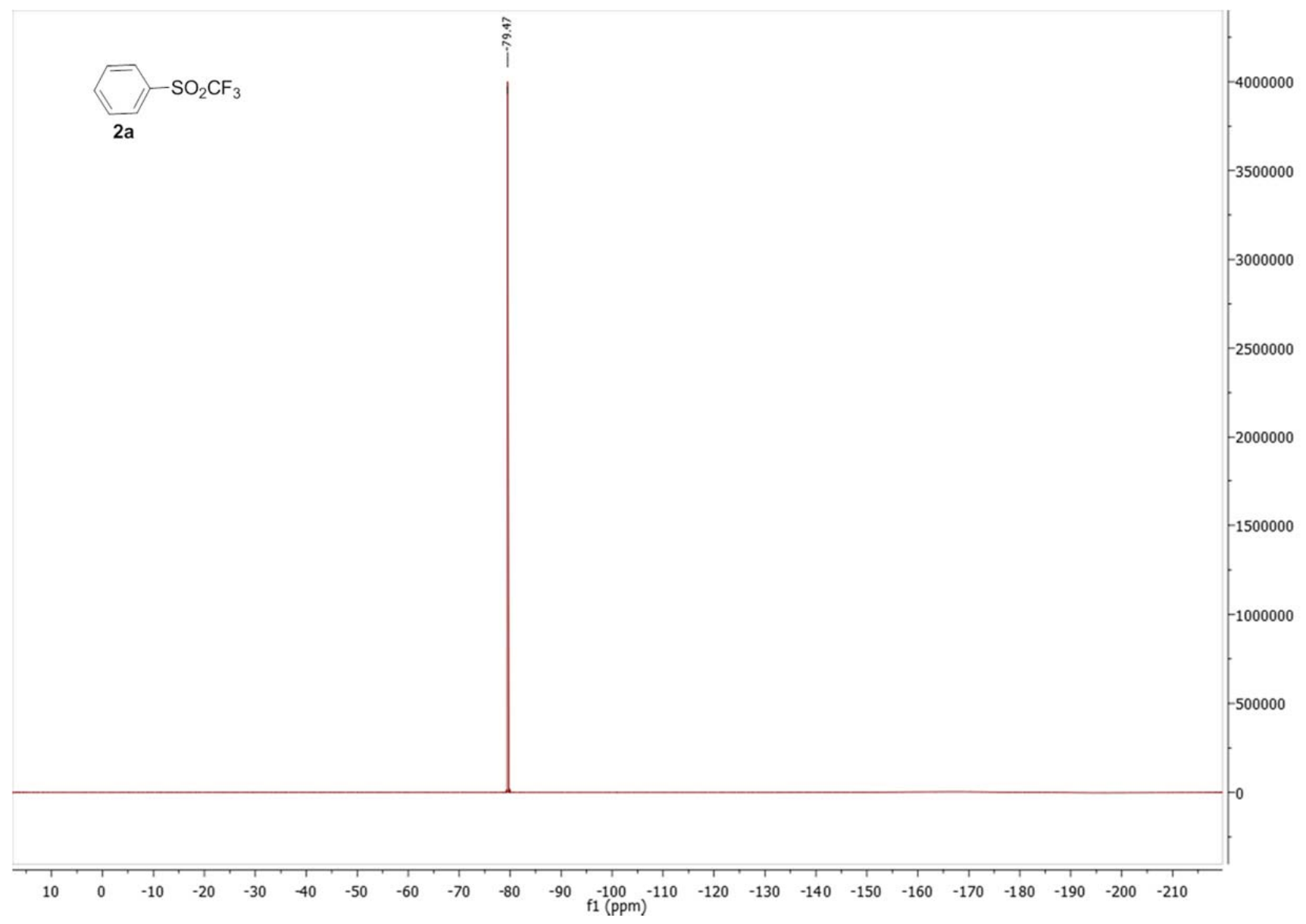




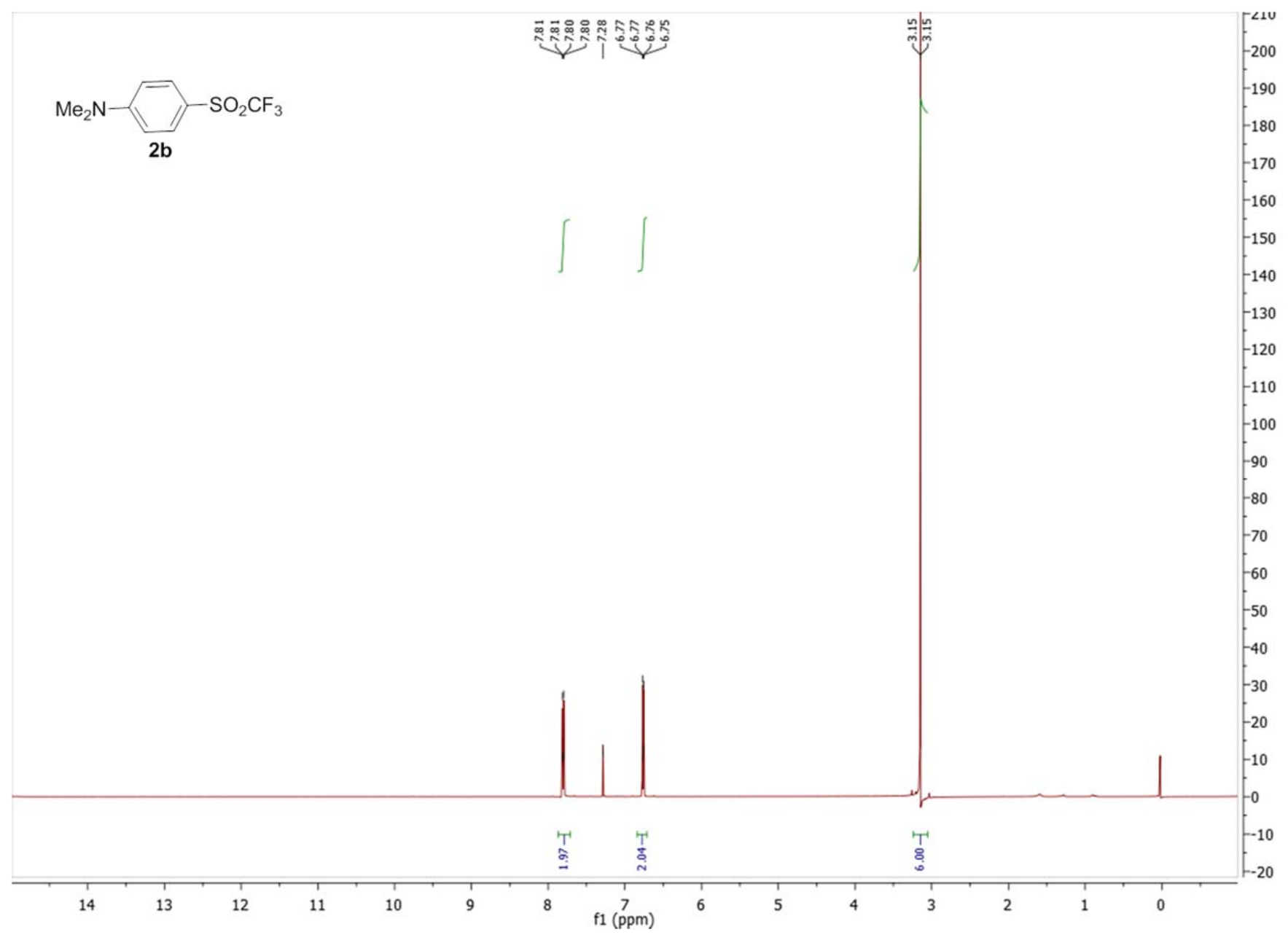




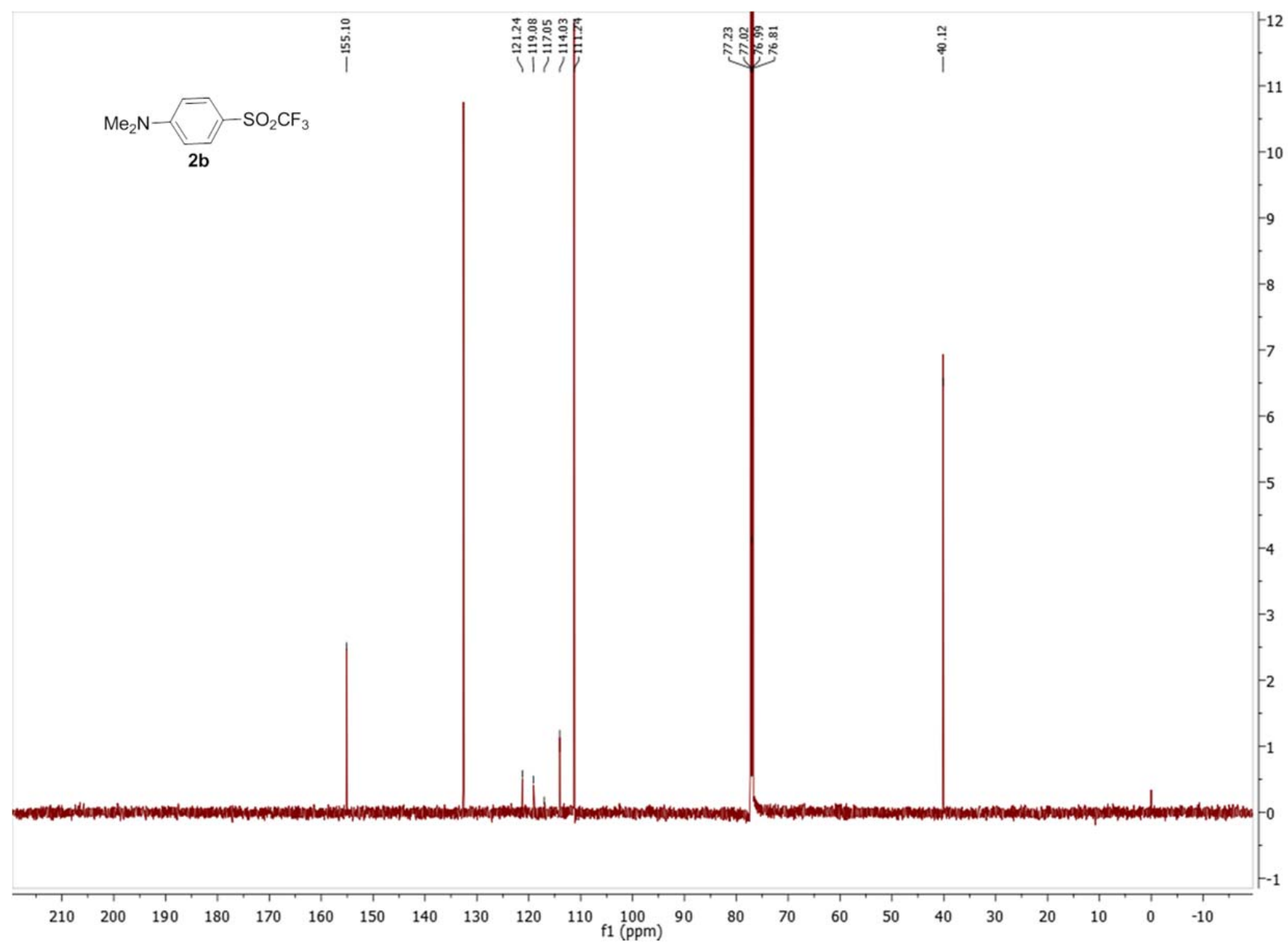




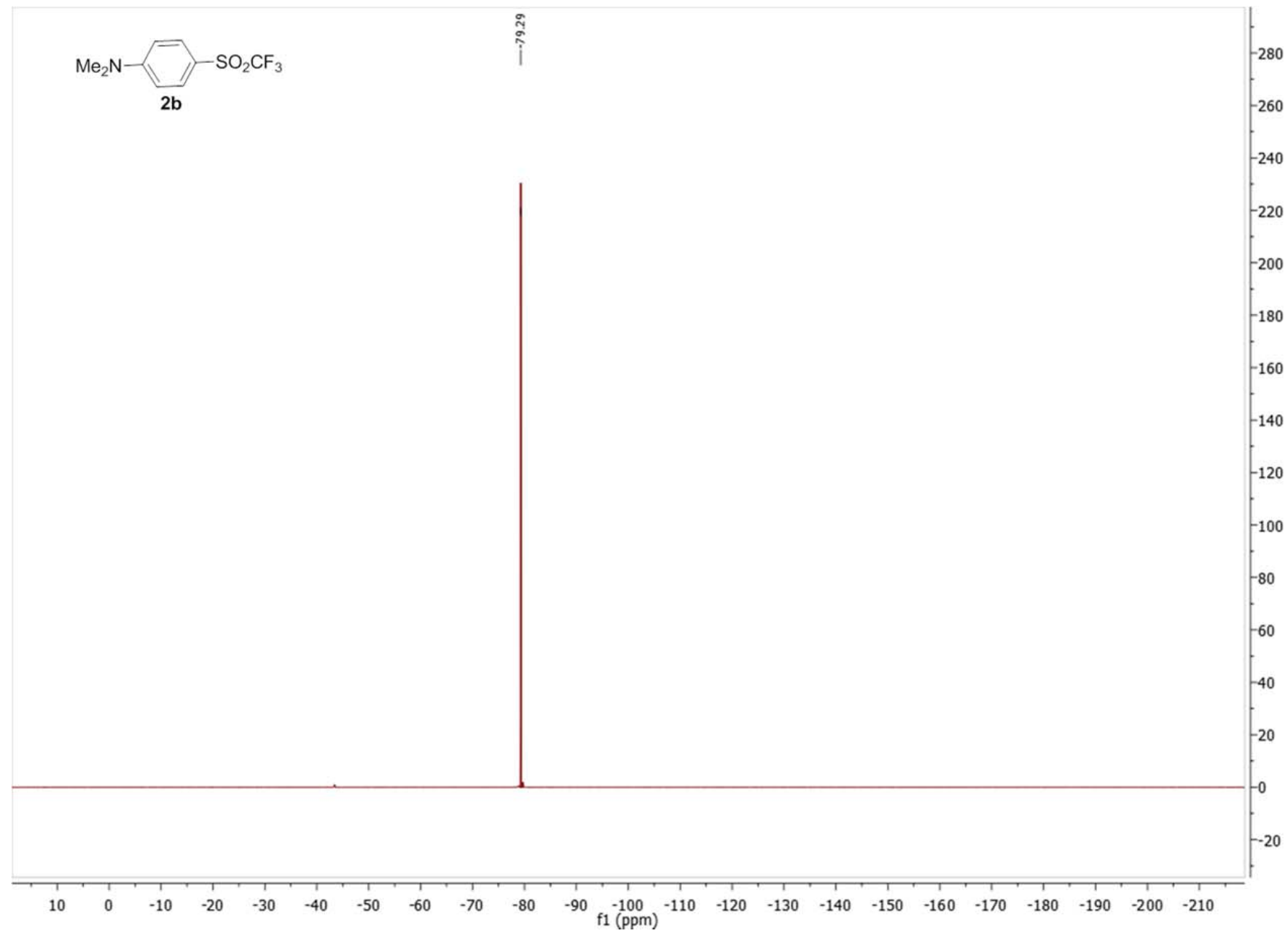




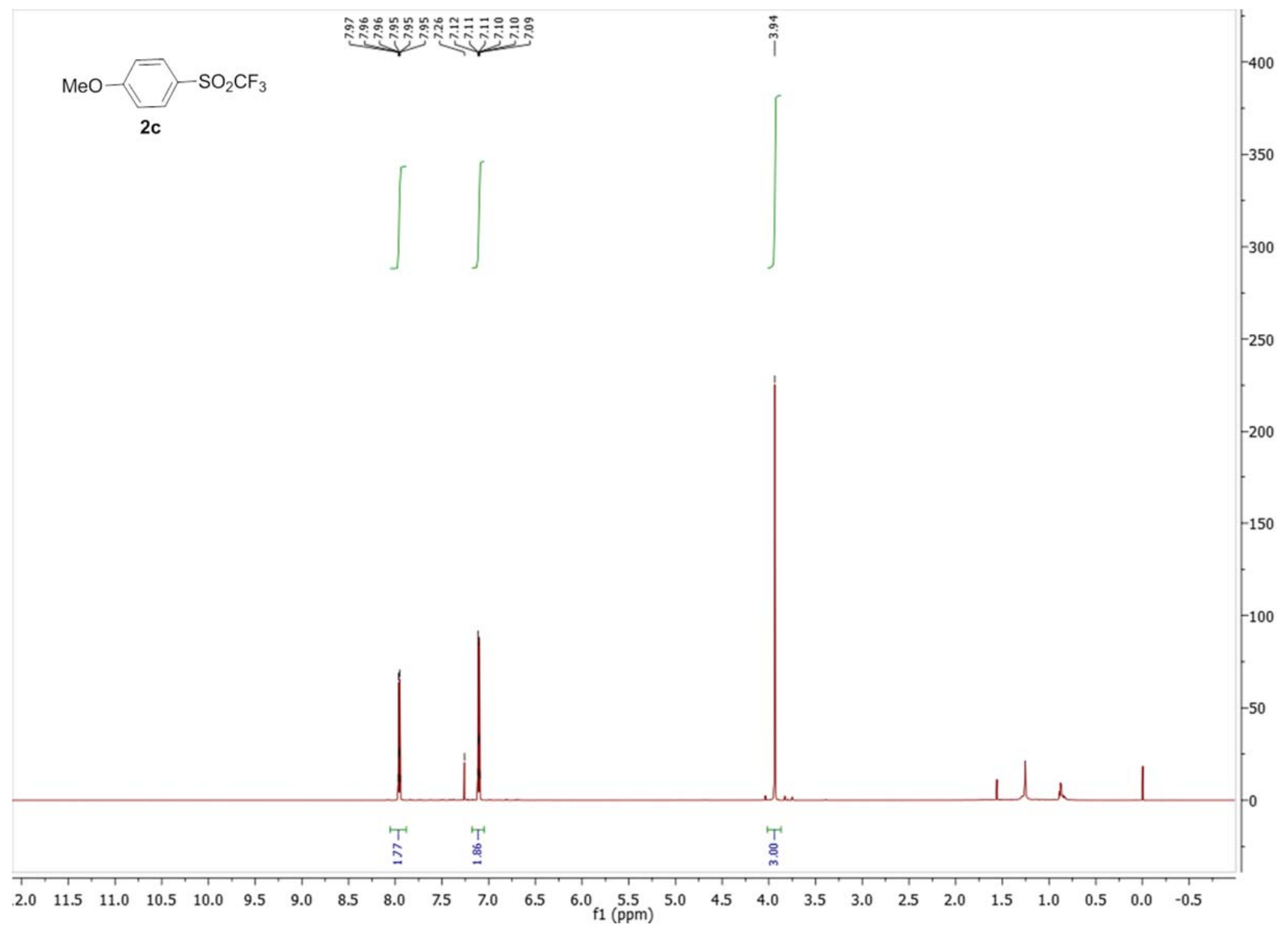




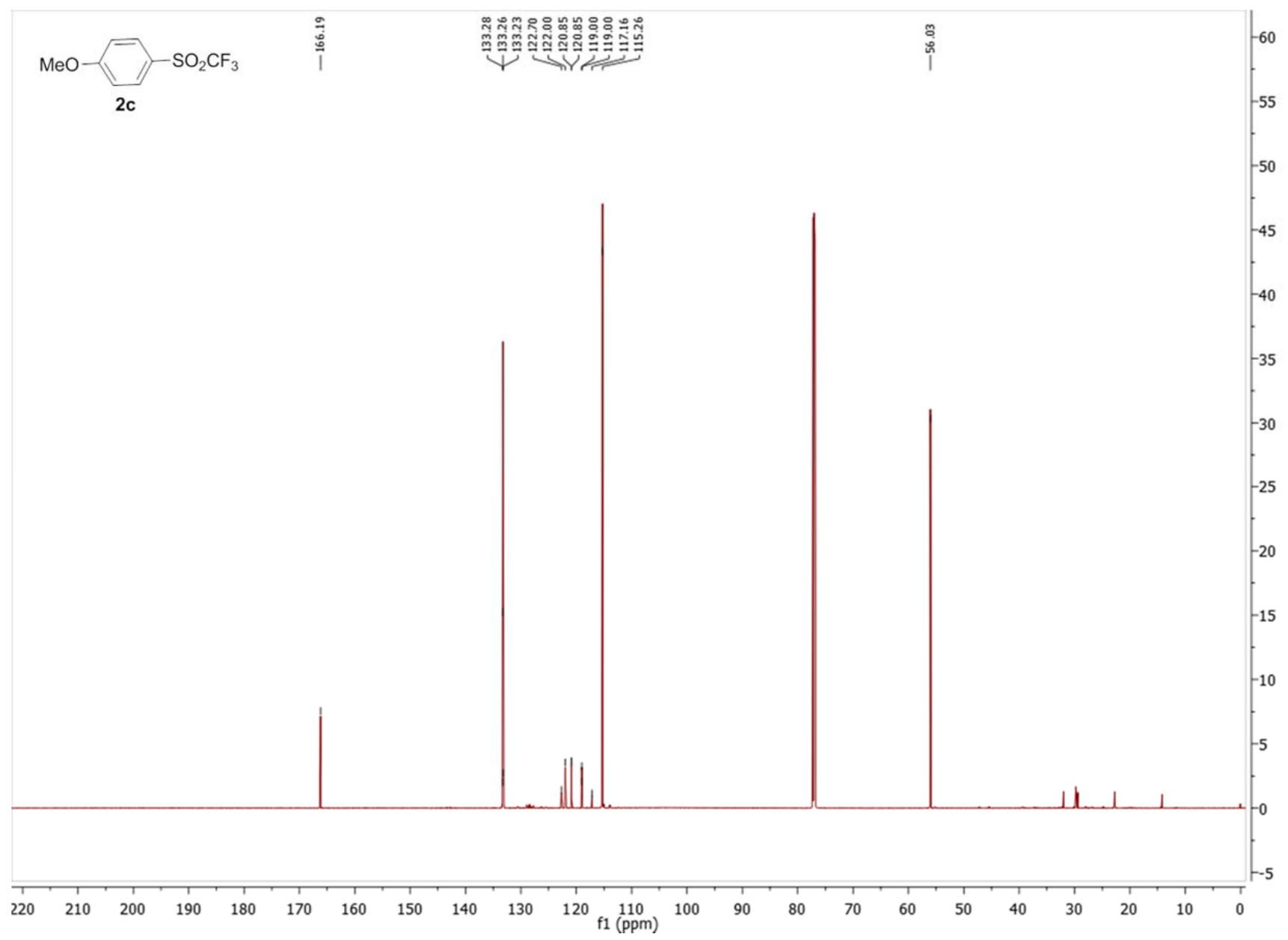




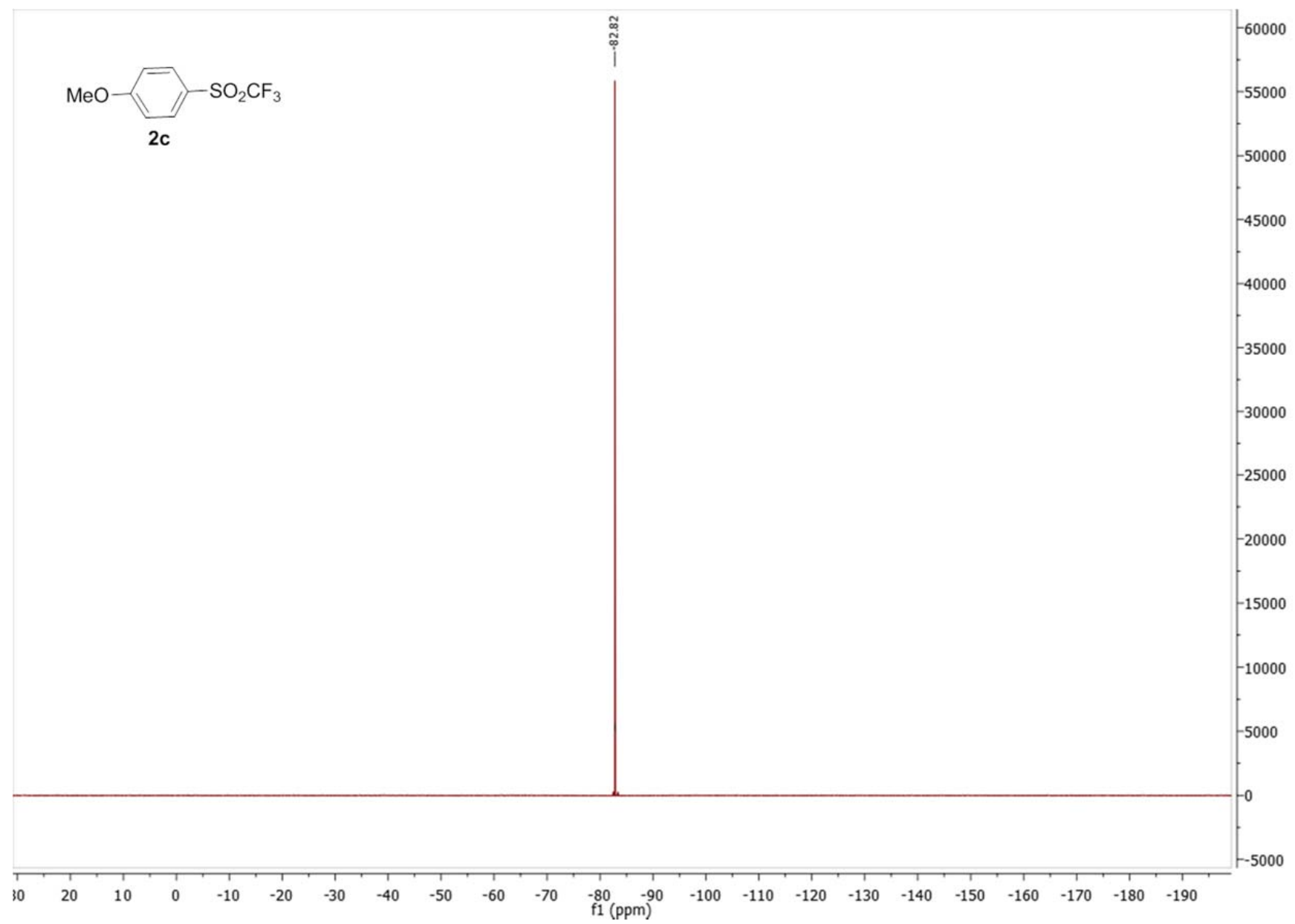




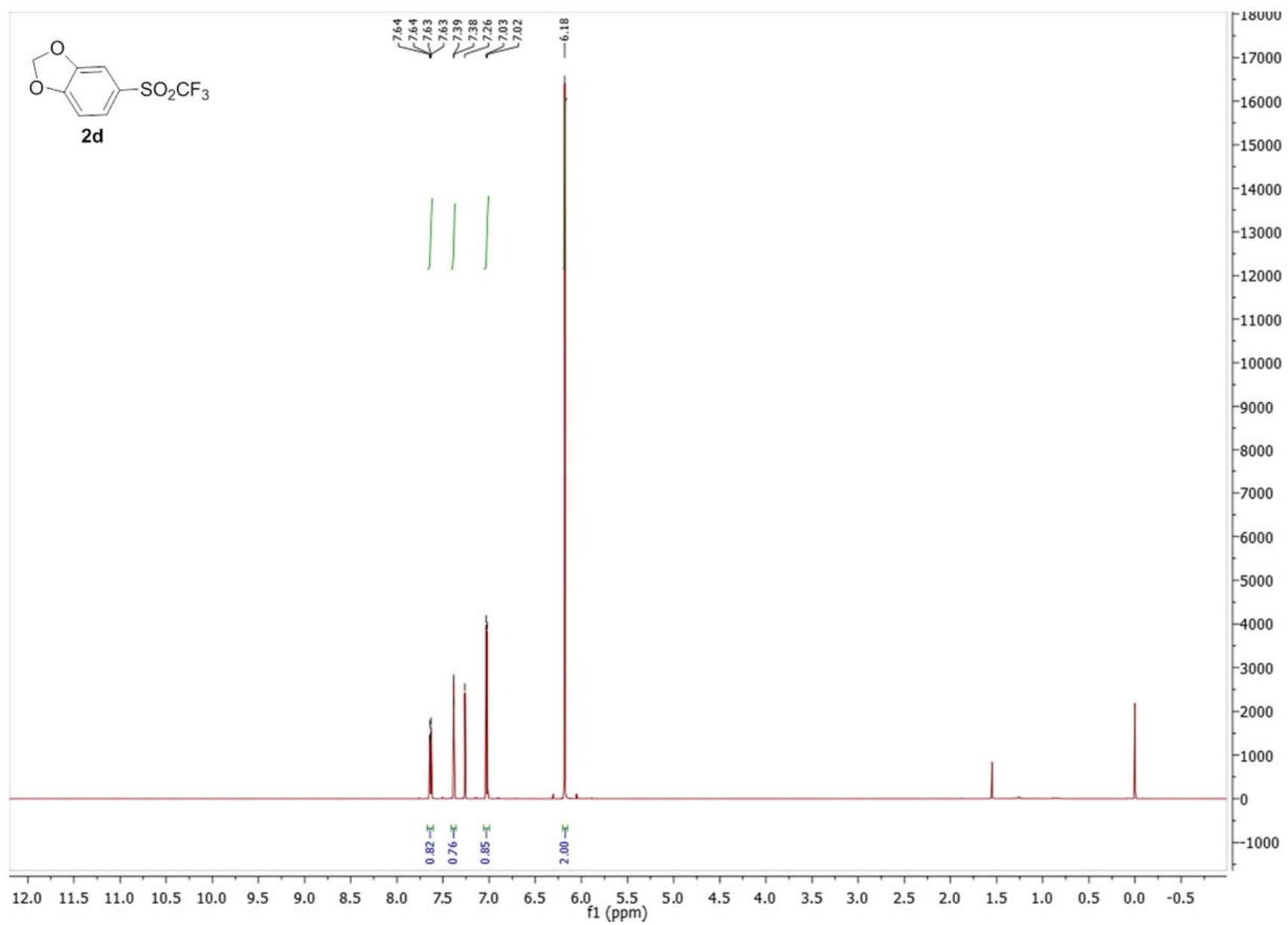




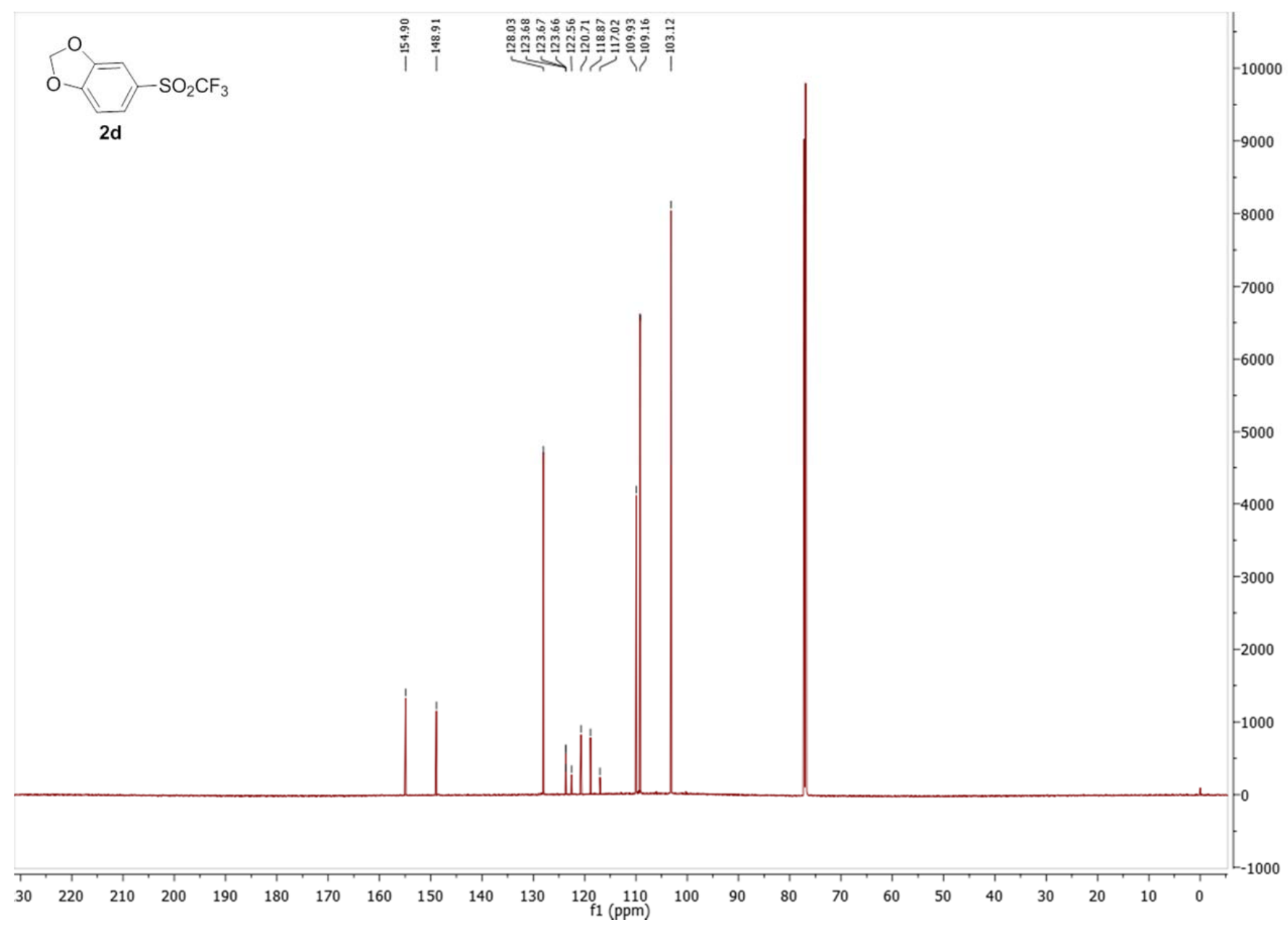




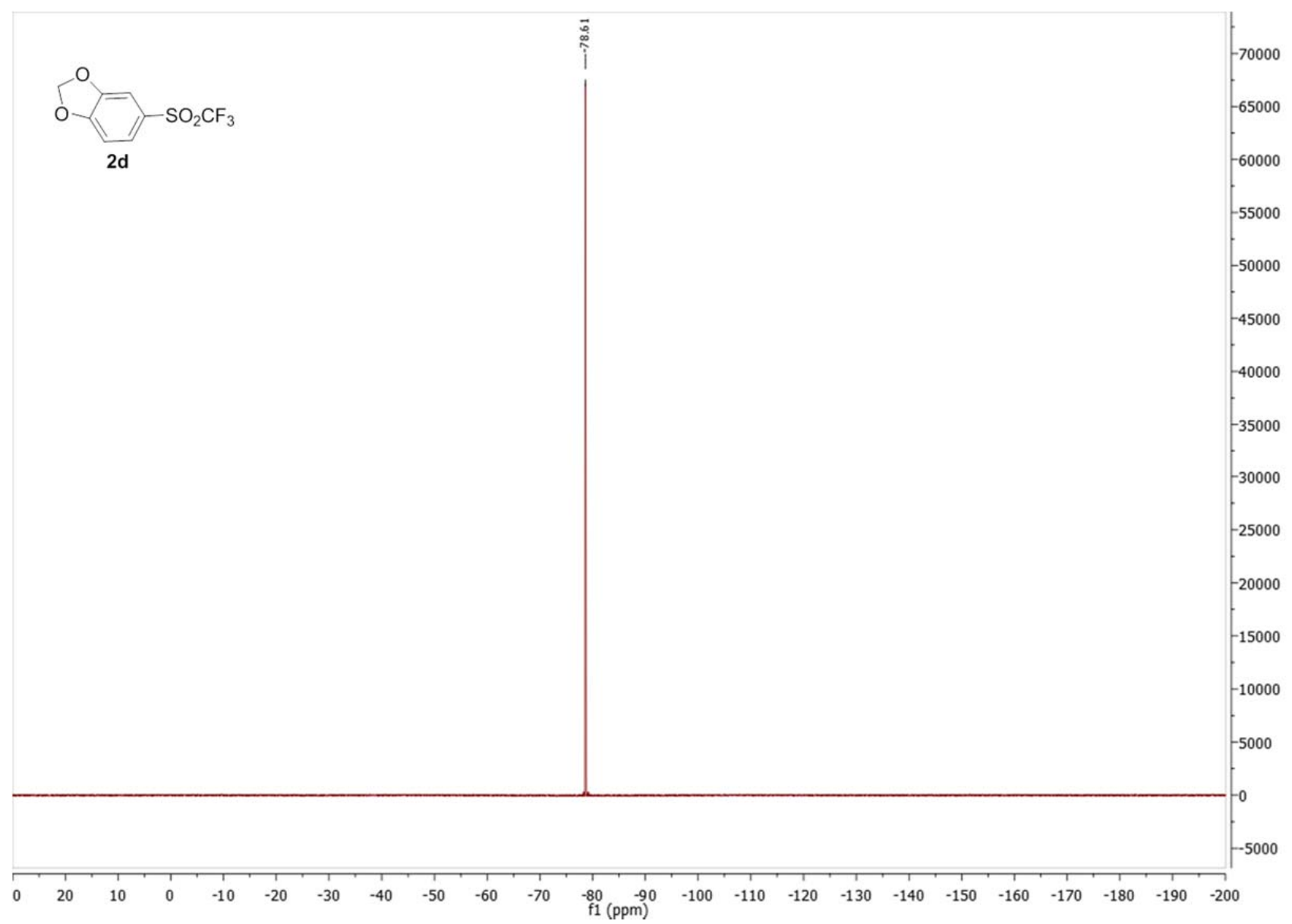




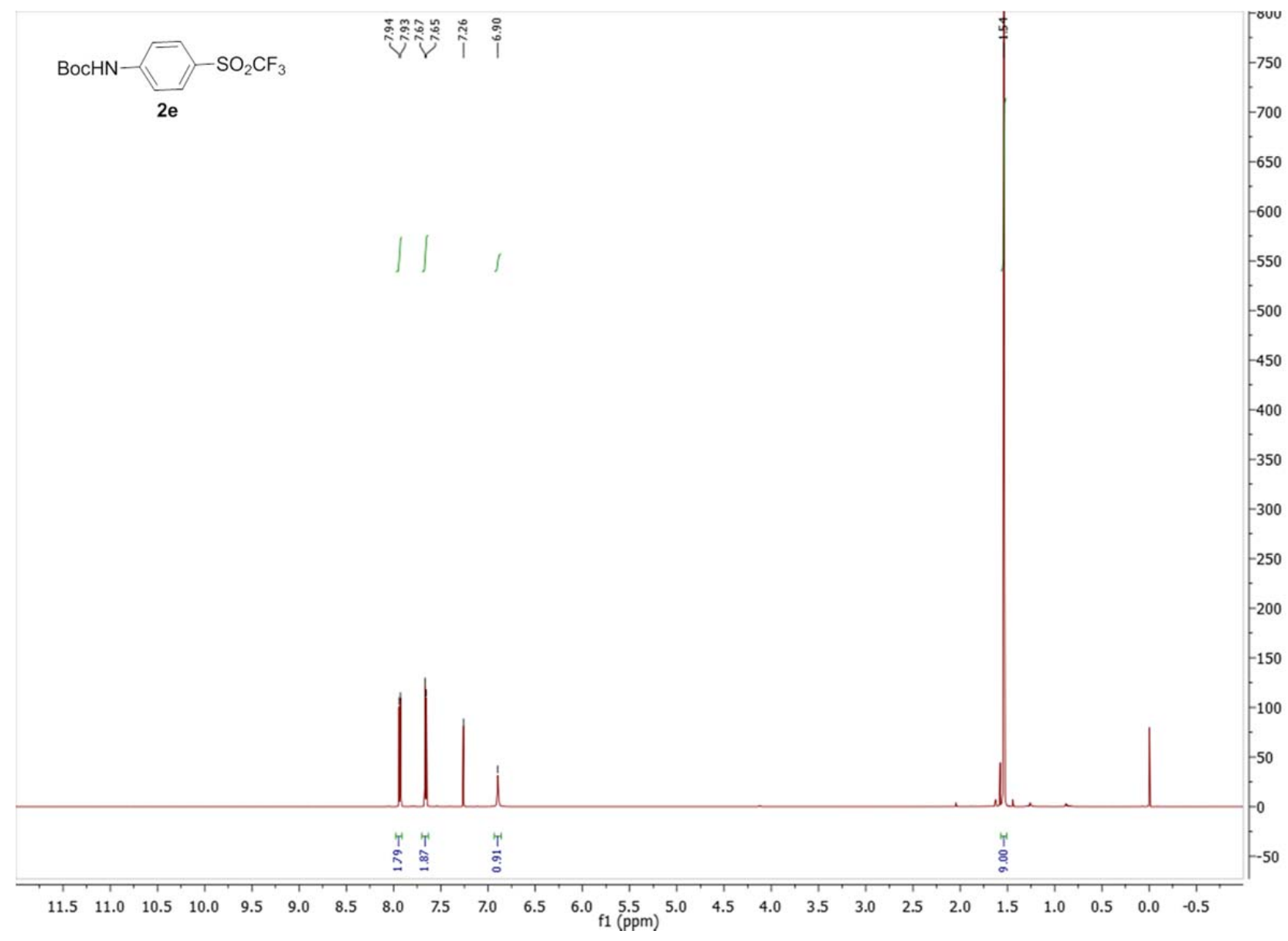




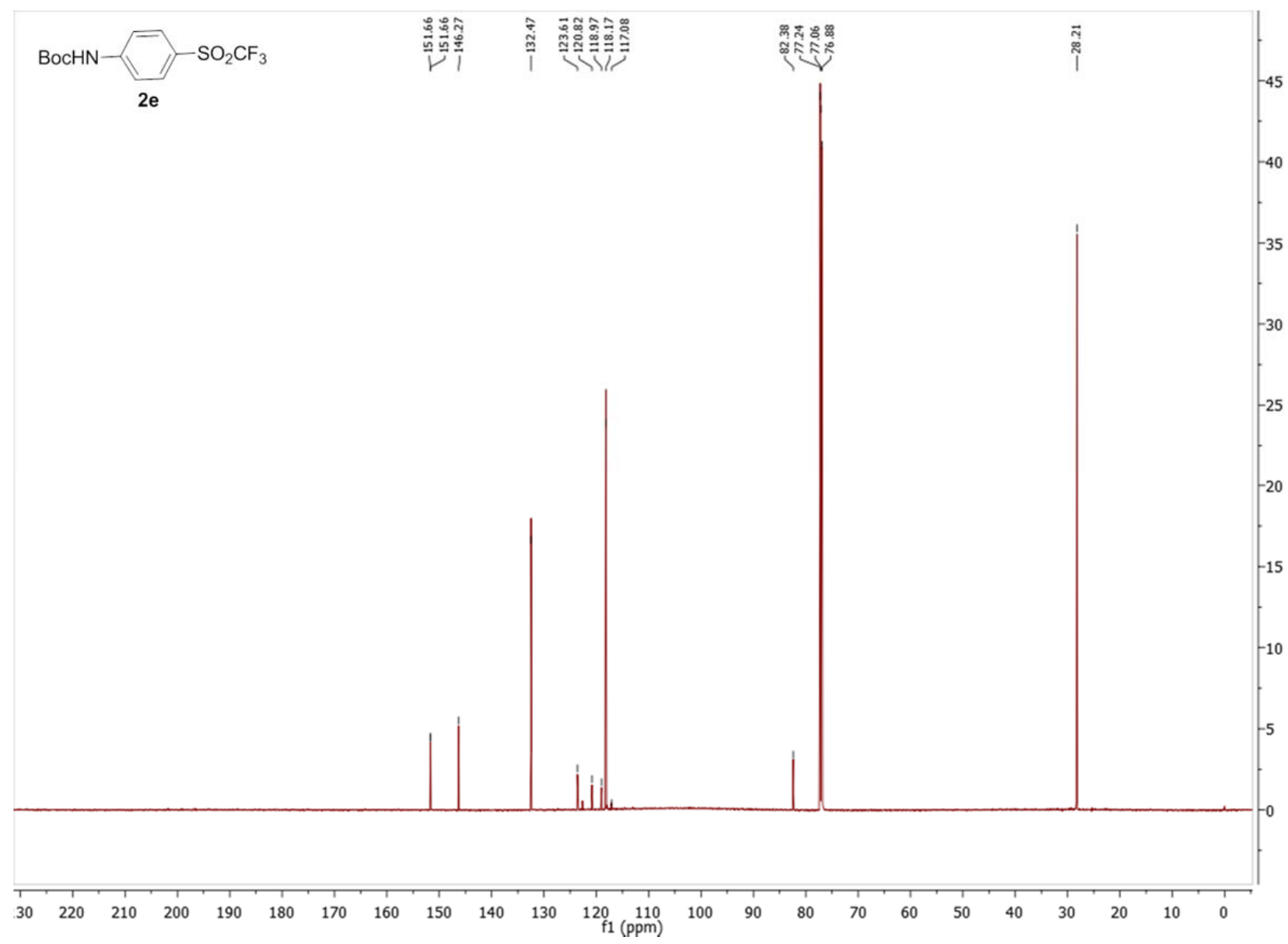




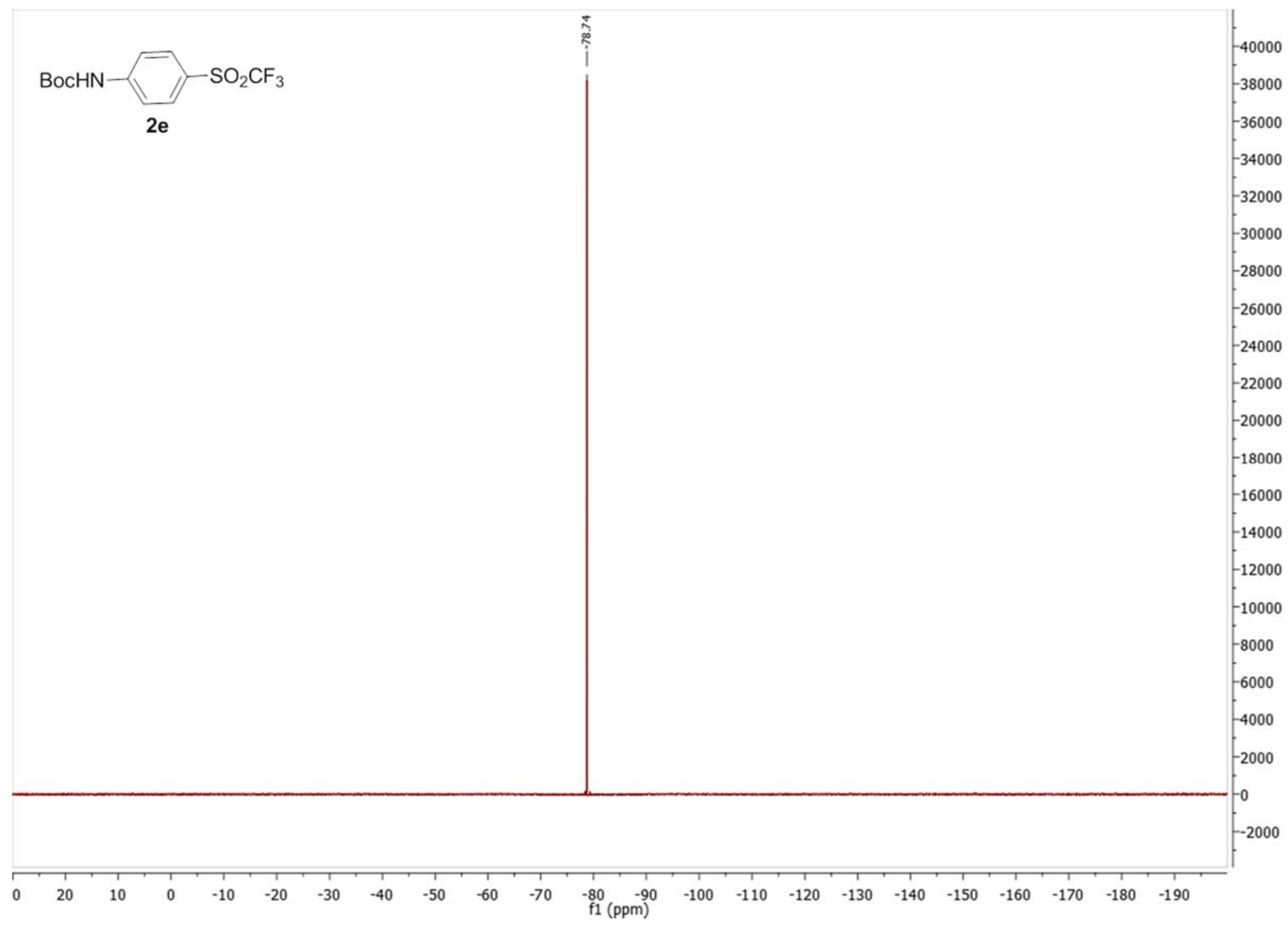




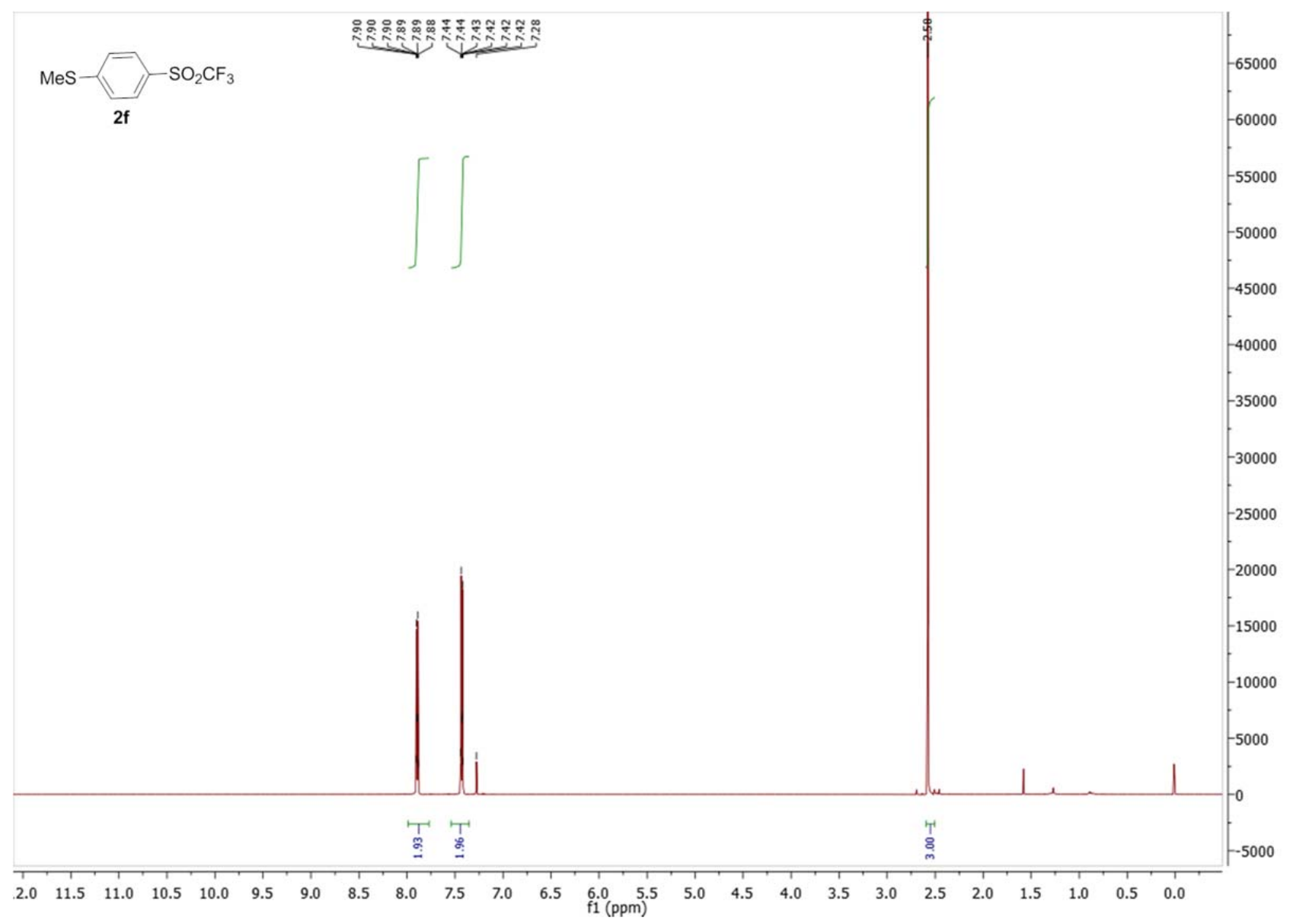




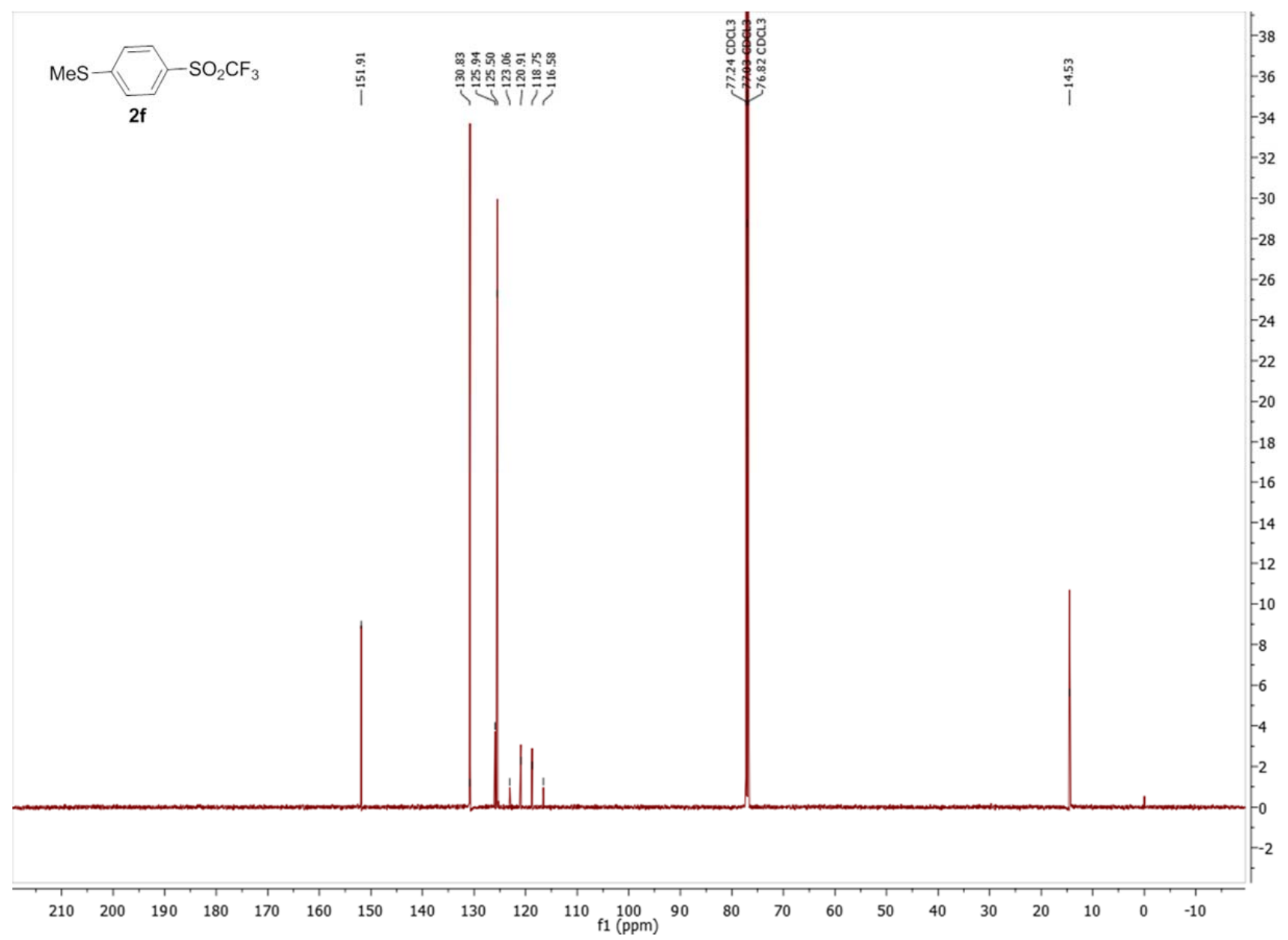




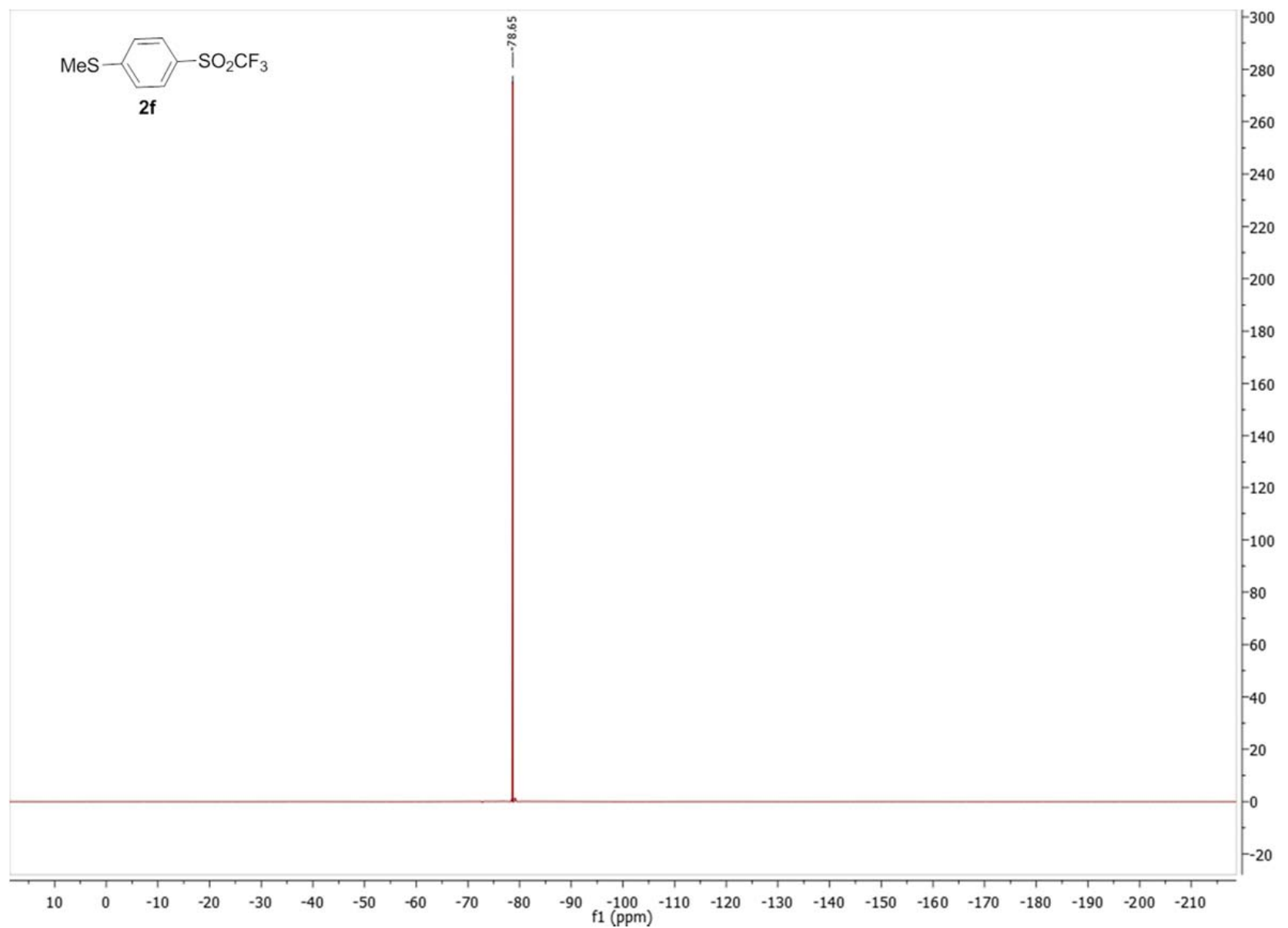




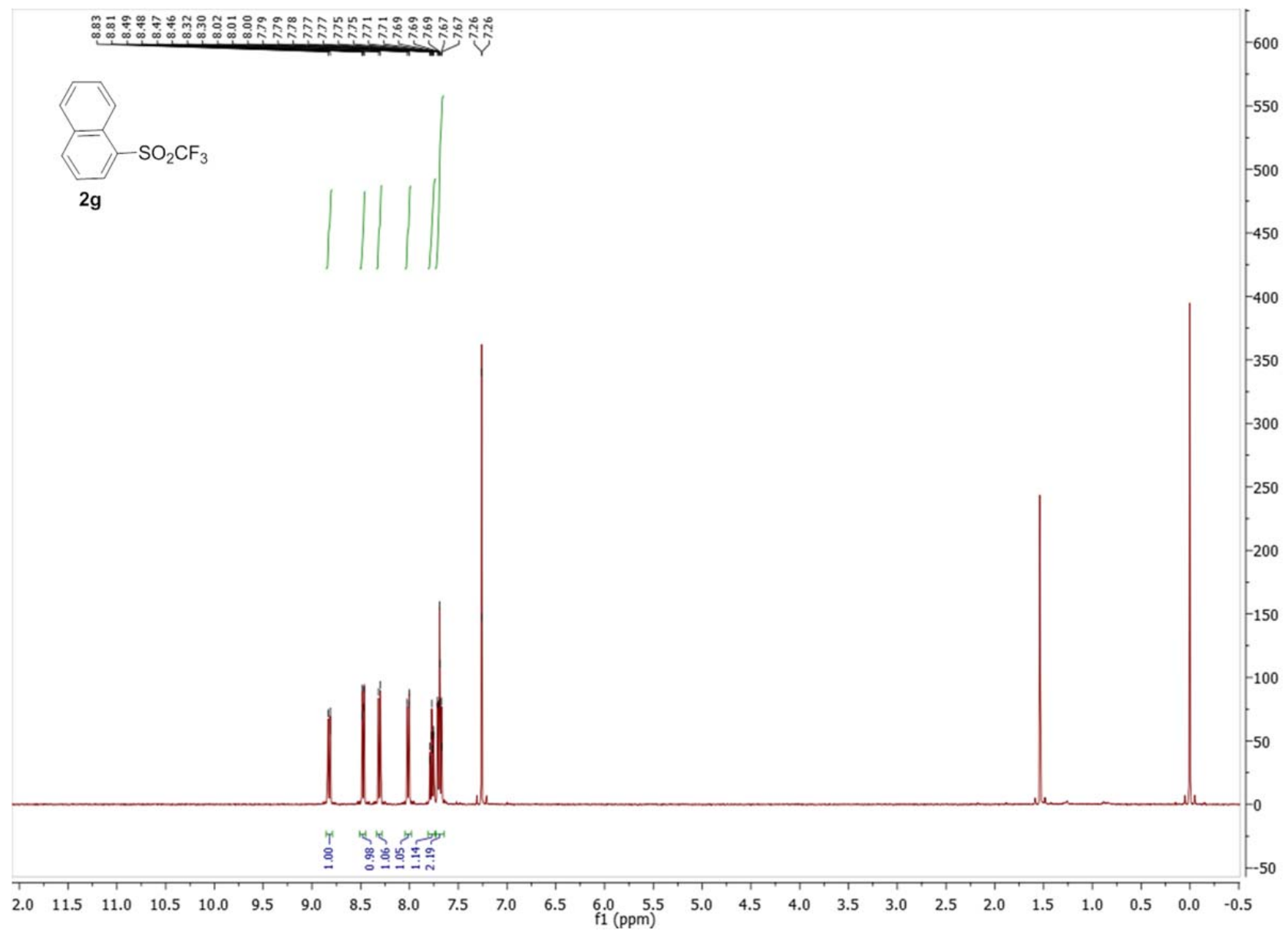




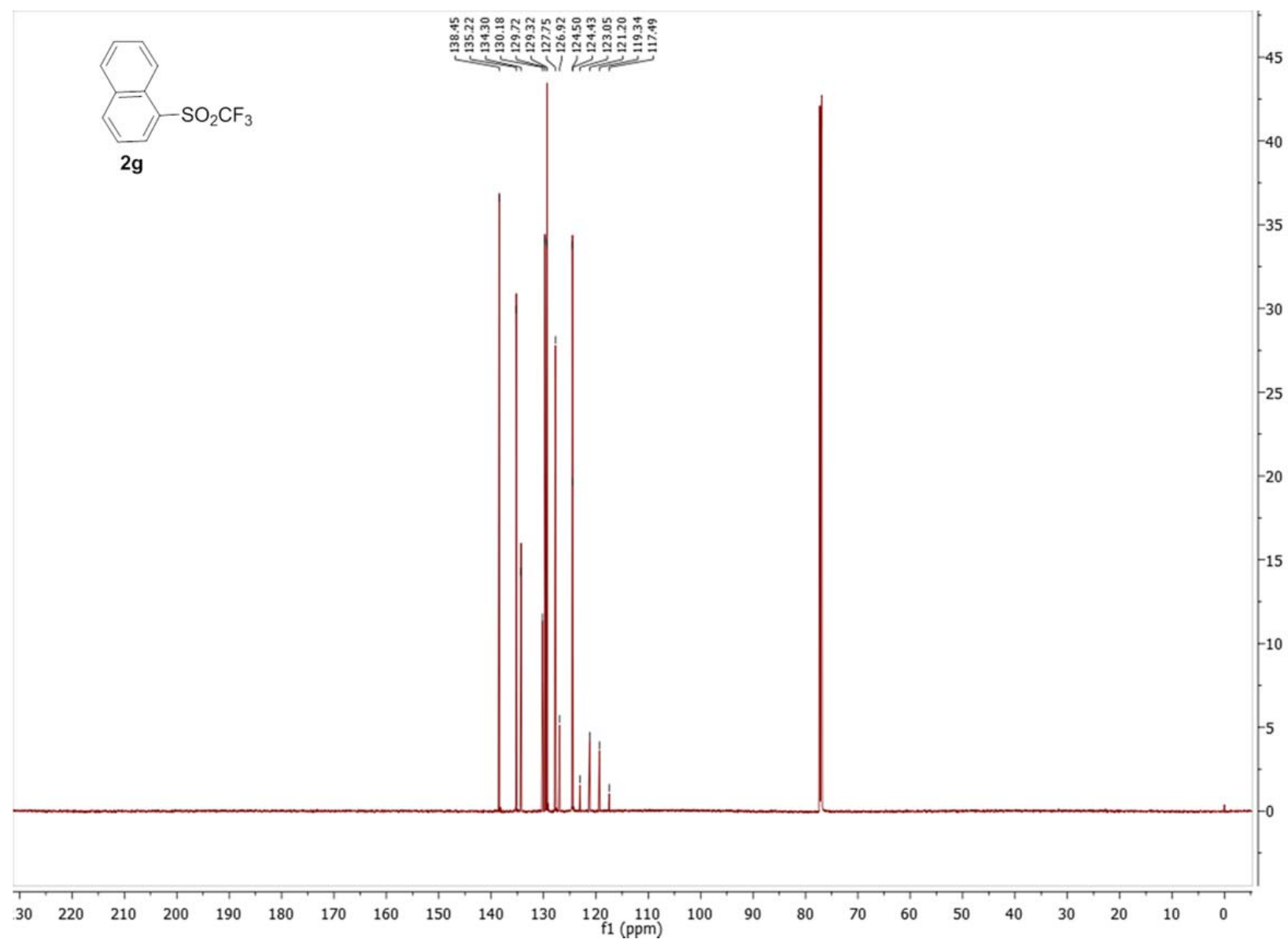




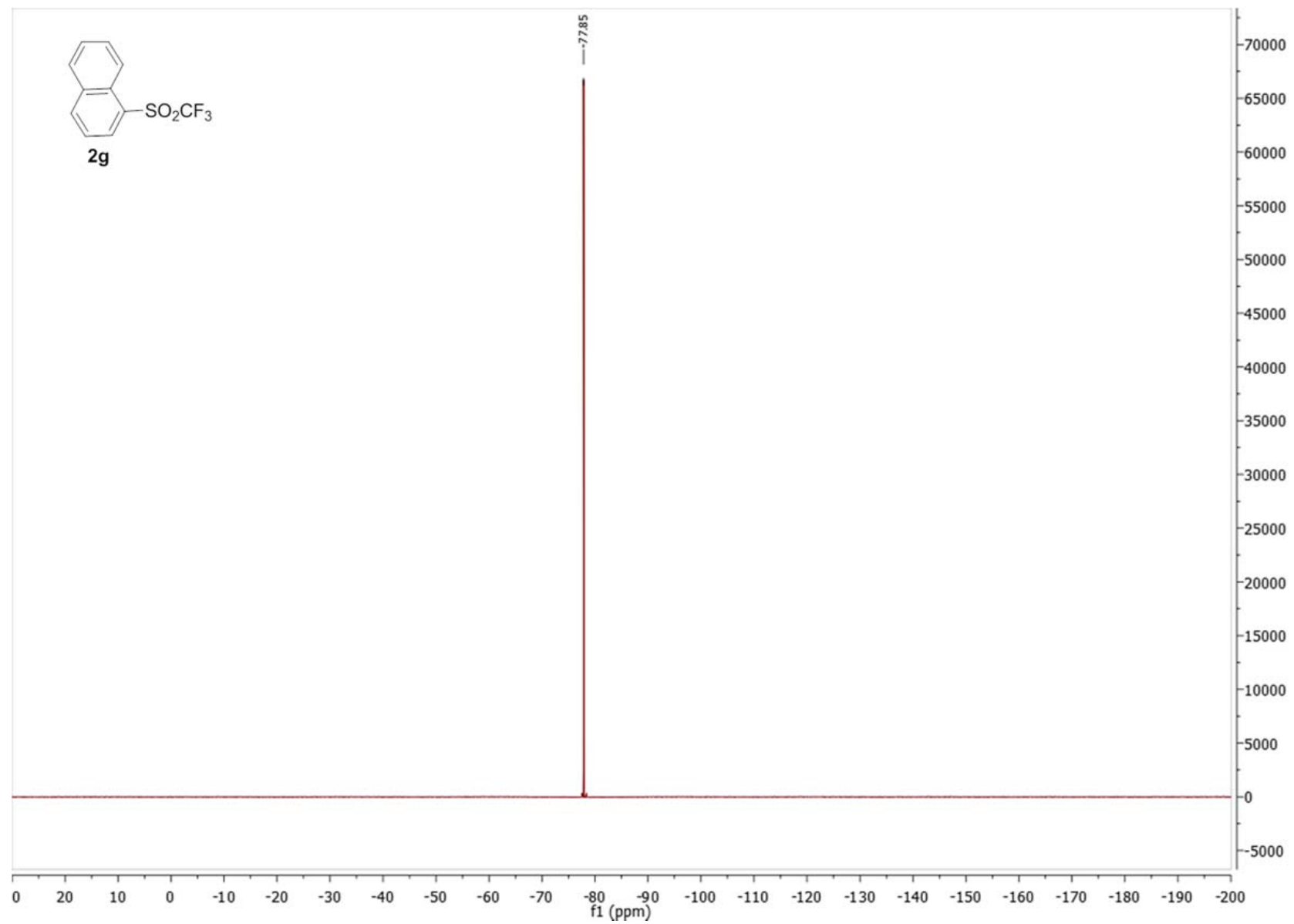




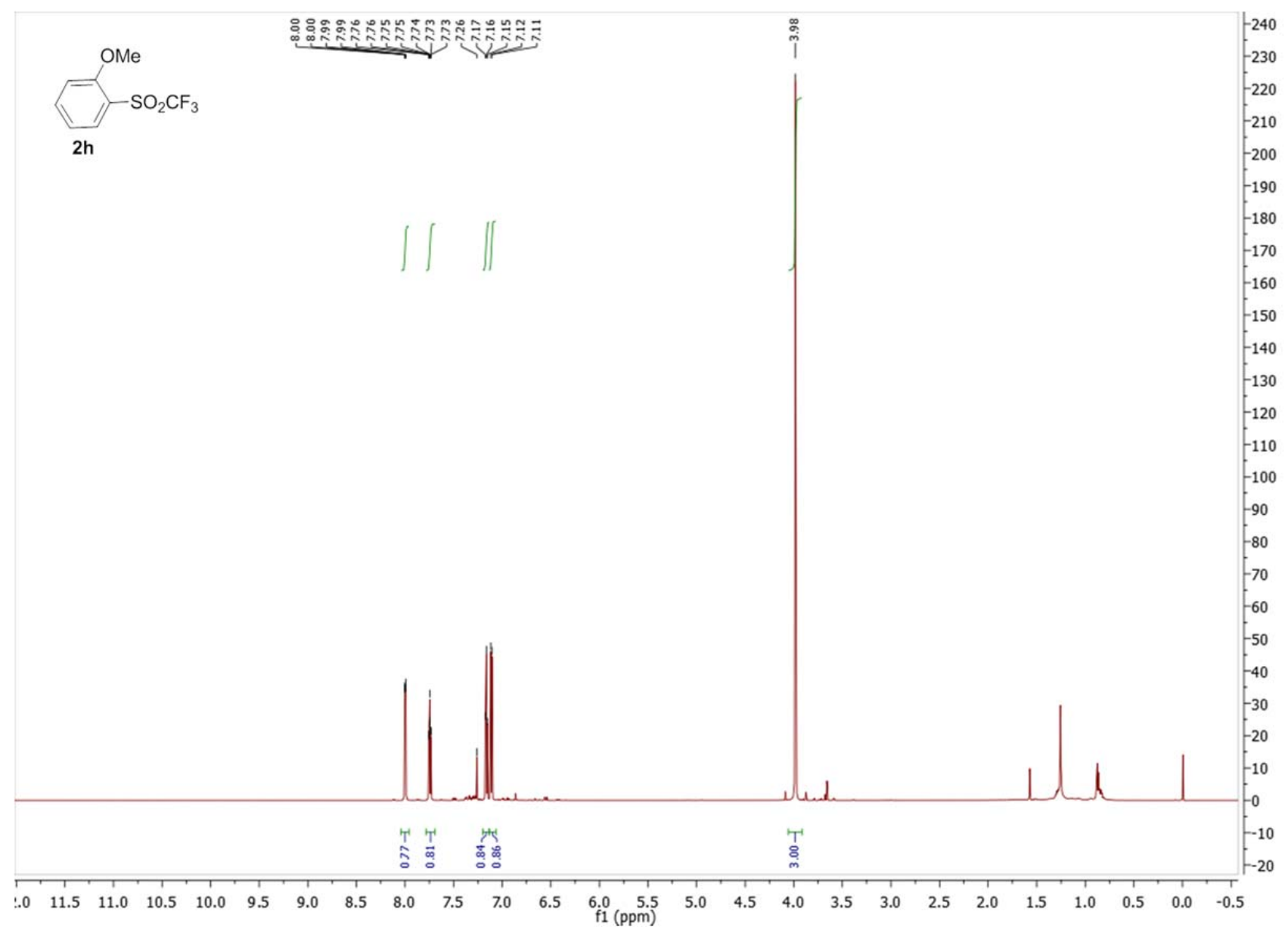




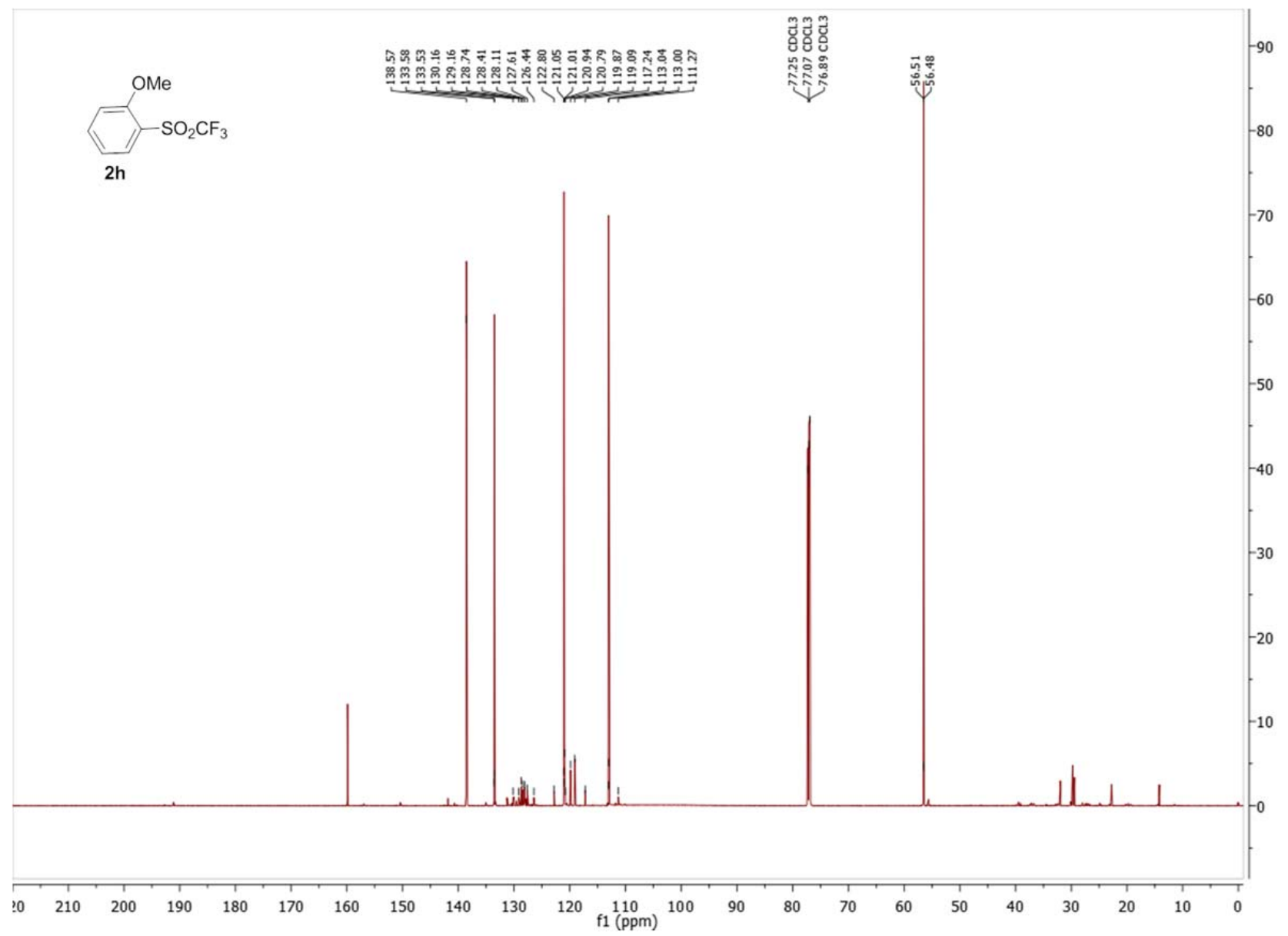




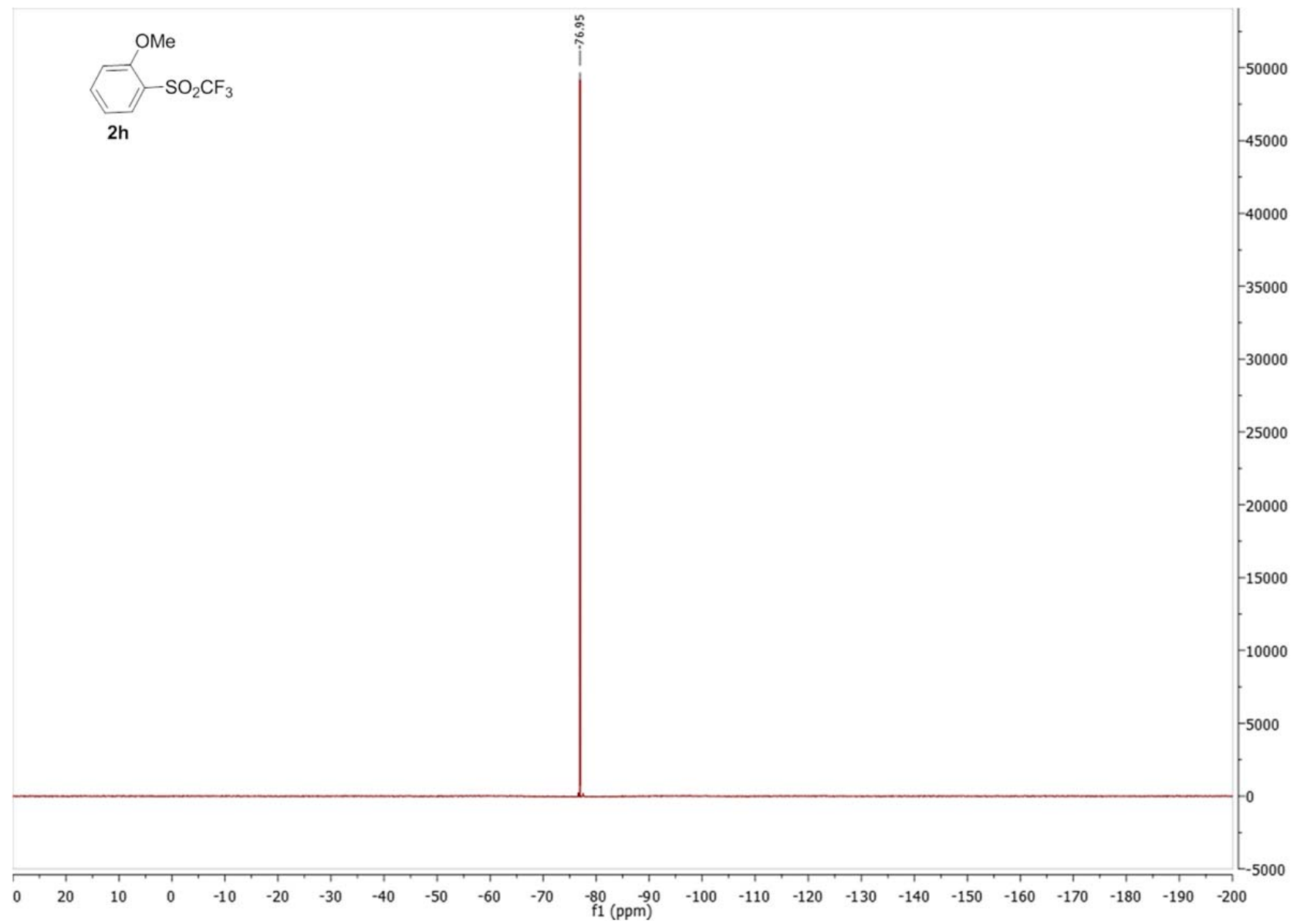




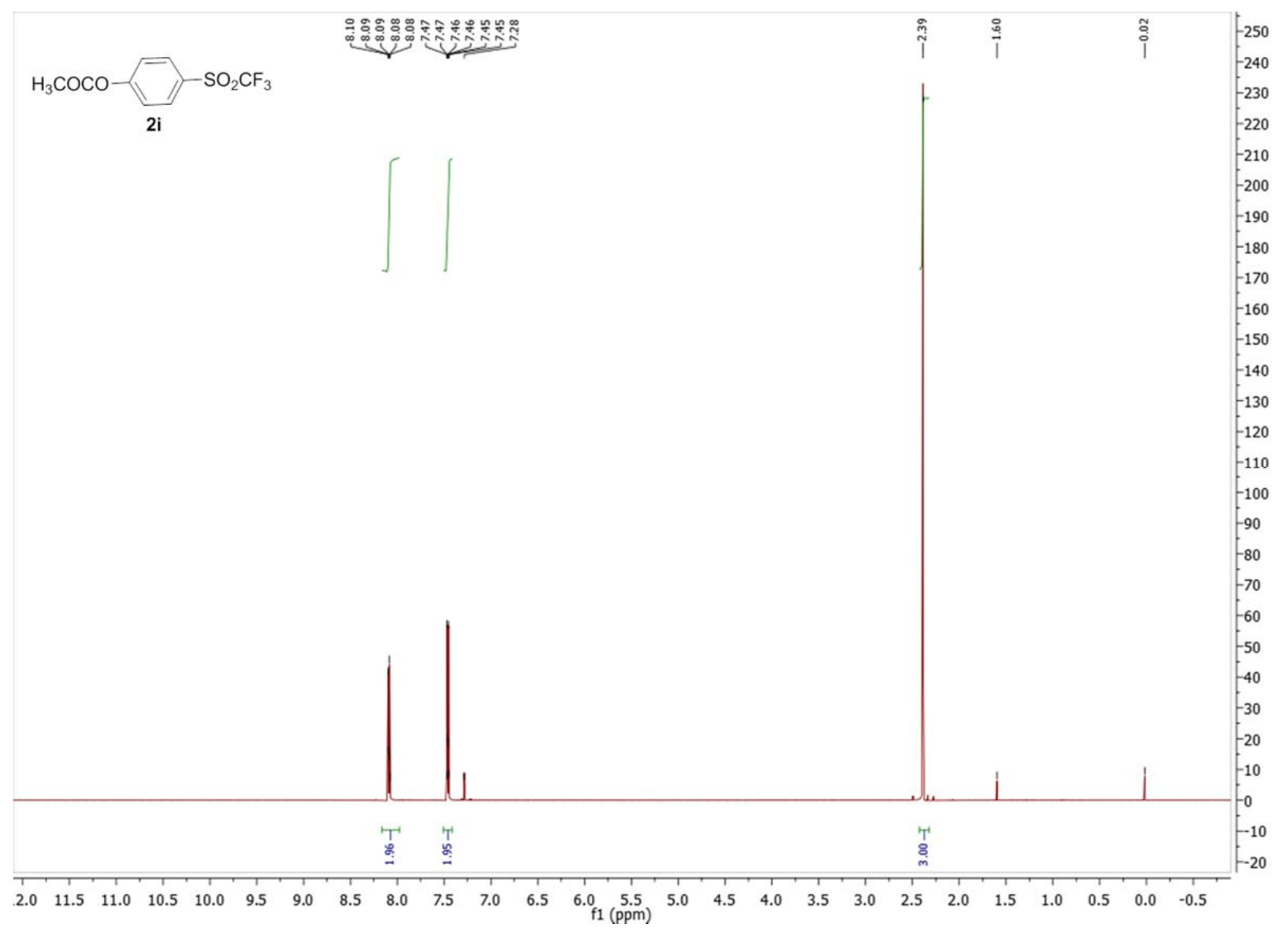




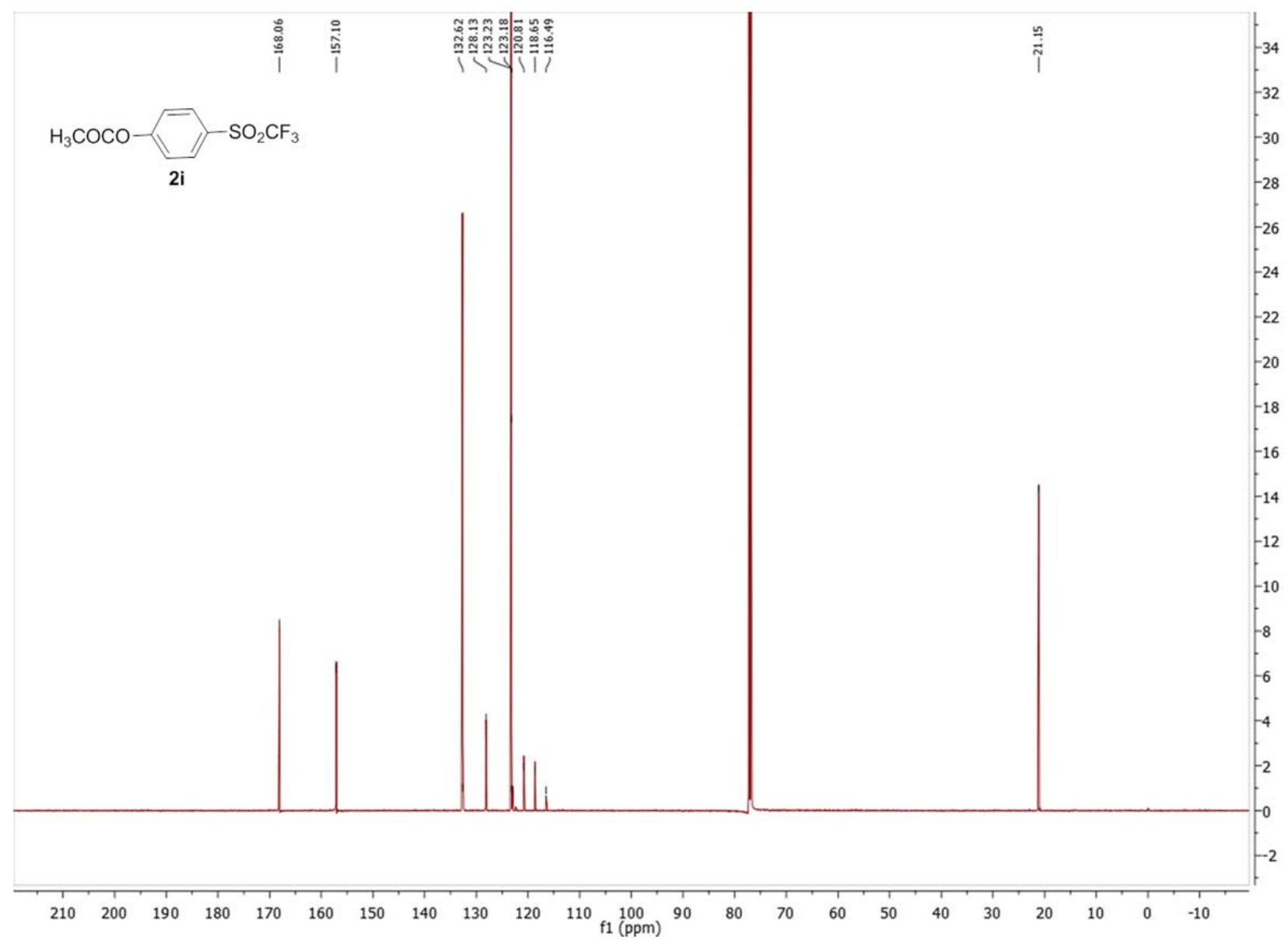




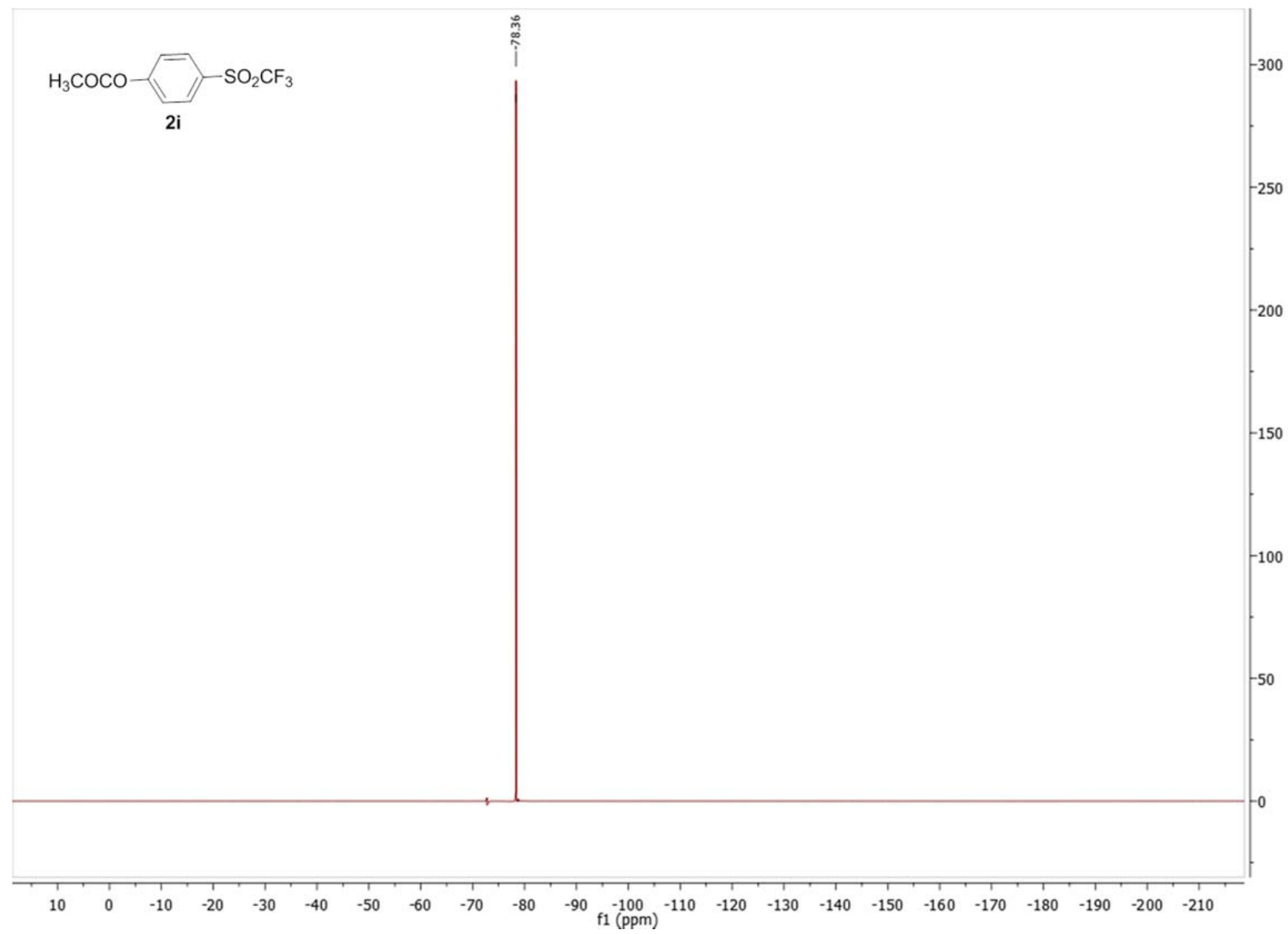




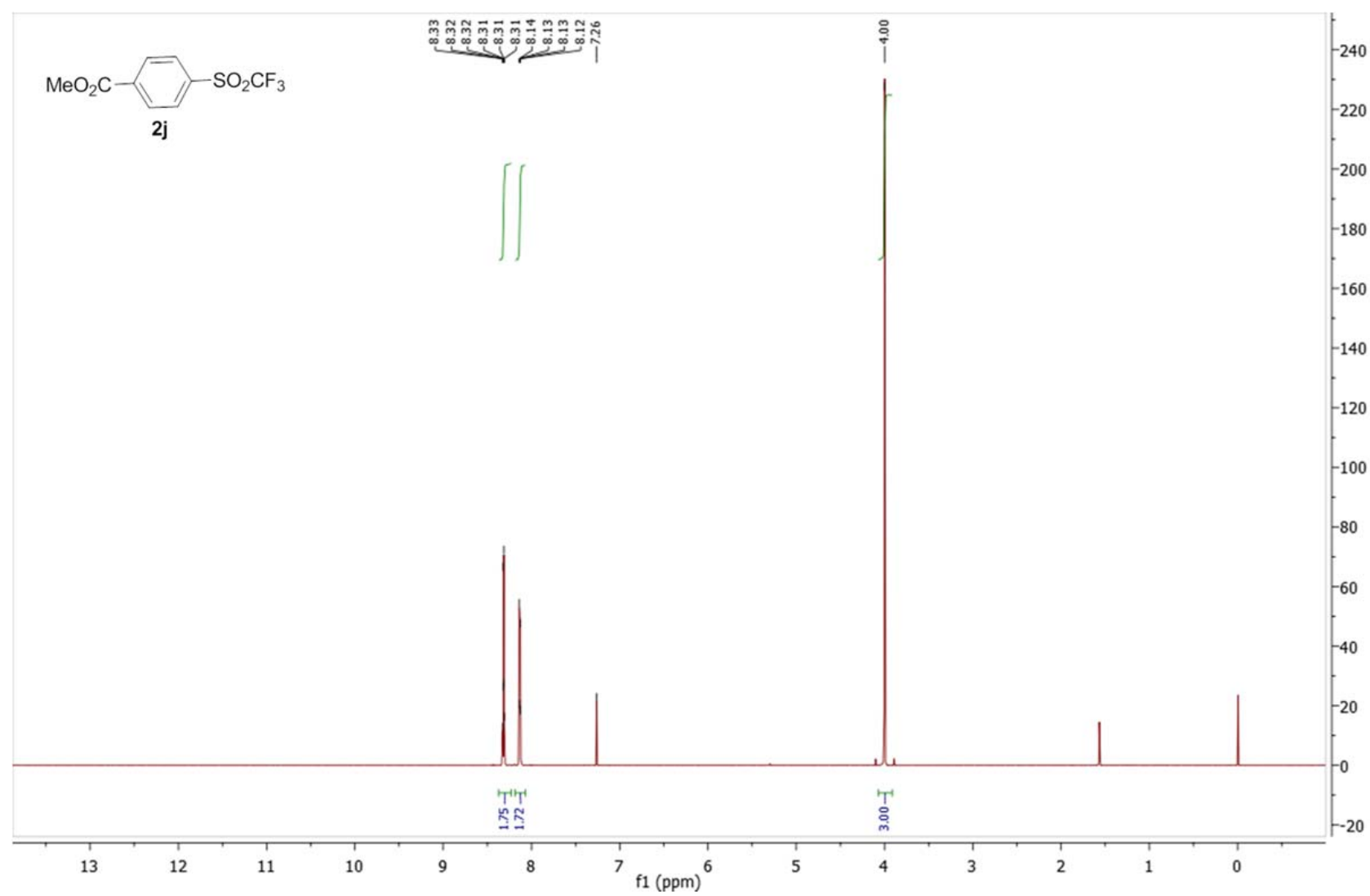




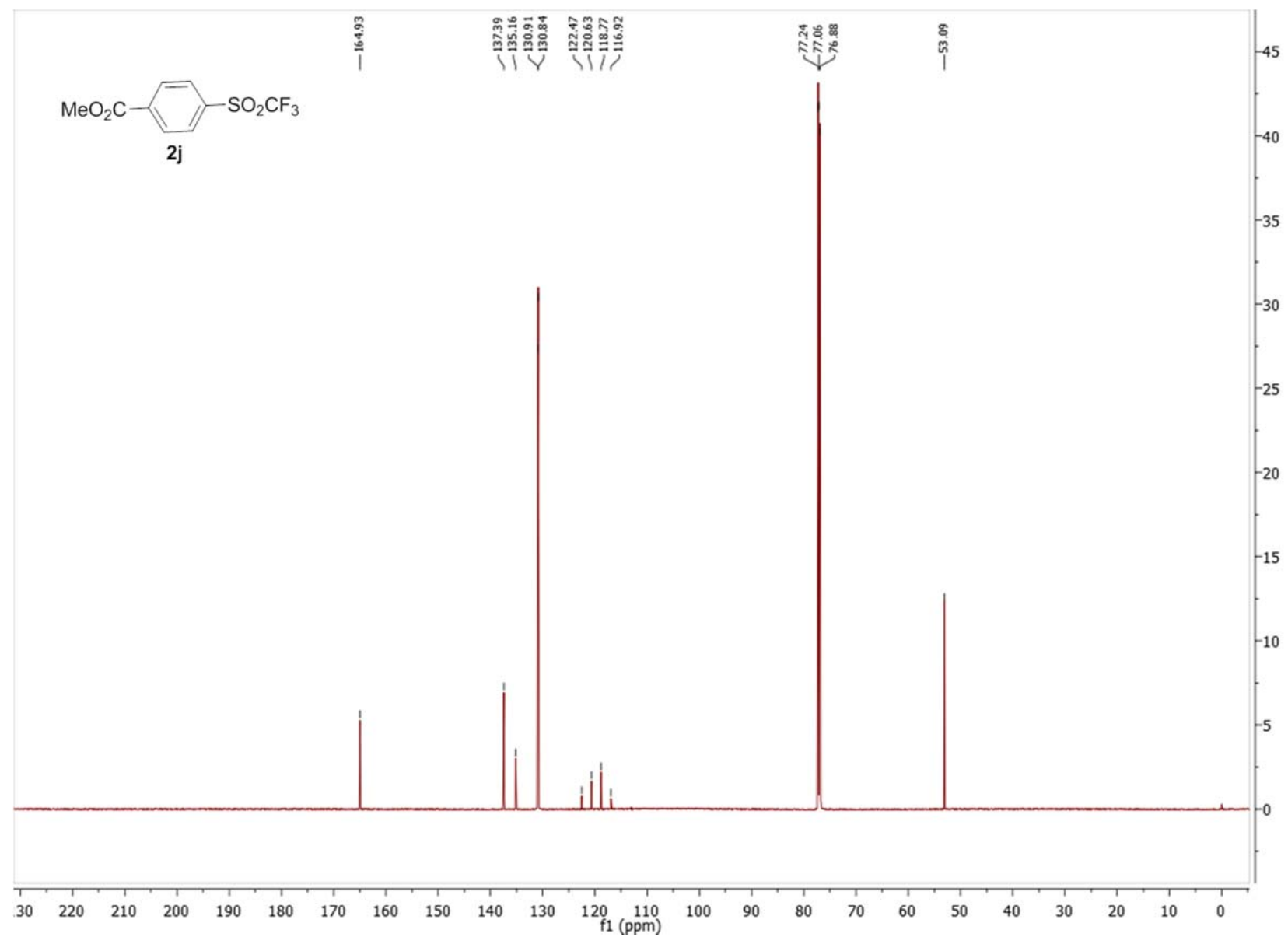




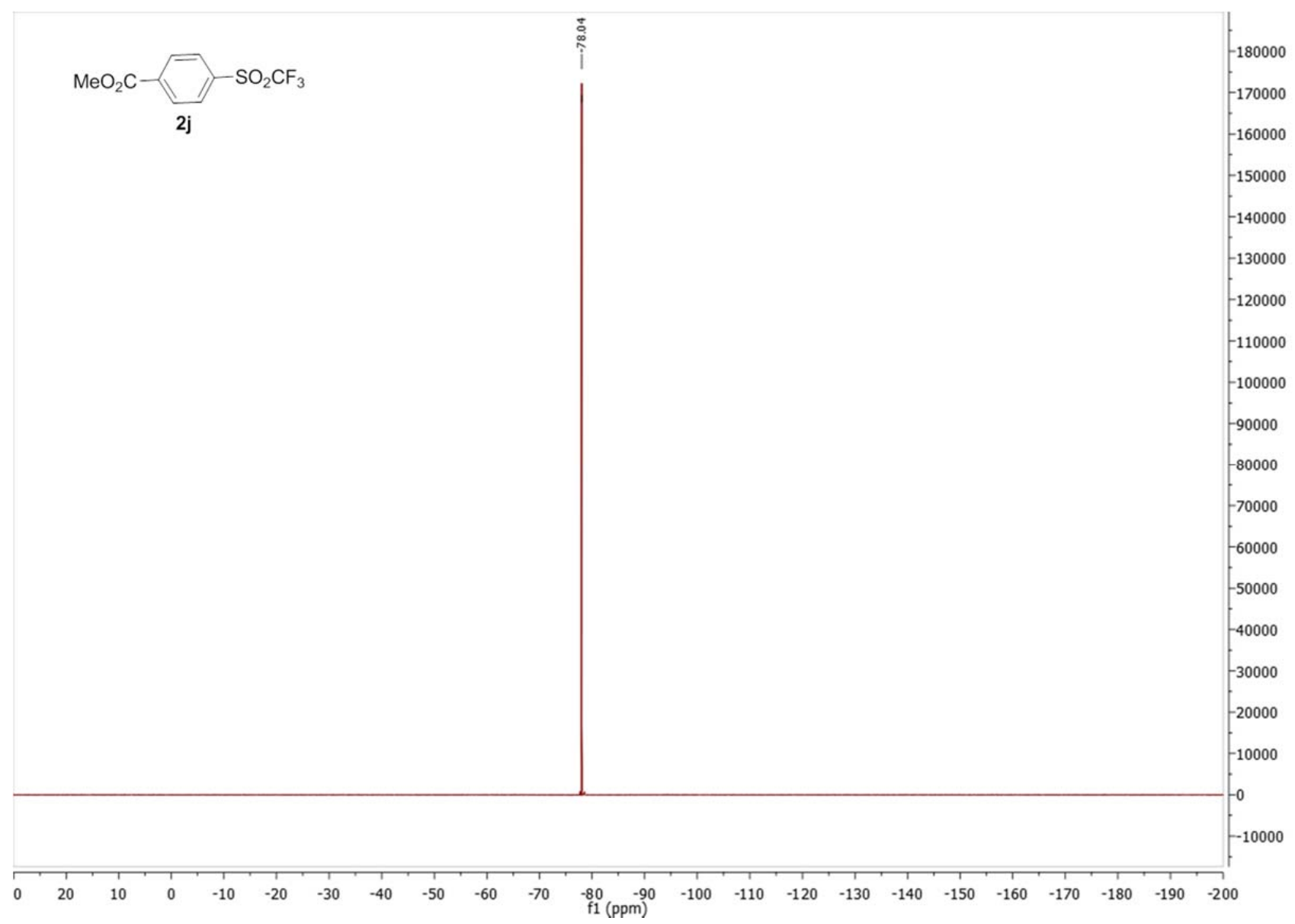




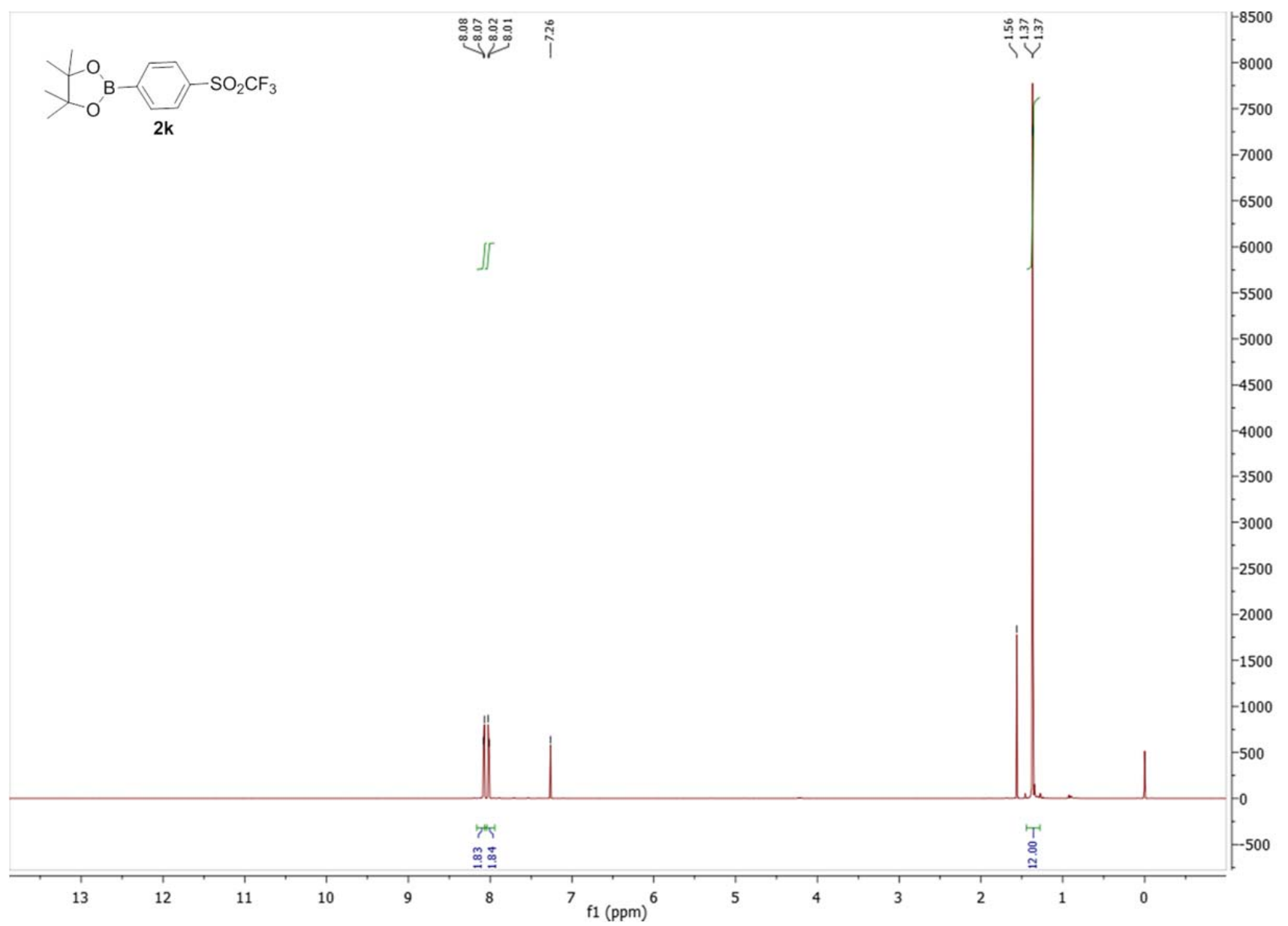




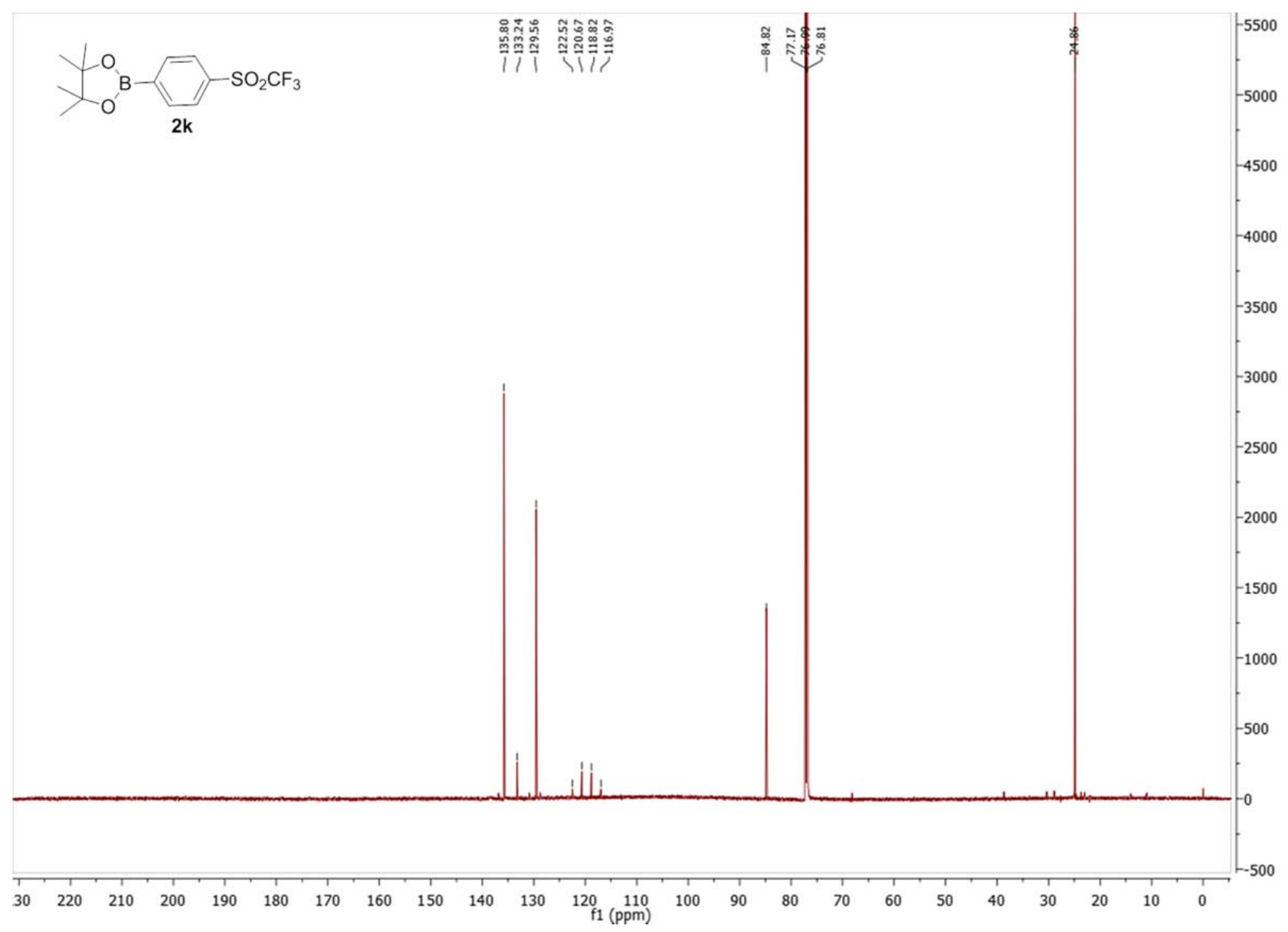




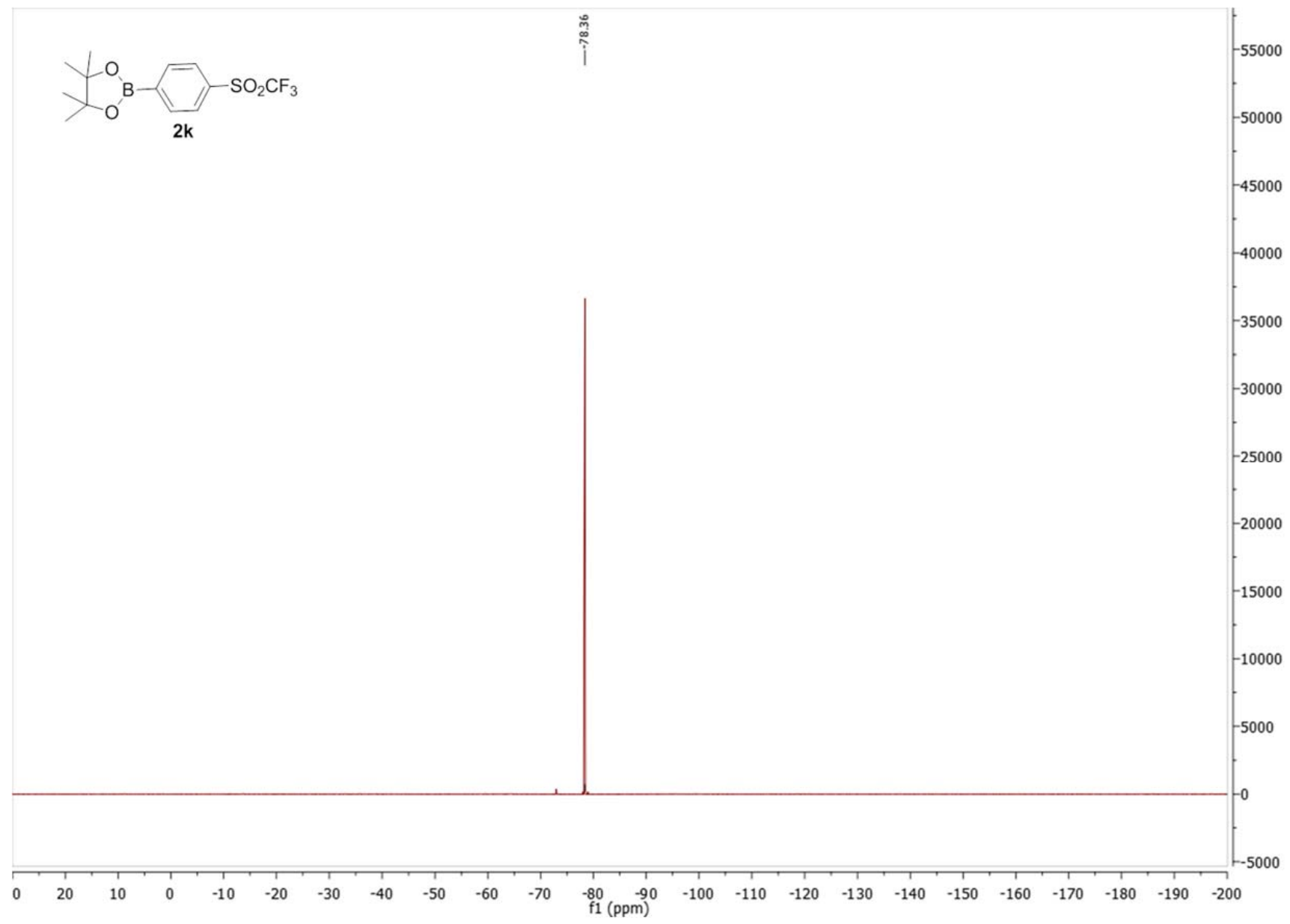




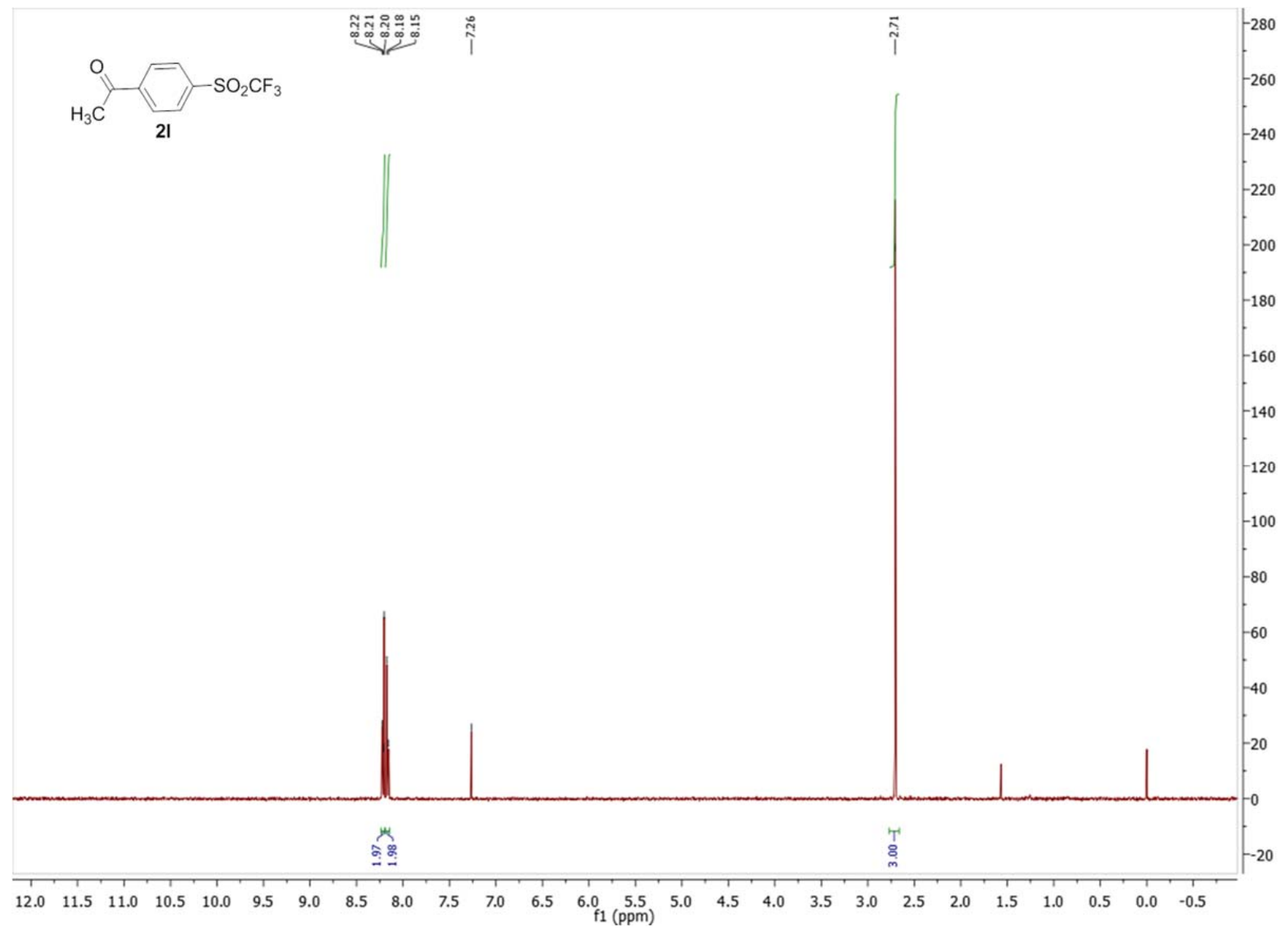




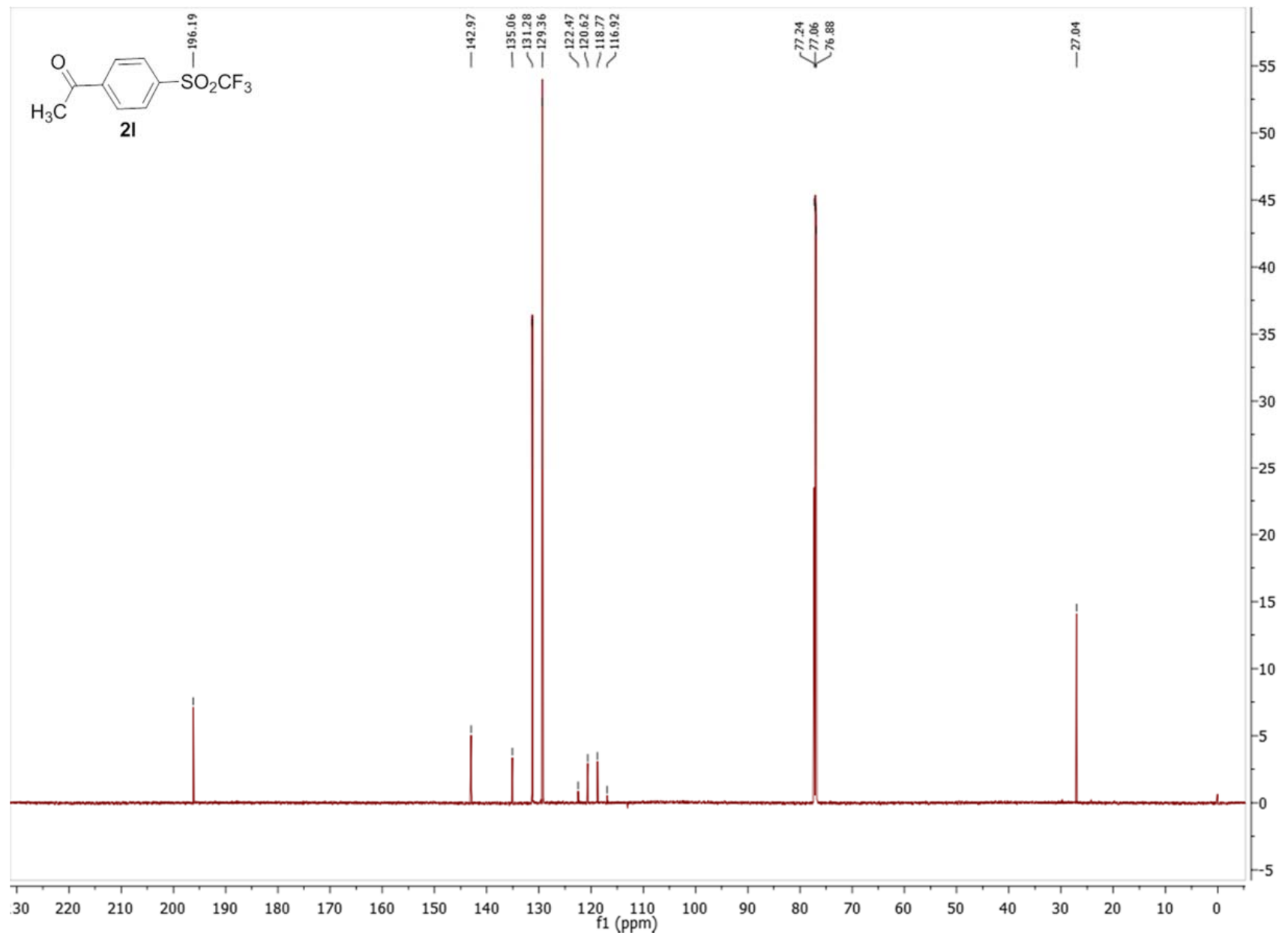




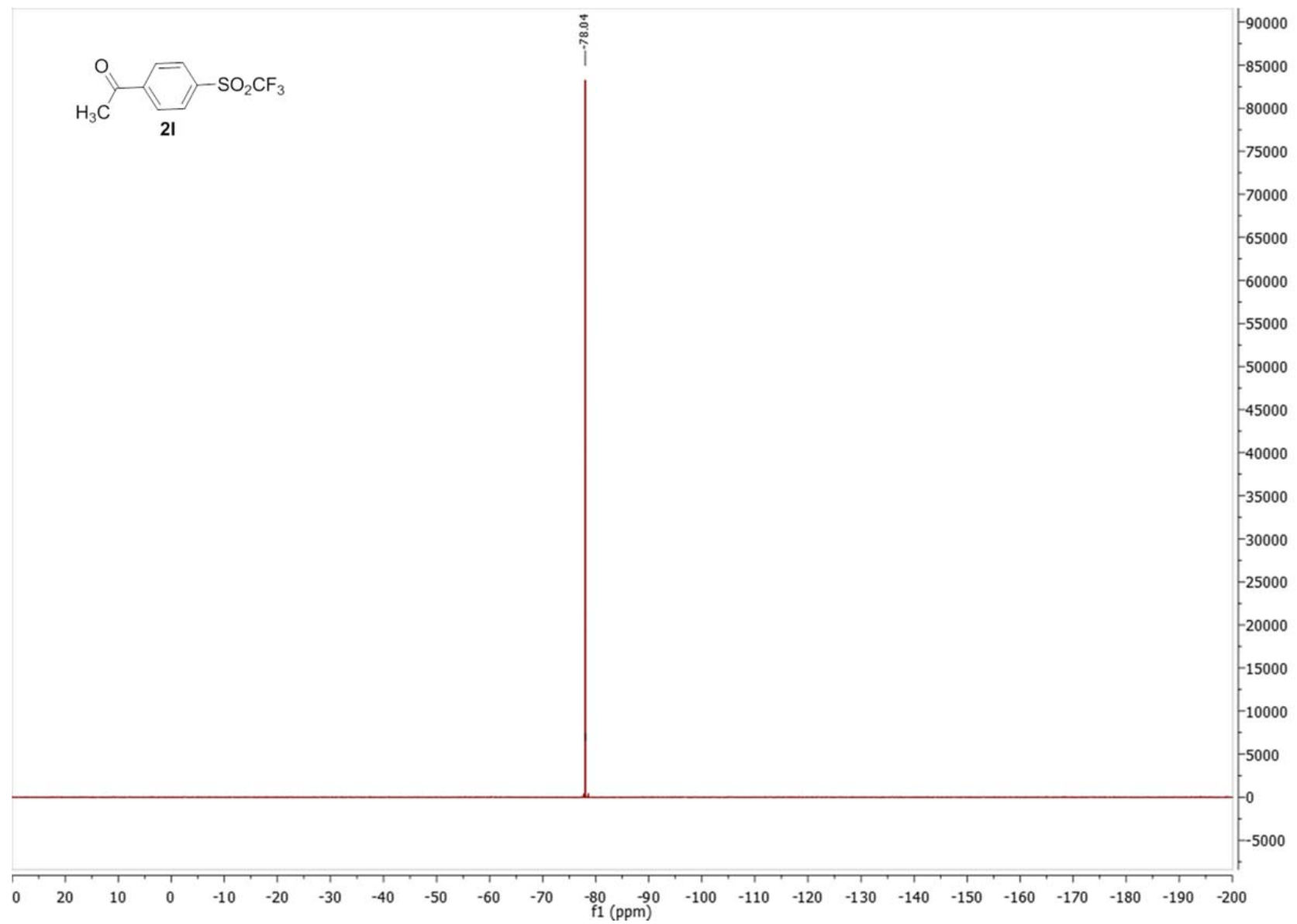




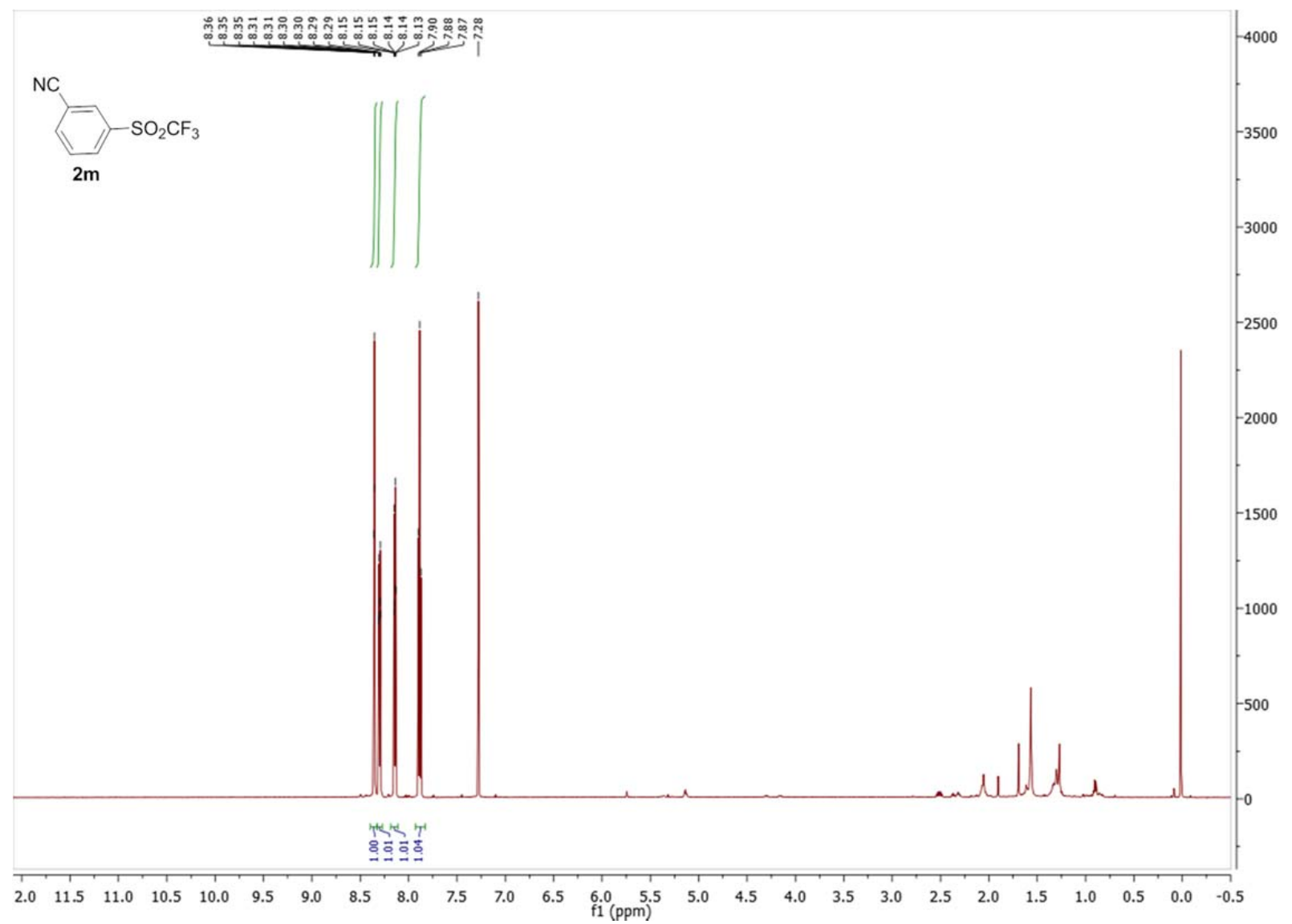




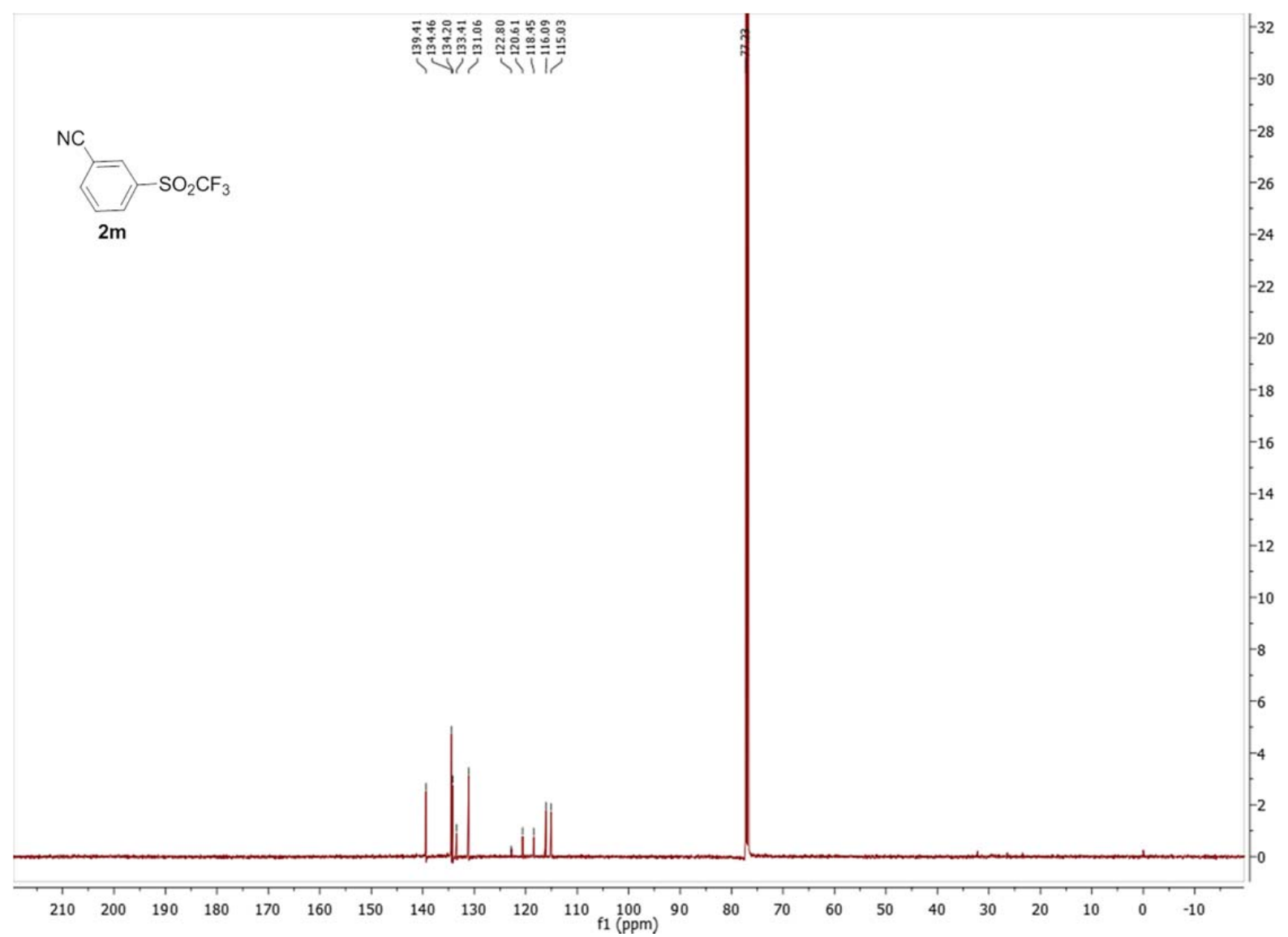




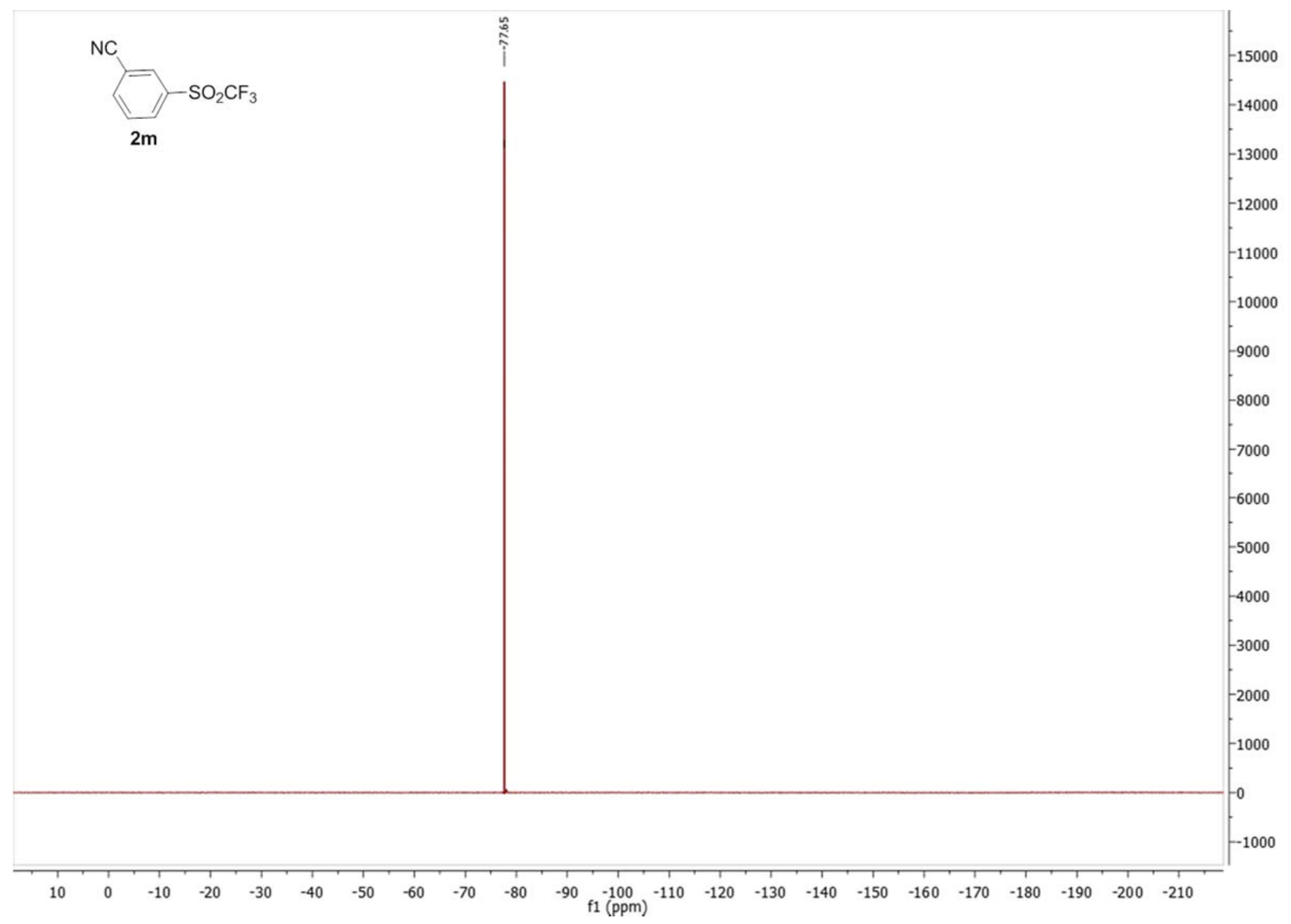




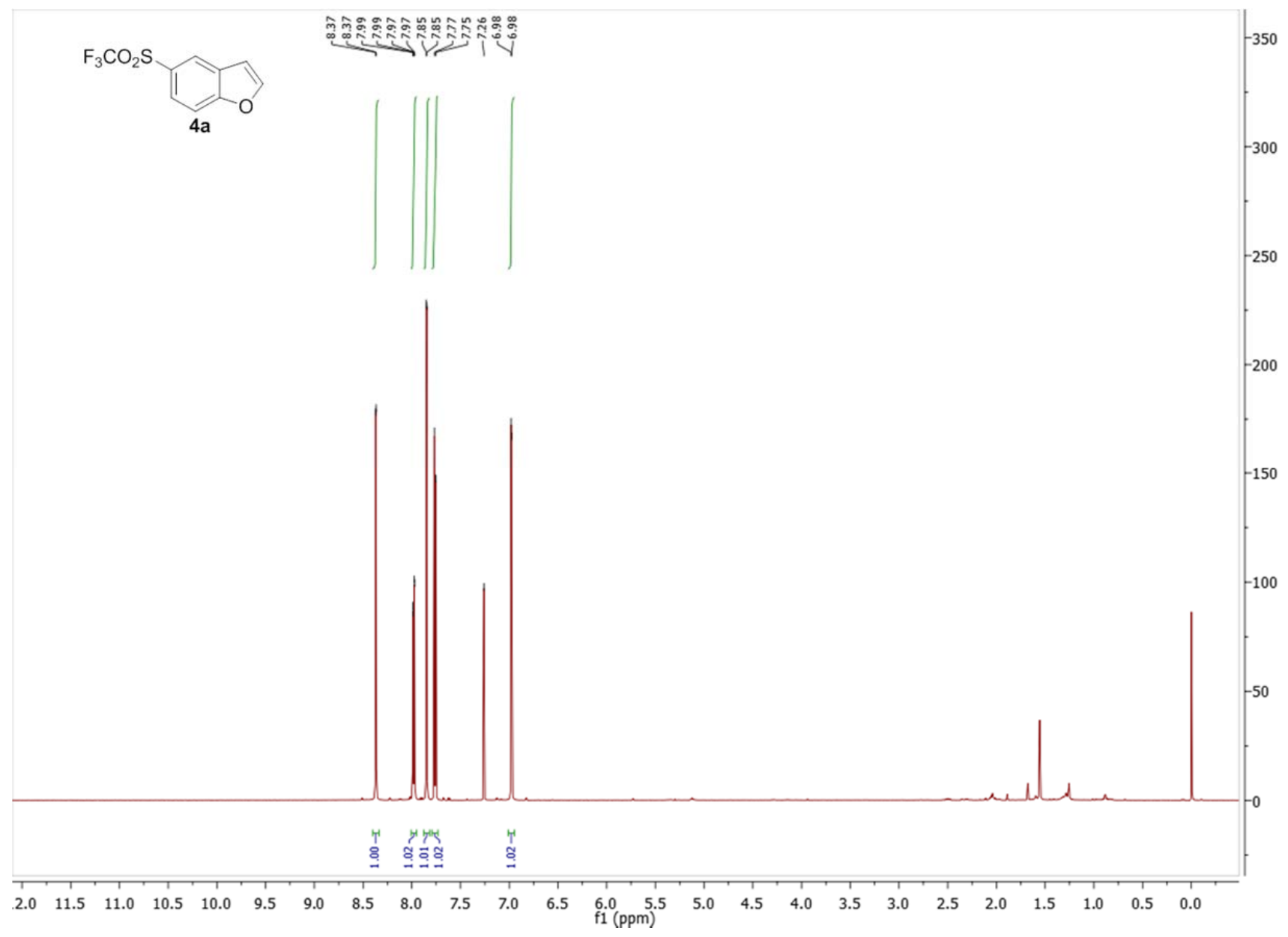




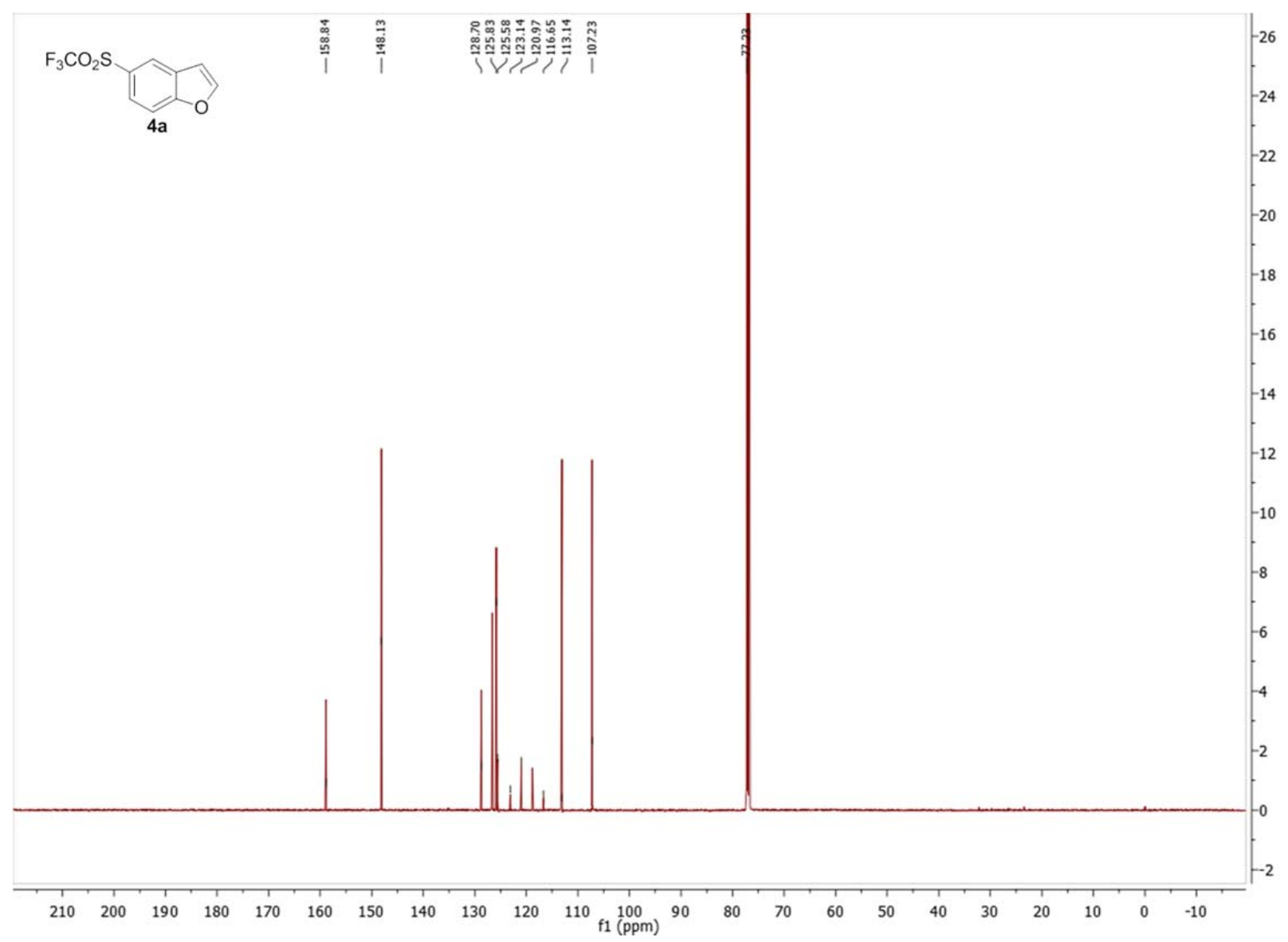




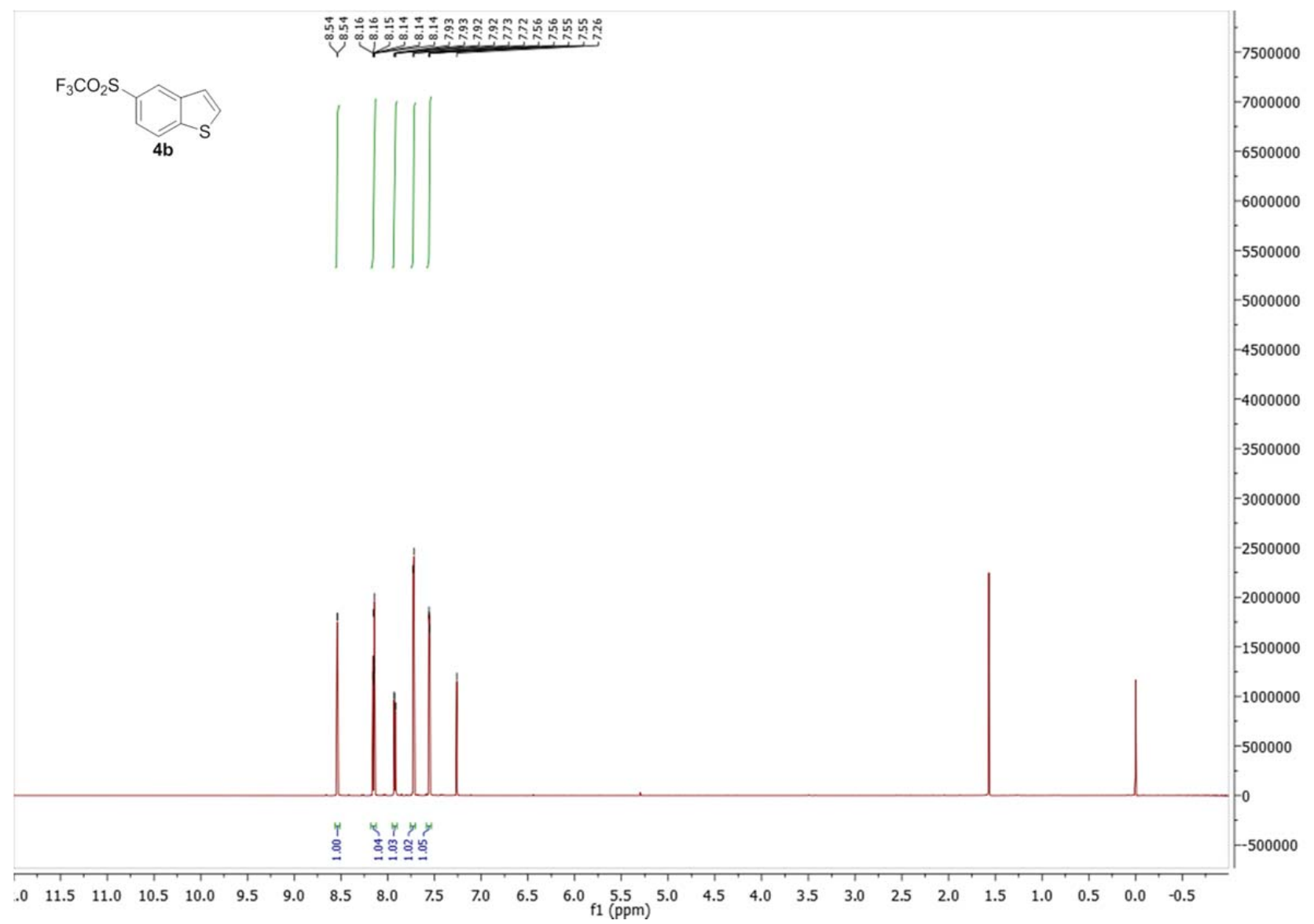




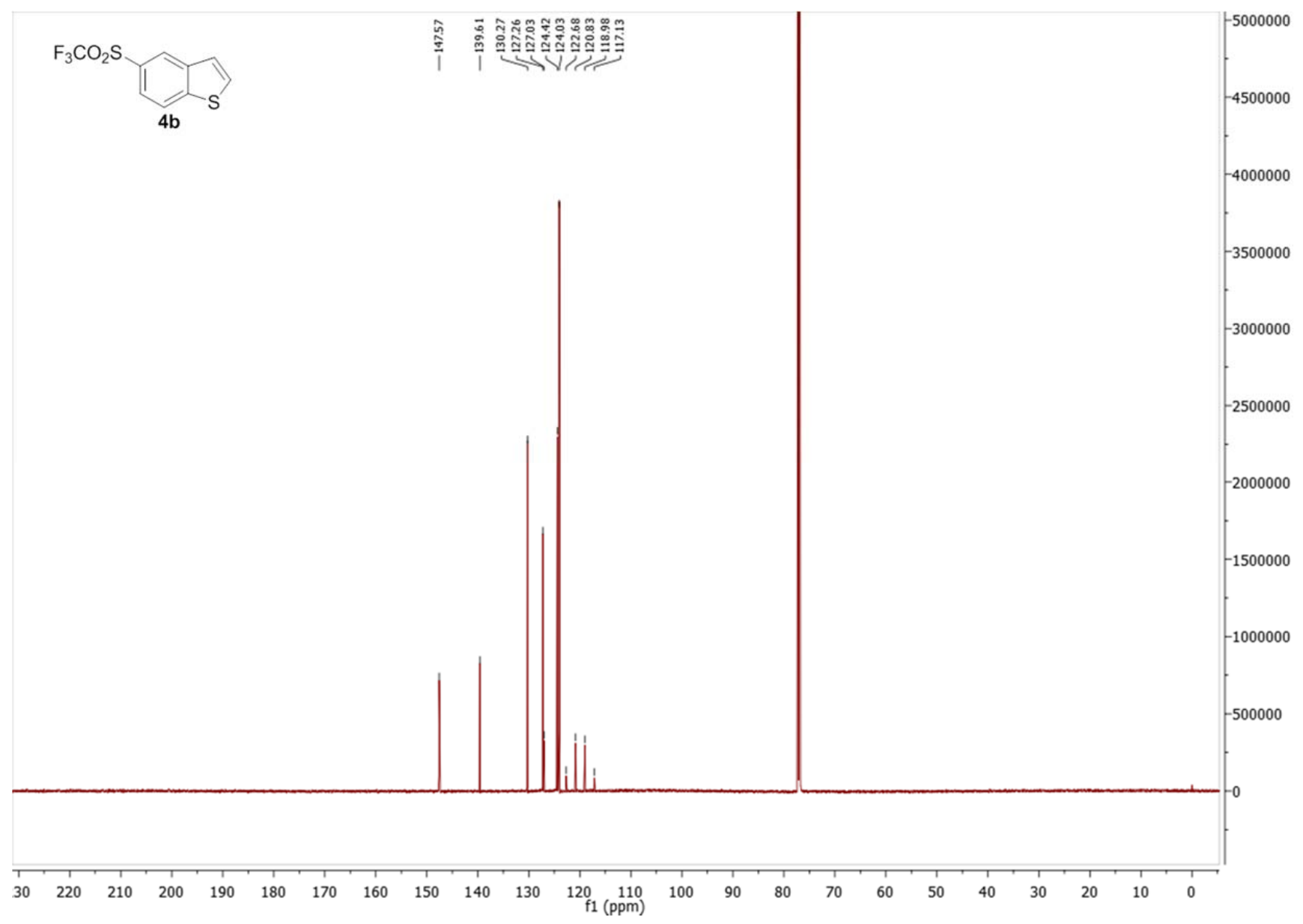




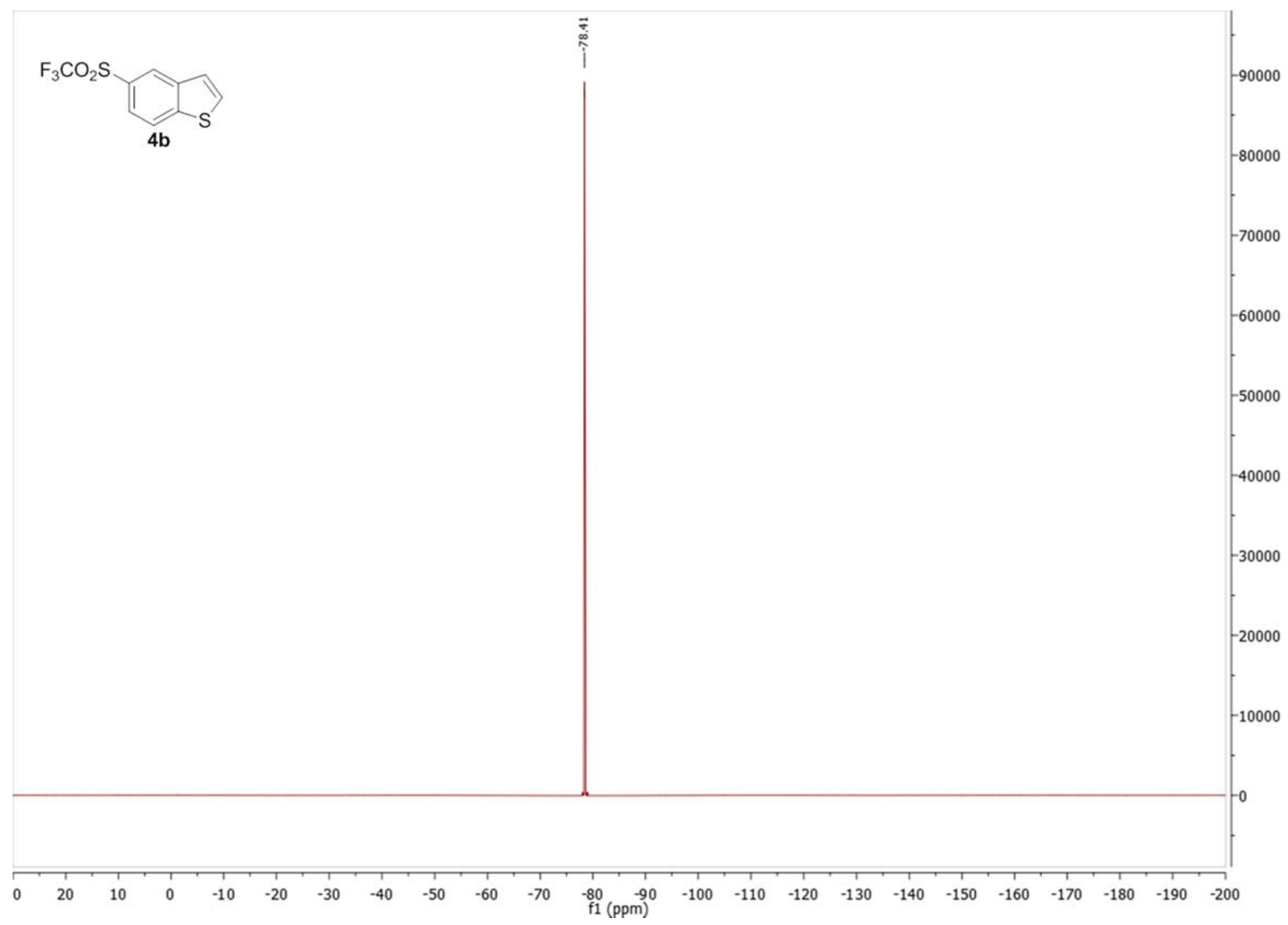




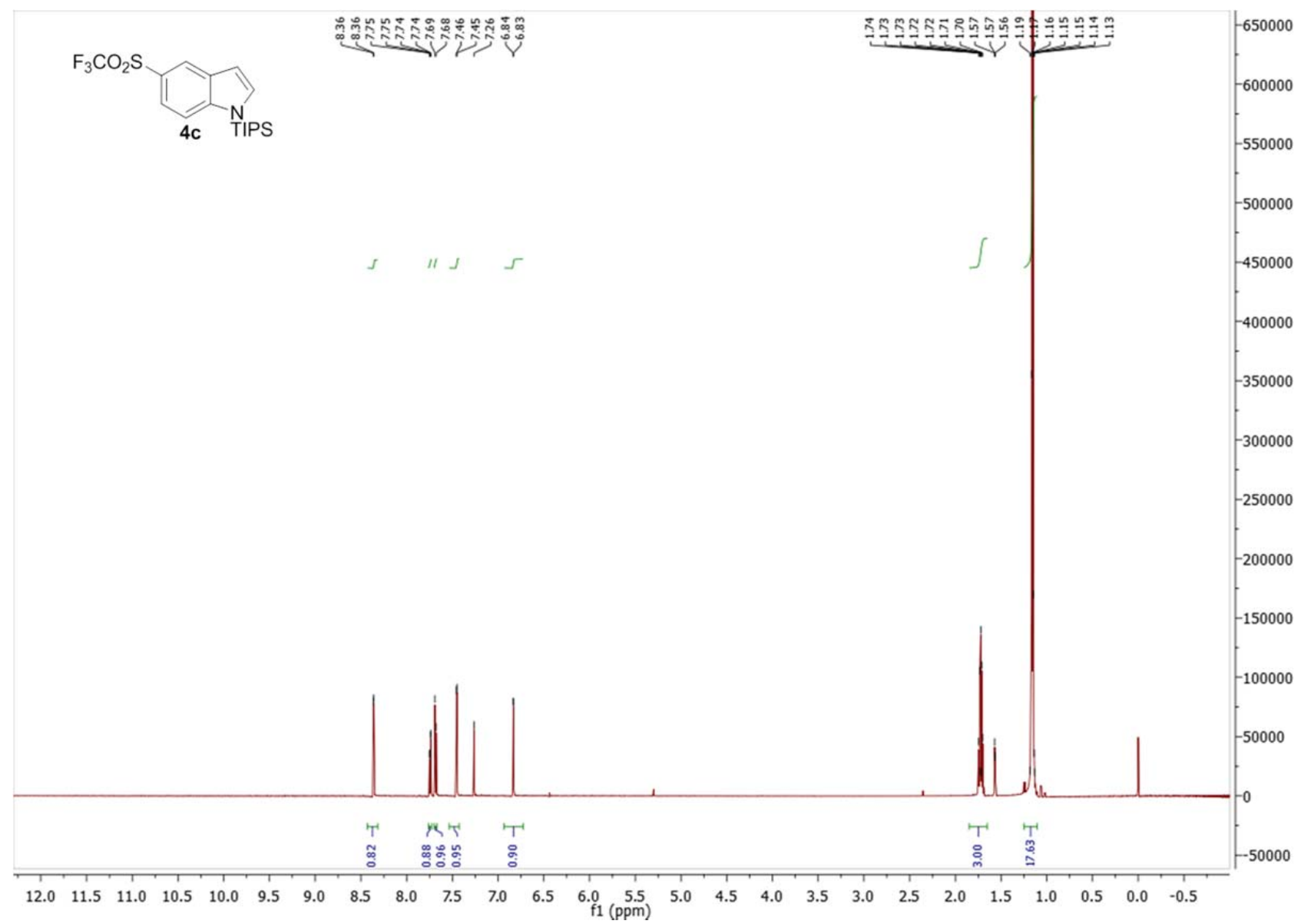




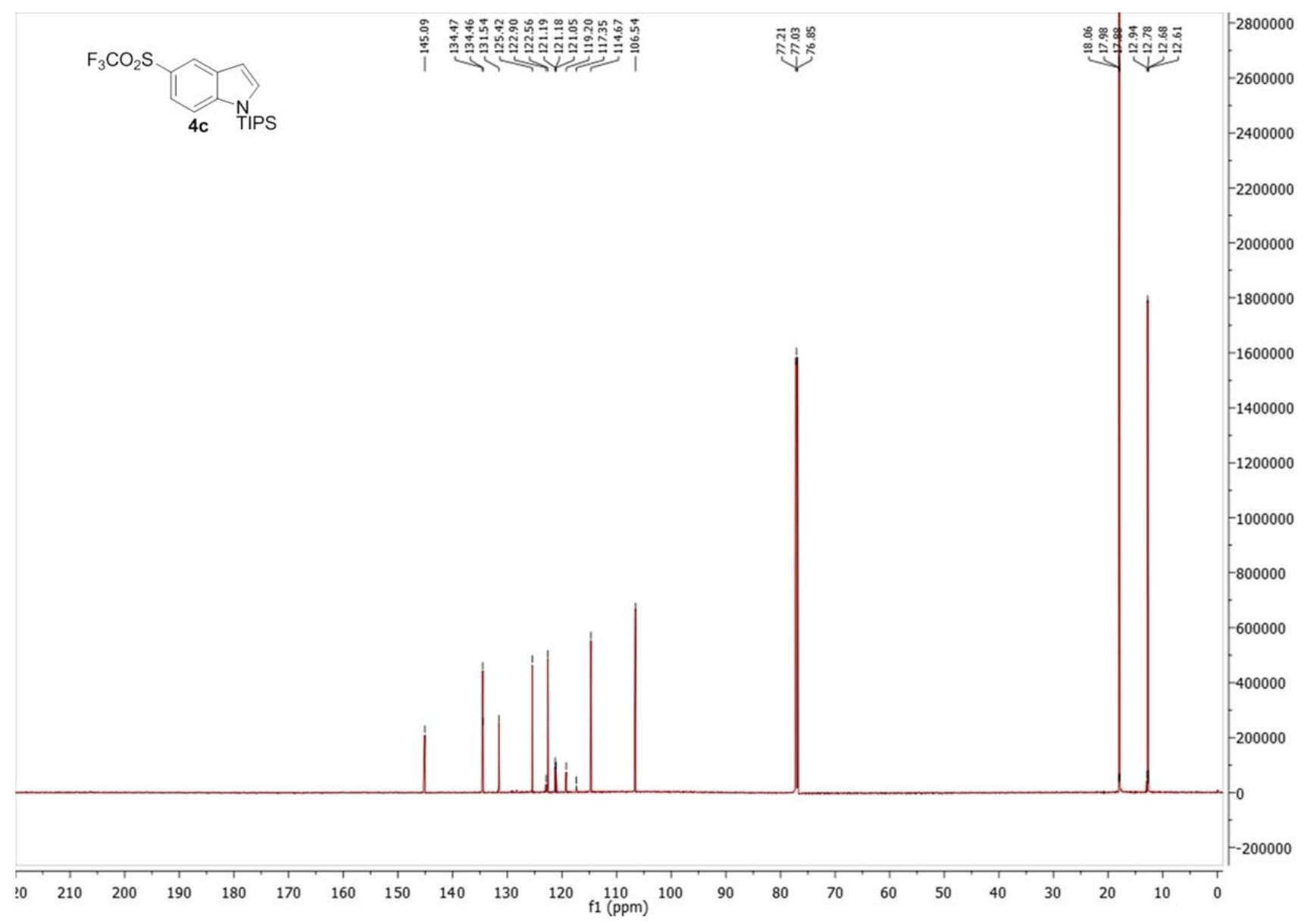




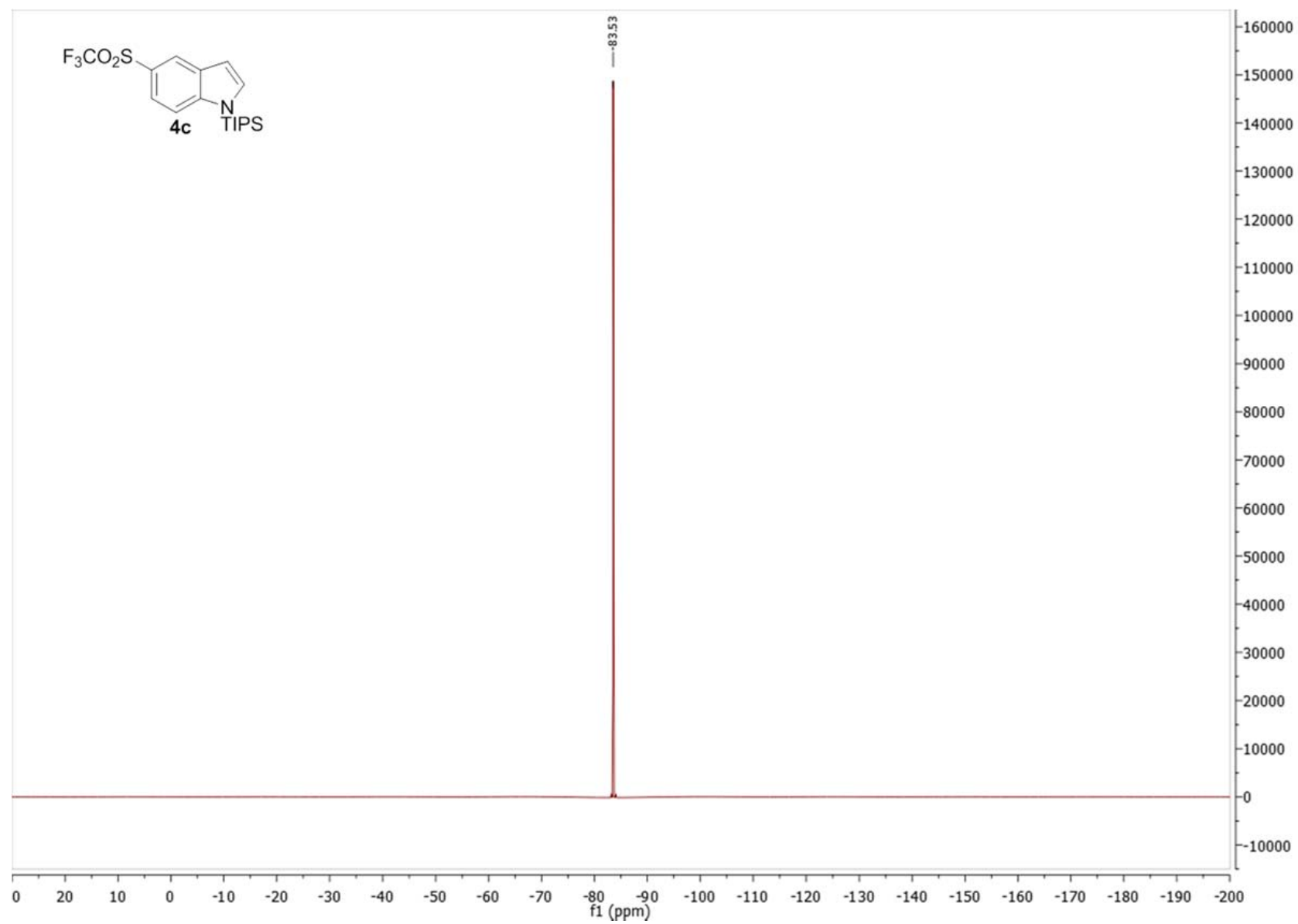




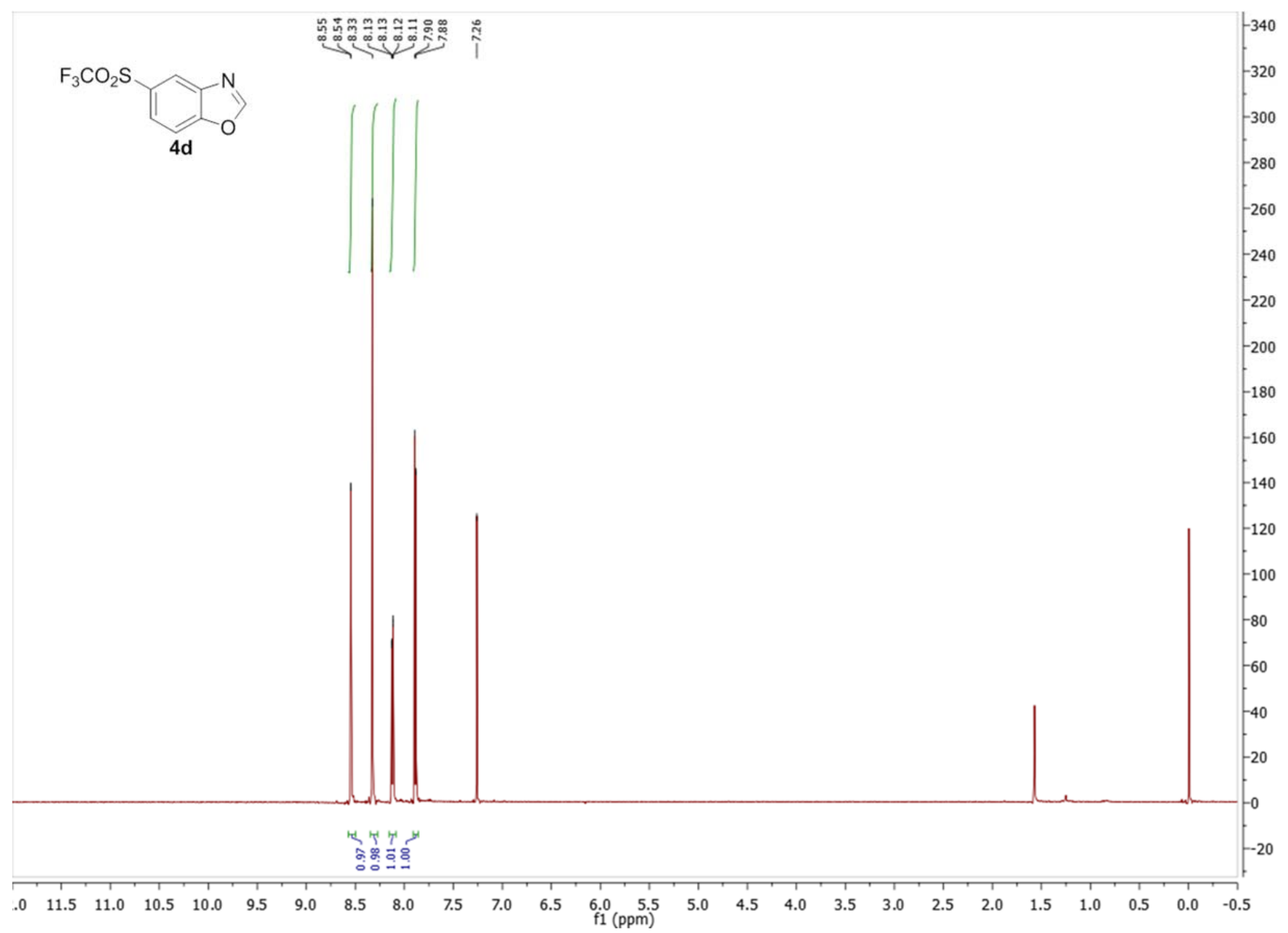




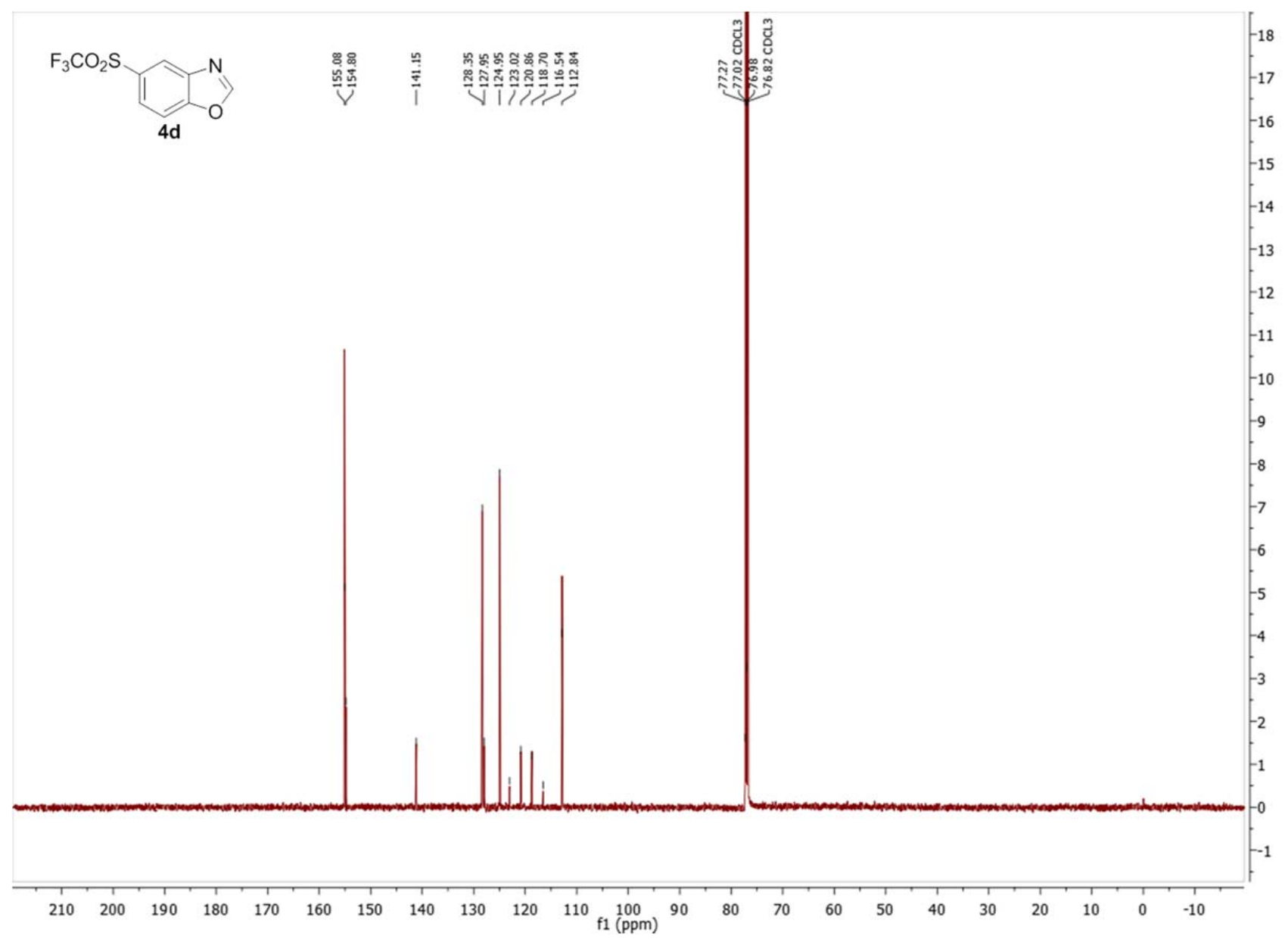




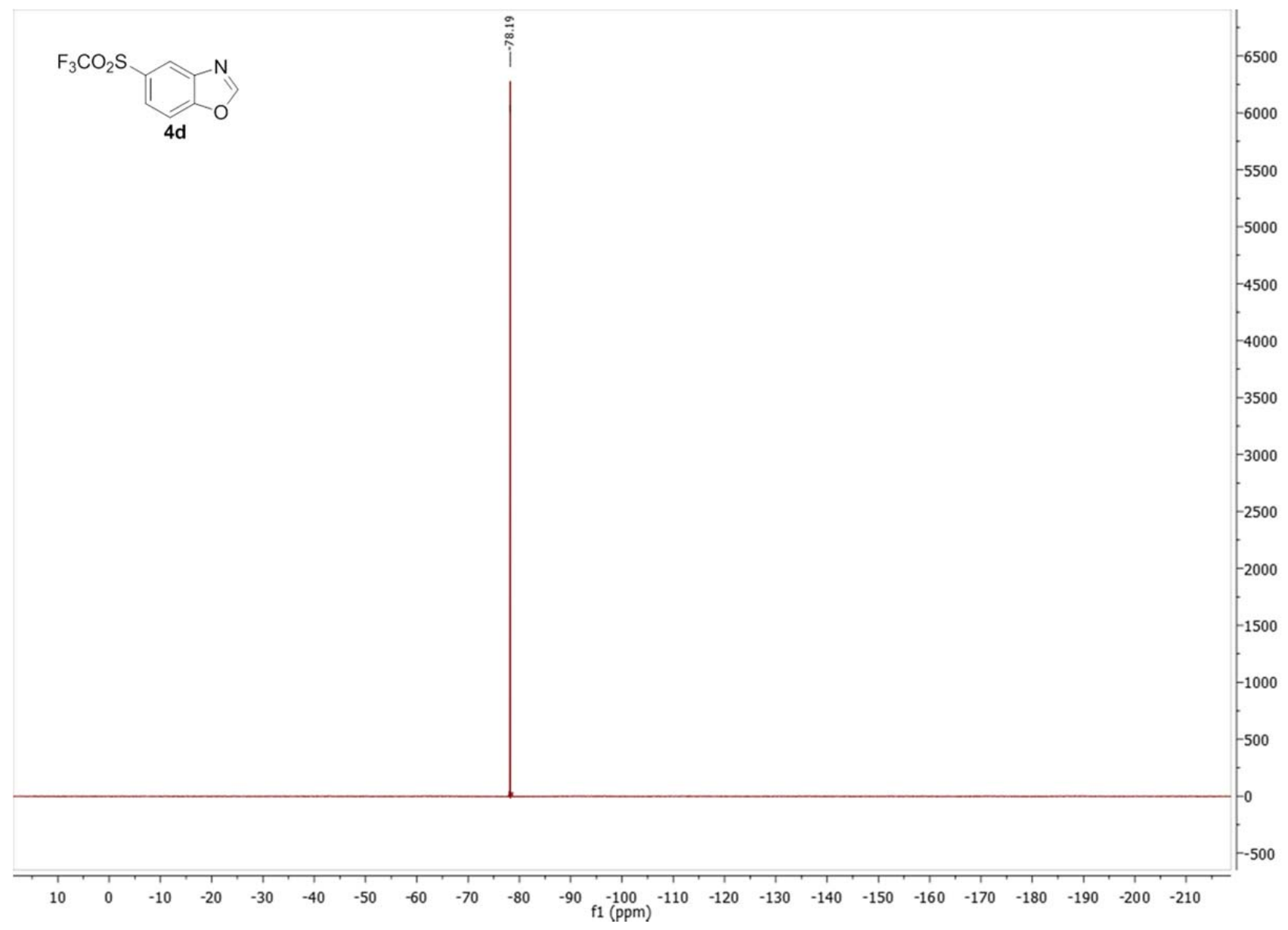




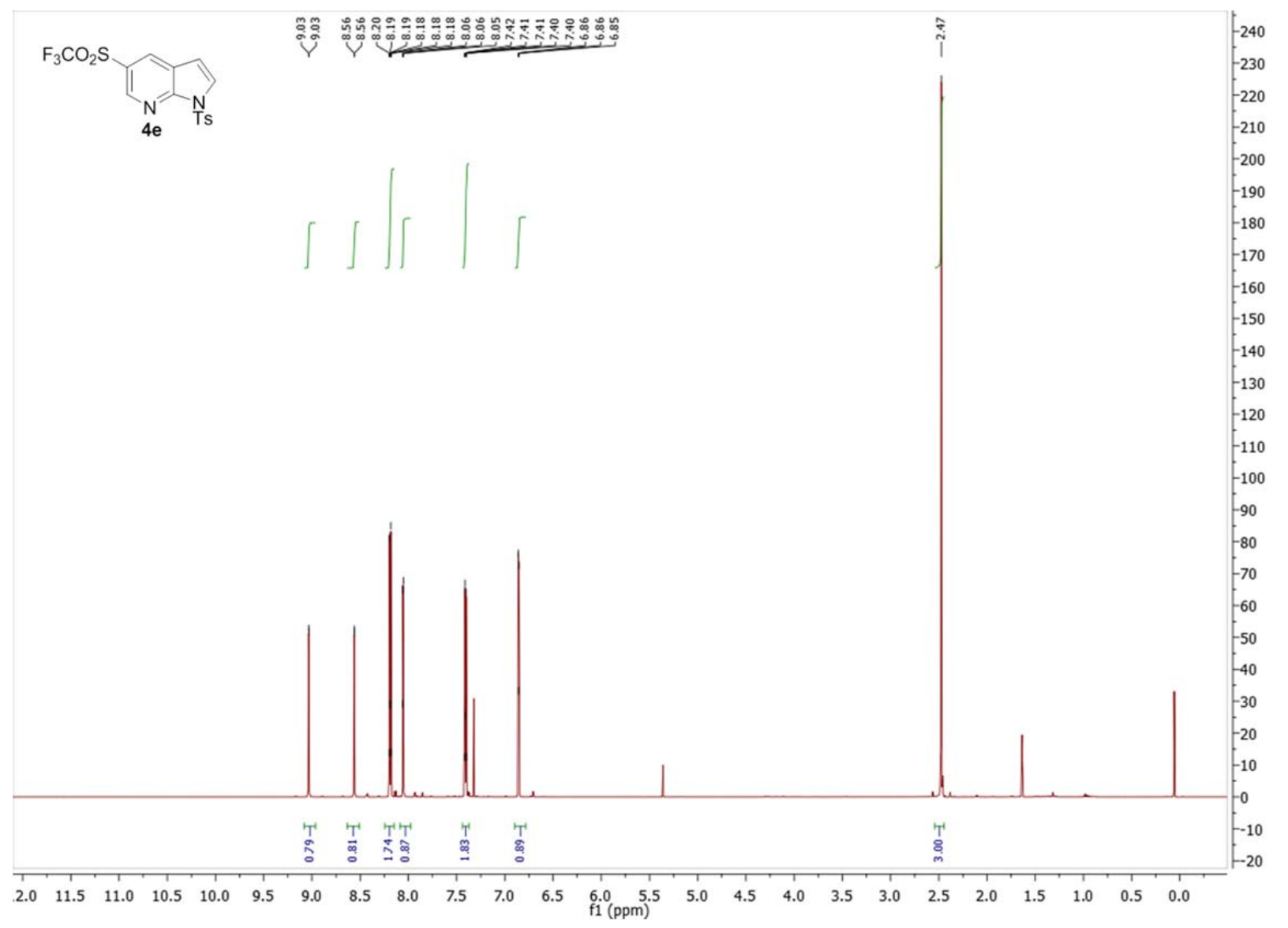




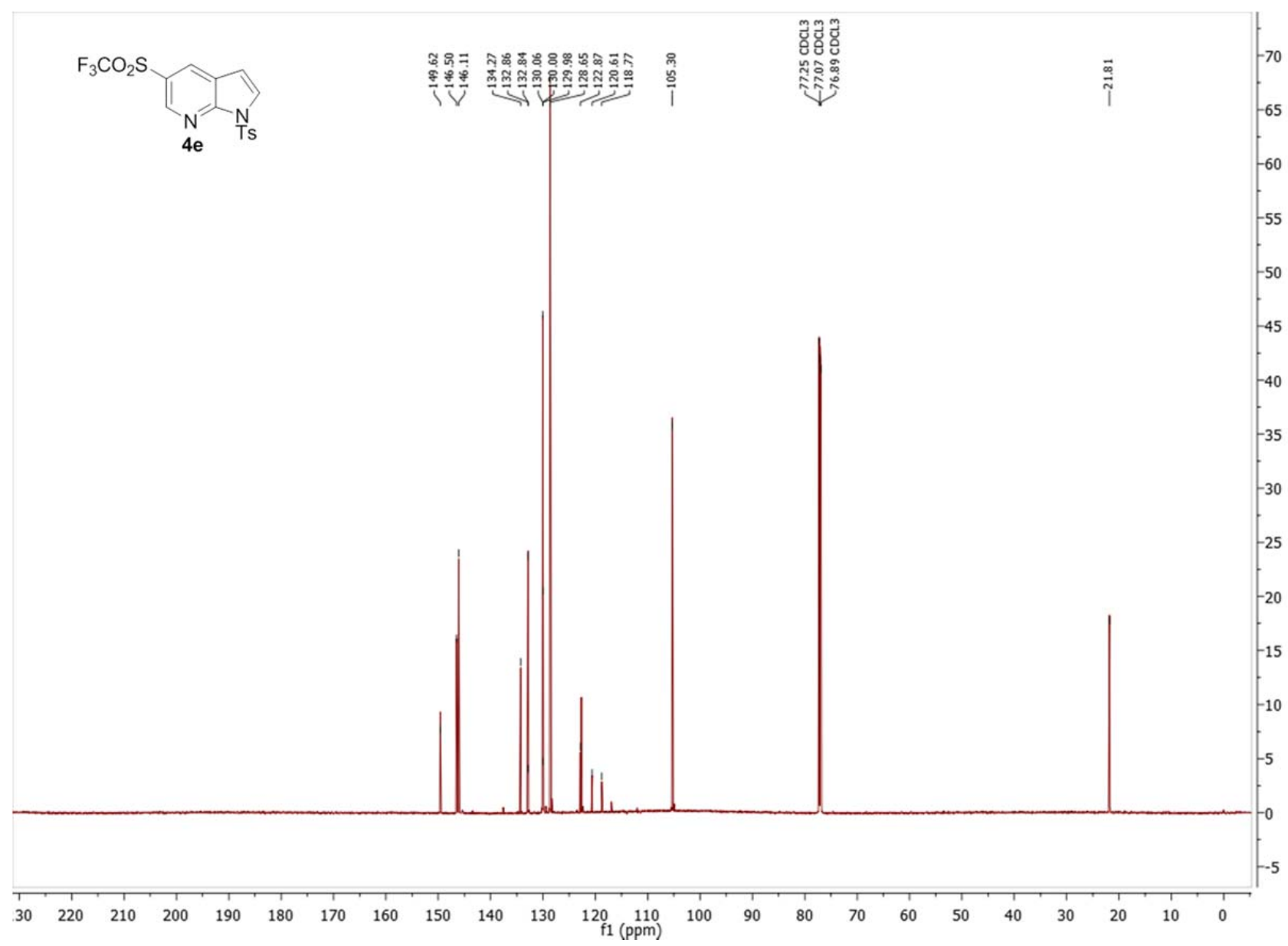




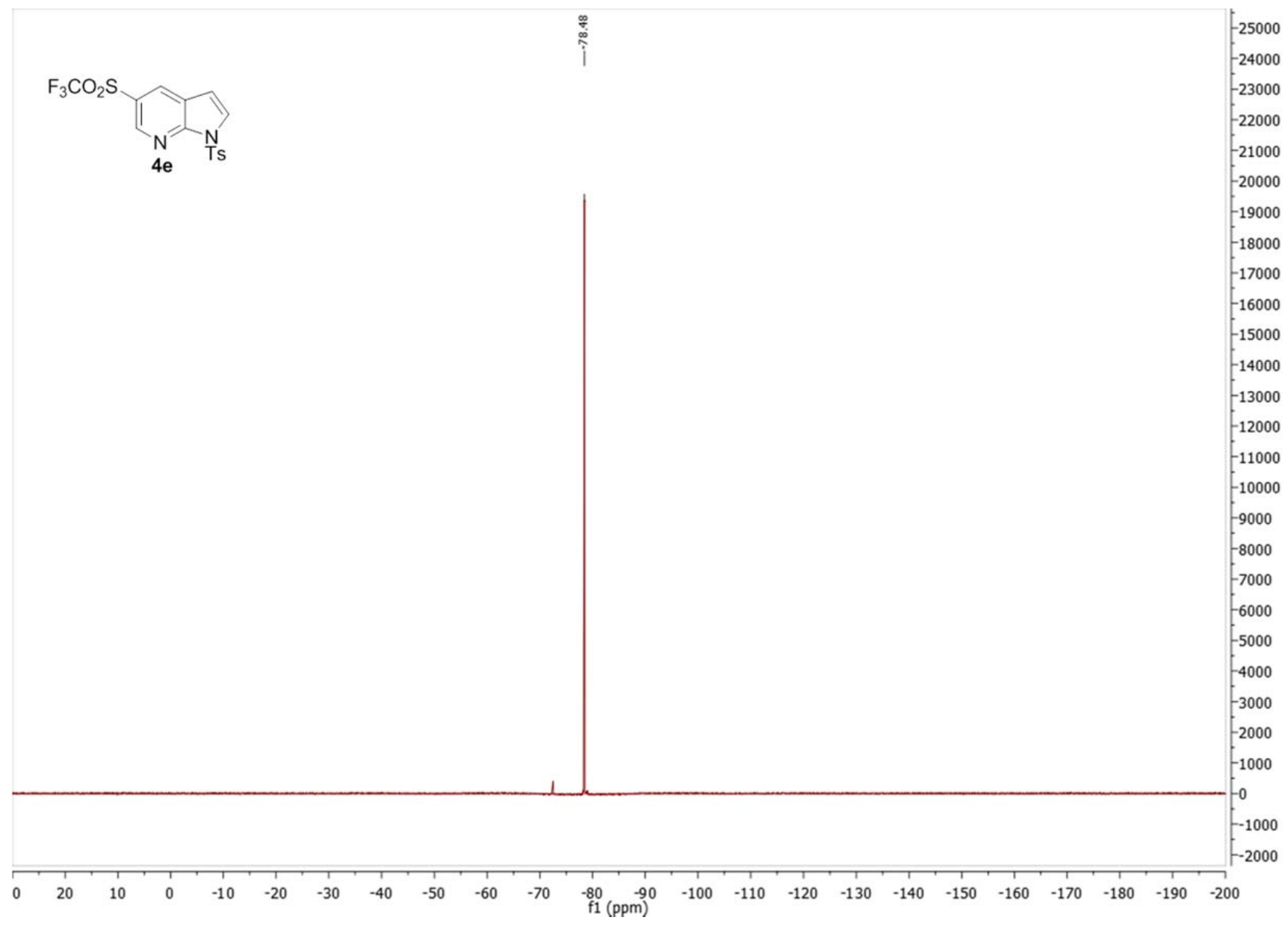




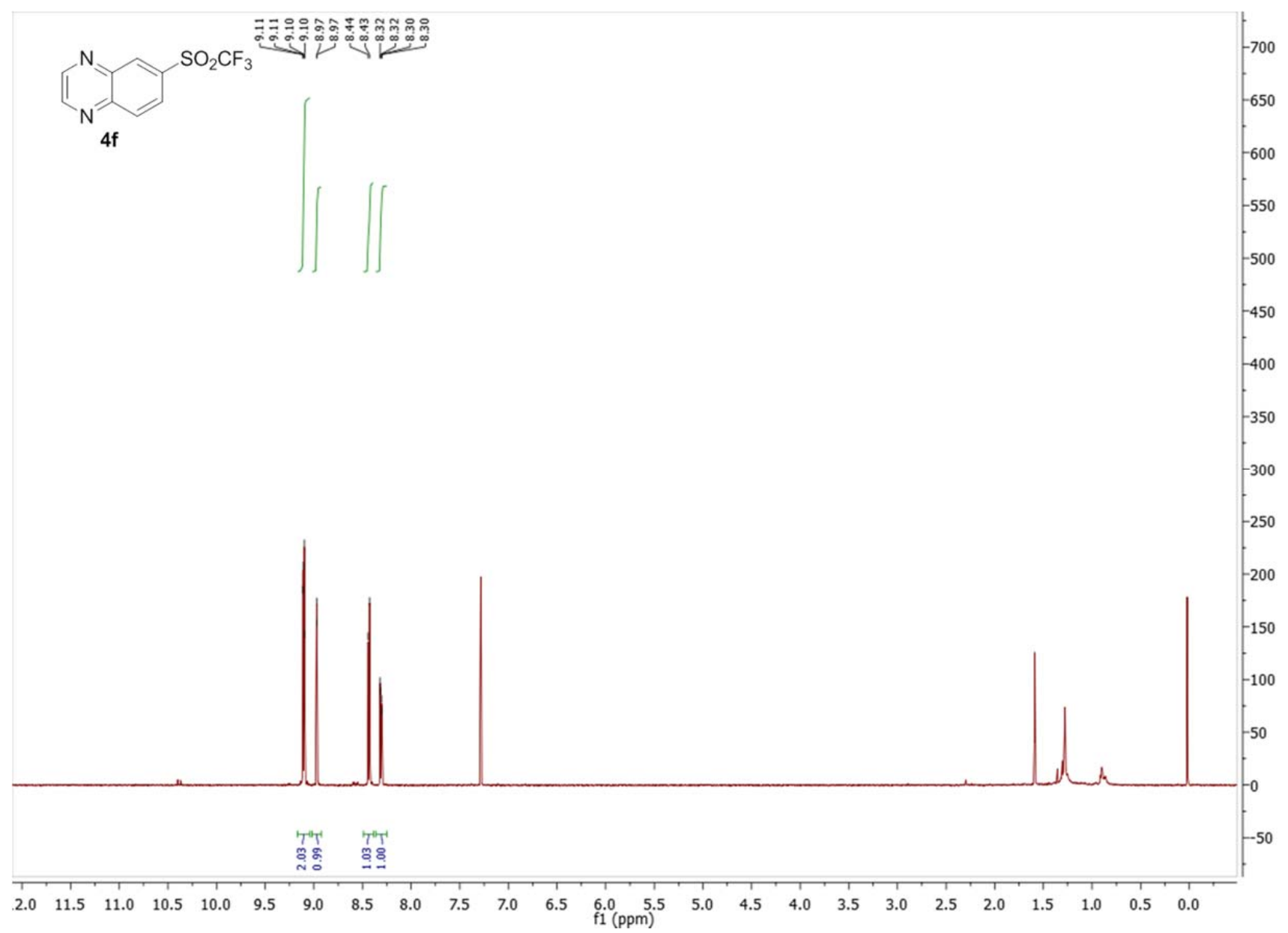




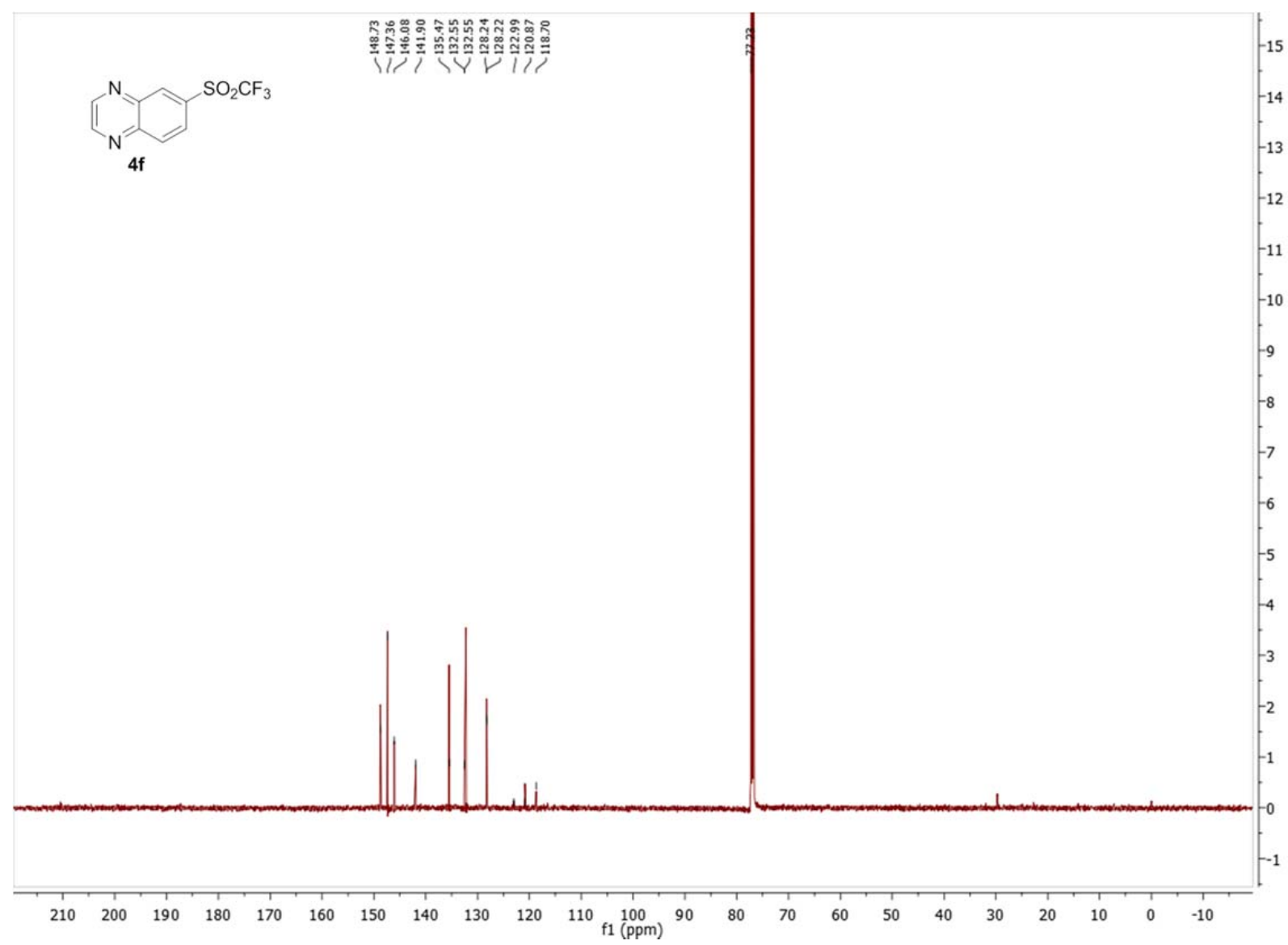




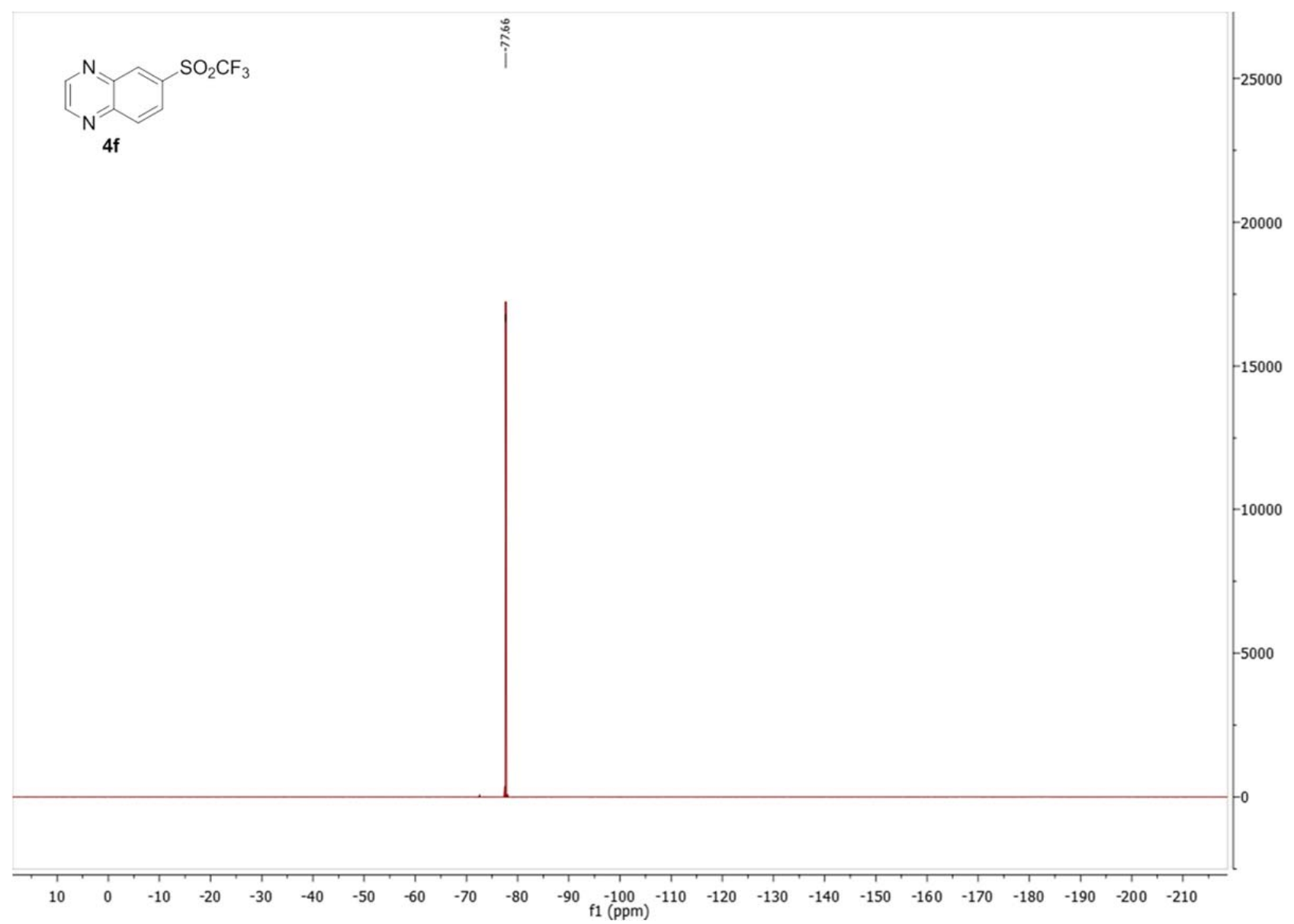




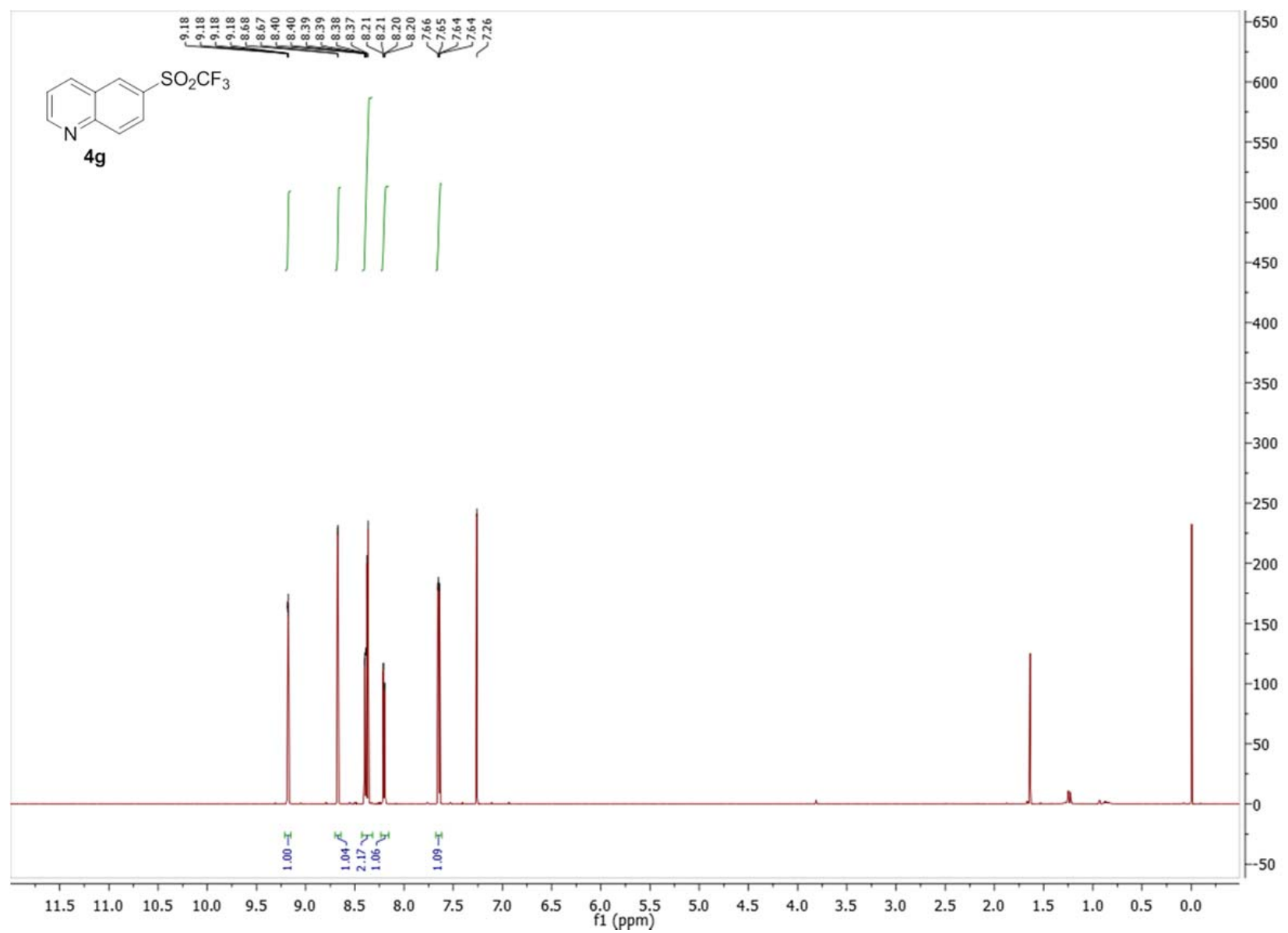




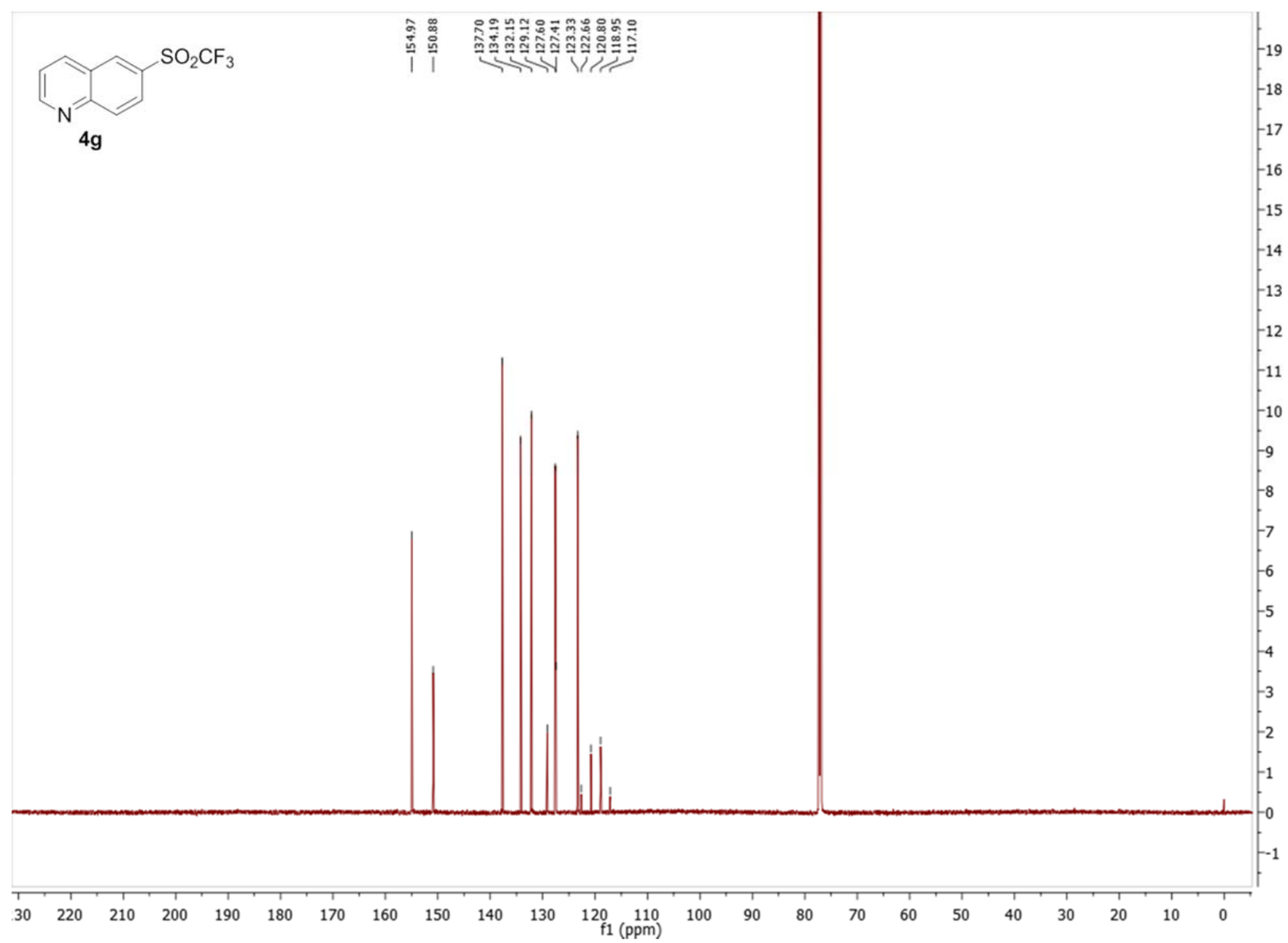




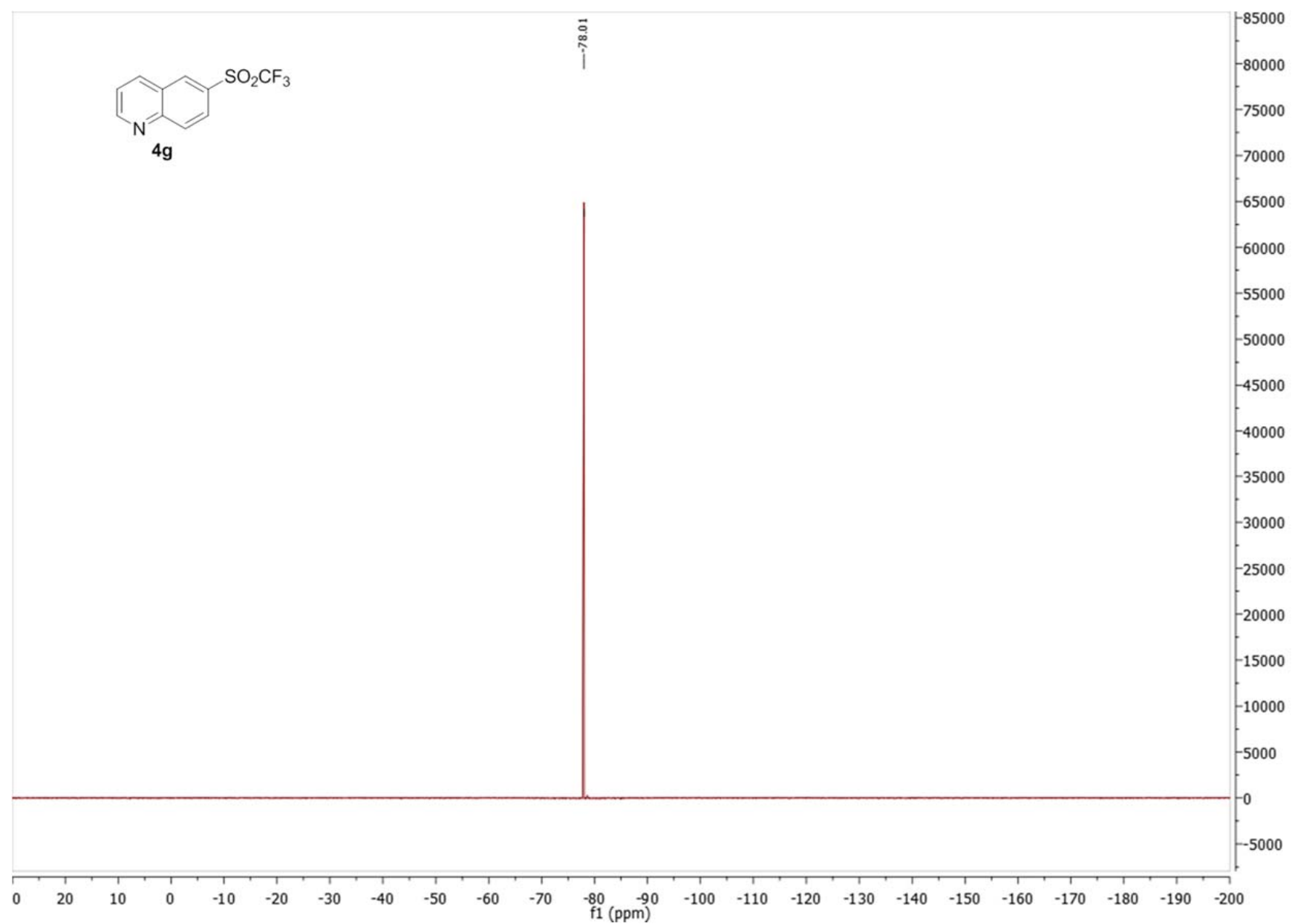




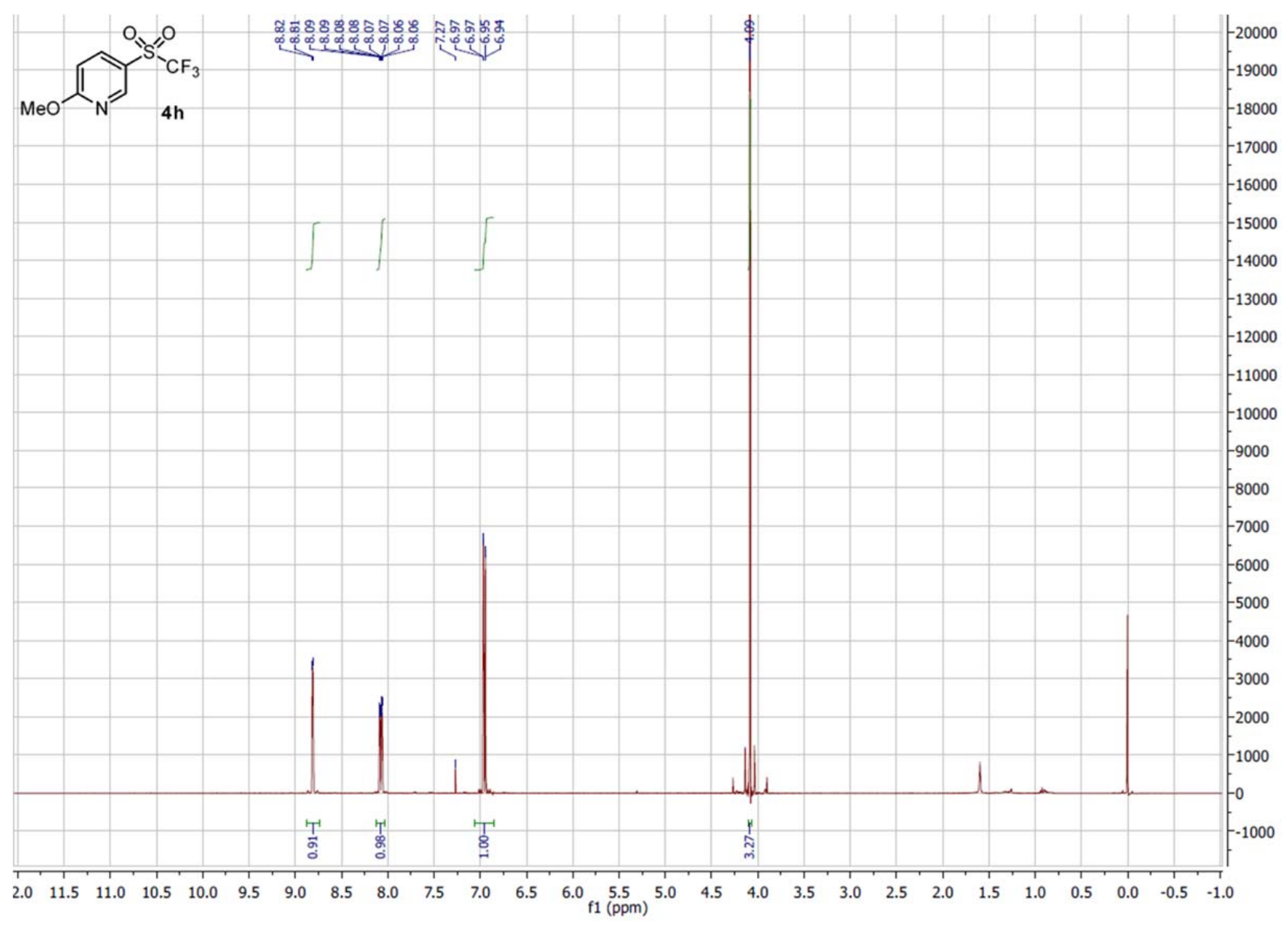




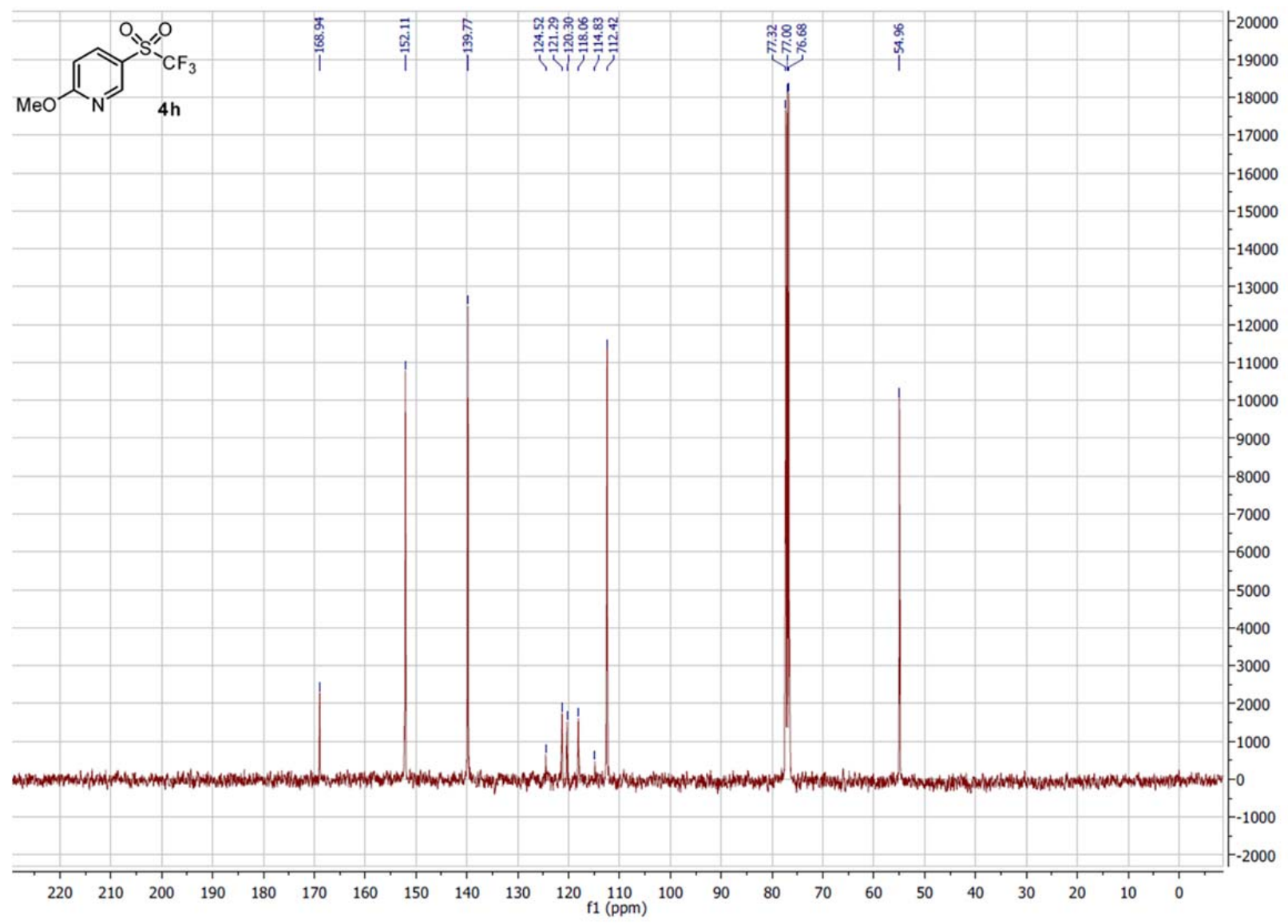




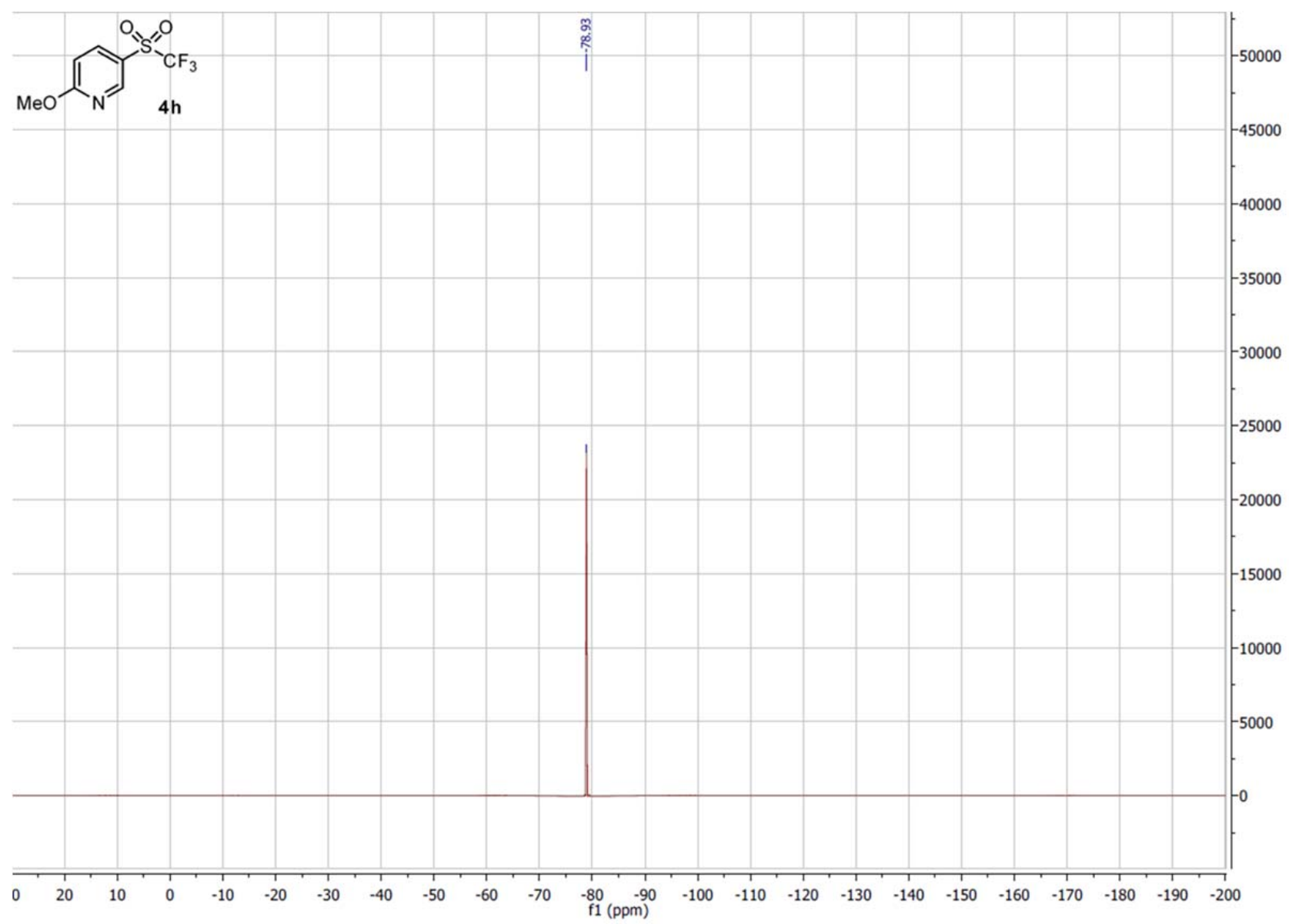




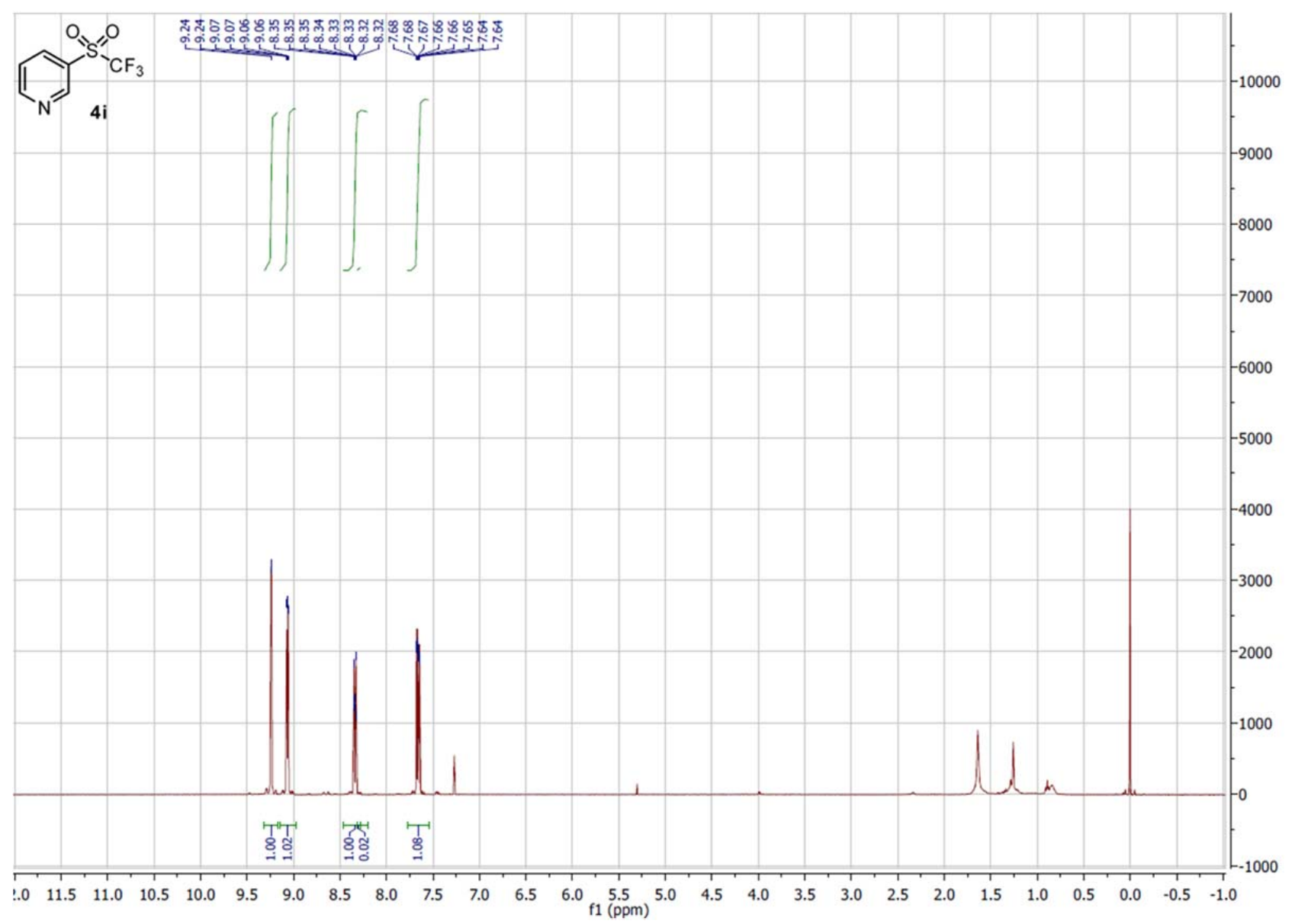




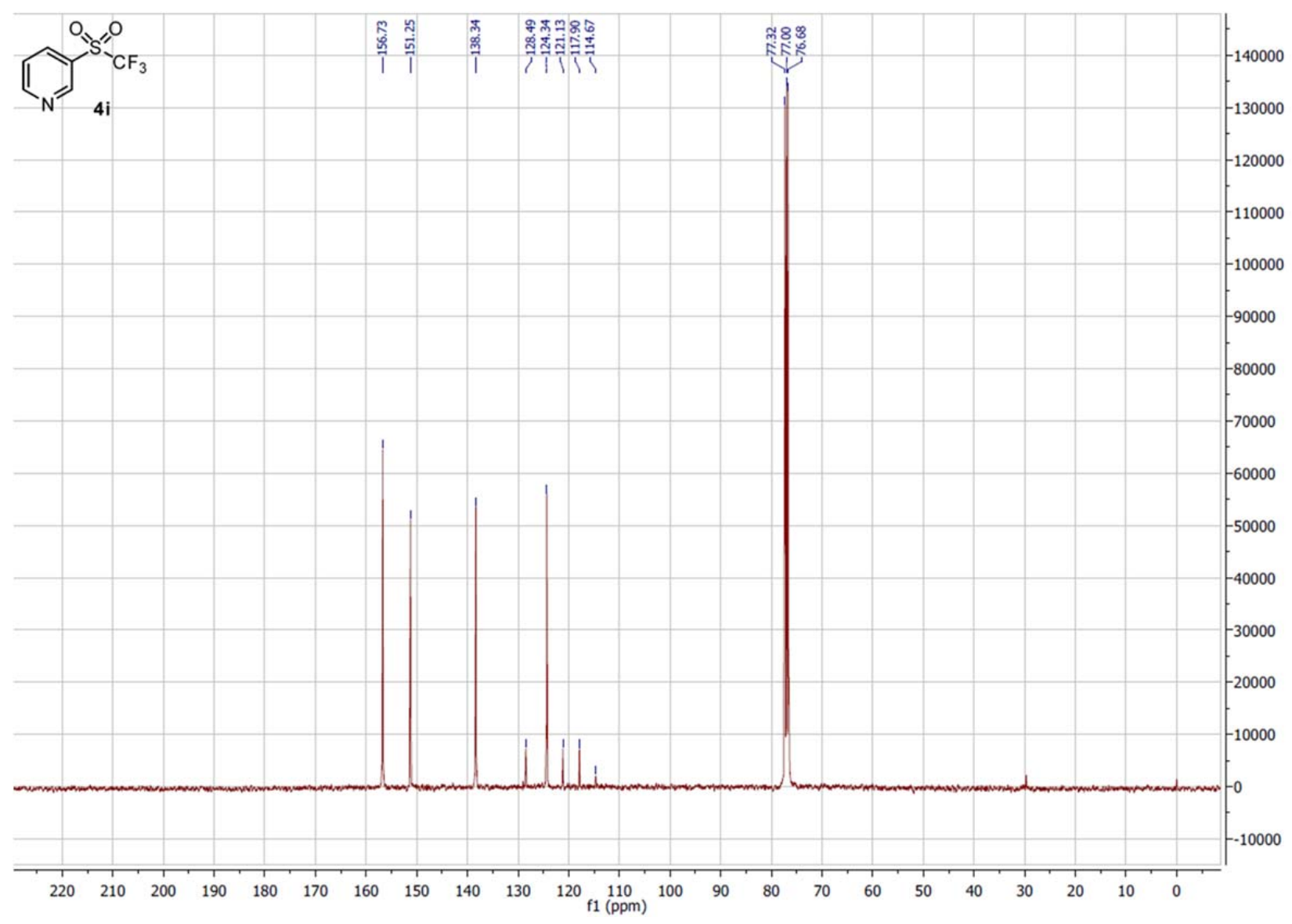




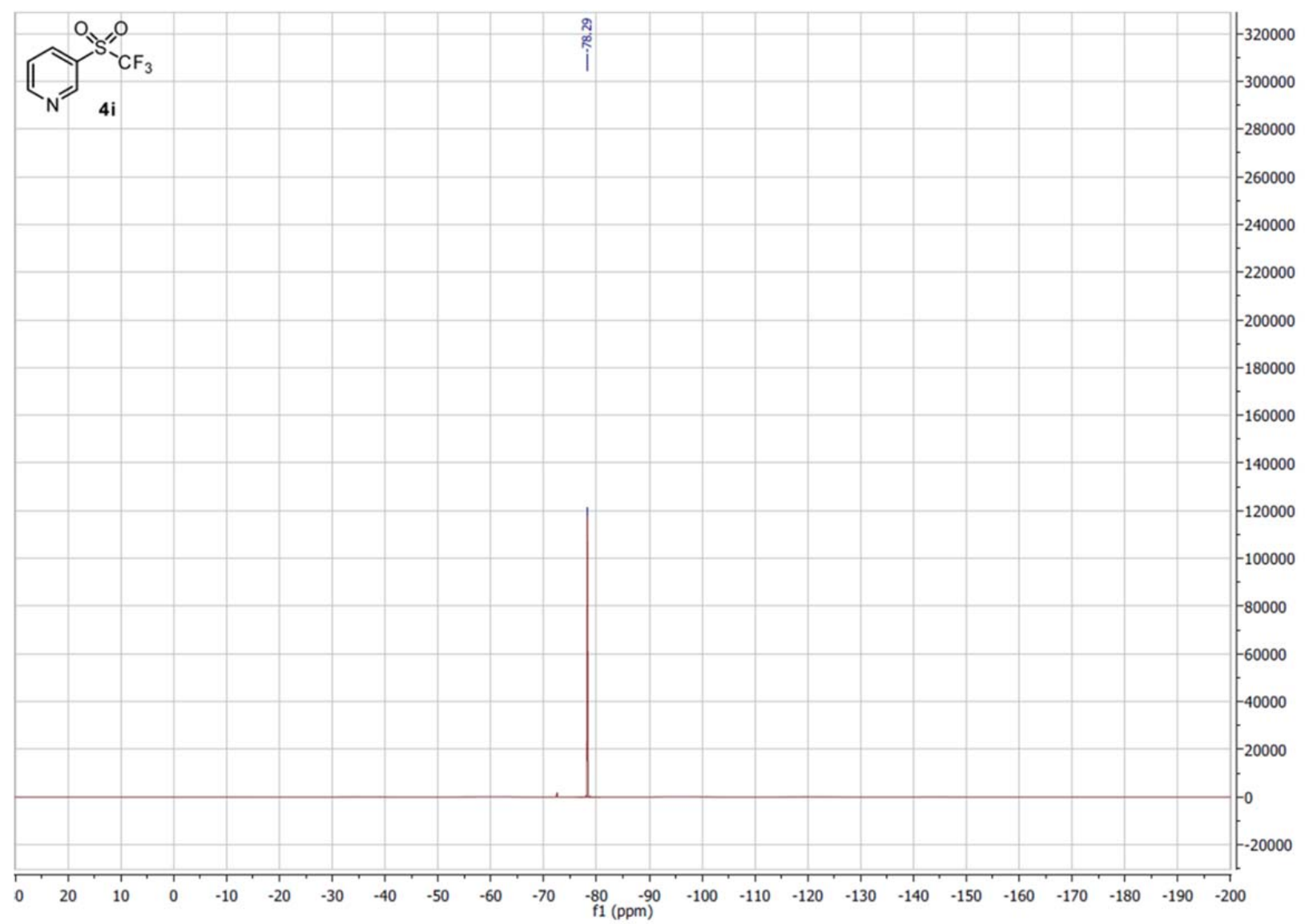

[1] B. P. Fors, P. Krattiger, E. Strieter, S. L. Buchwald, Org. Lett. 2008, 10, 3505-3508. 